Review

Check for updates

\section{OPEN ACCESS}

Received: Jul 6, 2019

Revised: Nov 5, 2019

Accepted: Nov 13, 2019

Correspondence to

Luo Zhang, MD, PhD

Department of Otolaryngology Head and Neck

Surgery, Beijing Tongren Hospital, Capital

Medical University, No. 1, Dongjiaominxiang,

Dongcheng District, Beijing 100730, China.

Tel: +86-10-6514-1136

Fax: +86-10-8511-5988

E-mail: dr.luozhang@139.com

Bing Zhou, MD, PhD

Department of Otolaryngology Head and Neck

Surgery, Beijing Tongren Hospital, Capital

Medical University, No. 1, Dongjiaominxiang,

Dongcheng District, Beijing 100730, China.

Tel: +86-10-5826-9106

Fax: +86-10-5826-9258

E-mail: entzhou@263.net

†Zheng Liu, Jianjun Chen, Lei Cheng, Huabin Li, Shixi Liu, Hongfei Lou, Jianbo Shi, Ying Sun, Dehui Wang, Chengshuo Wang, Xiangdong Wang, Yongxiang Wei, Weiping Wen, Pingchang Yang, Qintai Yang, Gehua Zhang, Yuan Zhang, Changqing Zhao, Dongdong Zhu and Li Zhu contributed equally to this work.

These guidelines represent a joint initiative of Chinese Society of Allergy (CSA) and Chinese Society of Otolaryngology Head and Neck Surgery, Rhinology Group.

Copyright (c) 2020 The Korean Academy of Asthma, Allergy and Clinical Immunology . The Korean Academy of Pediatric Allergy and Respiratory Disease

\title{
Chinese Society of Allergy and Chinese Society of Otorhinolaryngology-Head and Neck Surgery Guideline for Chronic Rhinosinusitis
}

\author{
Zheng Liu $\left(\mathbb{D},{ }^{1+}\right.$ Jianjun Chen $\mathbb{1},{ }^{2+}$ Lei Cheng $\mathbb{1},{ }^{3,4+}$ Huabin Li $\left(\mathbb{D},{ }^{5+}\right.$ Shixi Liu $\mathbb{1},{ }^{6+}$ \\ Hongfei Lou $\left(\mathbb{1},{ }^{7,8+}\right.$ Jianbo Shi $\left(\mathbb{D},{ }^{9+}\right.$ Ying Sun $\left(\mathbb{1},{ }^{10+}\right.$ Dehui Wang $(\mathbb{1}),{ }^{5+}$ \\ Chengshuo Wang (D, 7,8+ Xiangdong Wang (D, ${ }^{8+}$ Yongxiang Wei iD, ${ }^{11+}$ \\ Weiping Wen $D^{9,12+}$ Pingchang Yang ${ }^{1 D},{ }^{13+}$ Qintai Yang ${ }^{1 D},{ }^{14+}$ Gehua Zhang ${ }^{1 D},{ }^{14+}$

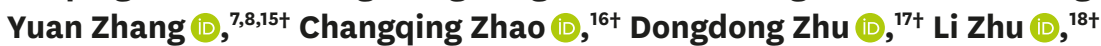 \\ Fenghong Chen ${ }^{D},{ }^{9}$ Yi Dong ${ }^{D},{ }^{8}$ Qingling Fu ${ }^{D},{ }^{9}$ Jingyun Li $\left(D,{ }^{8}\right.$ Yanqing Li (D), ${ }^{5}$ \\ Chengyao Liu (D, ${ }^{7}$ Feng Liu (D, ${ }^{6}$ Meiping Lu iD, ${ }^{3}$ Yifan Meng (D, ${ }^{7,8}$ Jichao Sha (D, ${ }^{17}$

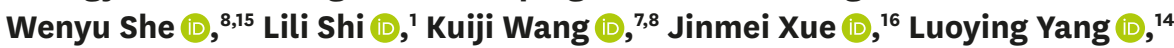

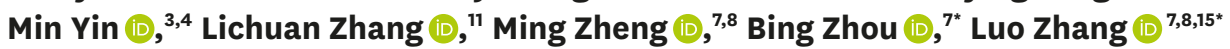

'Department of Otolaryngology Head and Neck Surgery, Tongji Hospital, Tongji Medical College, Huazhong University of Science and Technology, Wuhan, China

${ }^{2}$ Department of Otorhinolaryngology, Union Hospital, Tongji Medical College, Huazhong University of Science and Technology, Wuhan, China

${ }^{3}$ Department of Otorhinolaryngology, The First Affiliated Hospital, Nanjing Medical University, Nanjing, China ${ }^{4}$ International Centre for Allergy Research, Nanjing Medical University, Nanjing, China

${ }^{5}$ Department of Otolaryngology, Head and Neck Surgery, Affiliated Eye, Ear, Nose and Throat Hospital, Fudan University, Shanghai, China

${ }^{6}$ Department of Otolaryngology, West China Hospital, Sichuan University, Chengdu, China ${ }^{7}$ Department of Otolaryngology Head and Neck Surgery, Beijing Tongren Hospital, Capital Medical University, Beijing, China

${ }^{8}$ Beijing Key Laboratory of Nasal Diseases, Beijing Institute of Otolaryngology, Beijing, China ${ }^{9}$ Otorhinolaryngology Hospital, The First Affiliated Hospital, Sun Yat-sen University, Guangzhou, China ${ }^{10}$ Department of Immunology, School of Basic Medical Sciences, Capital Medical University, Beijing, China "Department of Otolaryngology Head and Neck Surgery, Beijing Anzhen Hospital, Capital Medical University, Beijing, China

${ }^{12}$ Otorhinolaryngology Hospital, The Sixth Affiliated Hospital, Sun Yat-sen University, Guangzhou, China ${ }^{13}$ Research Center of Allergy \& Immunology, Shenzhen University School of Medicine, Shenzhen, China ${ }^{14}$ Department of Otolaryngology Head and Neck Surgery, The Third Affiliated Hospital of Sun Yat-sen University, Guangzhou, China

${ }^{15}$ Department of Allergy, Beijing Tongren Hospital, Capital Medical University, Beijing, China

${ }^{16}$ Department of Otolaryngology Head and Neck Surgery, The Second Hospital, Shanxi Medical University, Taiyuan, China

${ }^{17}$ Department of Otolaryngology Head and Neck Surgery, China-Japan Union Hospital of Jilin University, Changchun, China

${ }^{18}$ Department of Otolaryngology Head and Neck Surgery, Peking University Third Hospital, Beijing, China

\section{ABSTRACT}

The current document is based on a consensus reached by a panel of experts from the Chinese Society of Allergy and the Chinese Society of Otorhinolaryngology-Head and Neck Surgery, Rhinology Group. Chronic rhinosinusitis (CRS) affects approximately $8 \%$ of Chinese adults. The inflammatory and remodeling mechanisms of CRS in the Chinese population differ from those observed in the populations of European descent. Recently, 
This is an Open Access article distributed under the terms of the Creative Commons Attribution Non-Commercial License (https:// creativecommons.org/licenses/by-nc/4.0/) which permits unrestricted non-commercial use, distribution, and reproduction in any medium, provided the original work is properly cited.

ORCID iDs

Zheng Liu (D)

https://orcid.org/0000-0002-4168-6702 Jianjun Chen (iD)

https://orcid.org/0000-0002-8631-4558 Lei Cheng (iD)

https://orcid.org/0000-0001-6541-7702

Huabin Li (iD)

https://orcid.org/0000-0002-2477-2879

Shixi Liu (iD)

https://orcid.org/0000-0003-4083-6737 Hongfei Lou (D)

https://orcid.org/0000-0002-8553-812X Jianbo Shi (iD

https://orcid.org/0000-0001-7733-8833 Ying Sun (iD)

https://orcid.org/0000-0003-4052-2498 Dehui Wang (D)

https://orcid.org/0000-0003-0346-3193 Chengshuo Wang (D)

https://orcid.org/0000-0003-0646-5135 Xiangdong Wang (ID

https://orcid.org/0000-0002-0409-322X Yongxiang Wei (iD)

https://orcid.org/0000-0002-4779-5491

Weiping Wen (ID)

https://orcid.org/0000-0002-1075-7475

Pingchang Yang (D)

https://orcid.org/0000-0002-6806-9464 Qintai Yang (D)

https://orcid.org/0000-0003-3377-737X Gehua Zhang (D)

https://orcid.org/0000-0002-1917-0283

Yuan Zhang (ID

https://orcid.org/0000-0003-1080-4267 Changqing Zhao (D)

https://orcid.org/0000-0002-3825-0940 Dongdong Zhu (D)

https://orcid.org/0000-0002-8495-5626 Li Zhu (D)

https://orcid.org/0000-0002-5988-5371 Fenghong Chen (D)

https://orcid.org/0000-0001-8015-3282 Yi Dong (D)

https://orcid.org/0000-0001-6864-4724 Qingling Fu (iD

https://orcid.org/0000-0002-5969-628X

Jingyun Li (D)

https://orcid.org/0000-0001-8066-4648 precision medicine has been used to treat inflammation by targeting key biomarkers that are involved in the process. However, there are no CRS guidelines or a consensus available from China that can be shared with the international academia. The guidelines presented in this paper cover the epidemiology, economic burden, genetics and epigenetics, mechanisms, phenotypes and endotypes, diagnosis and differential diagnosis, management, and the current status of CRS in China. These guidelines-with a focus on China-will improve the abilities of clinical and medical staff during the treatment of CRS. Additionally, they will help international agencies in improving the verification of CRS endotypes, mapping of eosinophilic shifts, the identification of suitable biomarkers for endotyping, and predicting responses to therapies. In conclusion, these guidelines will help select therapies, such as pharmacotherapy, surgical approaches and innovative biotherapeutics, which are tailored to each of the individual CRS endotypes.

Keywords: Chronic, sinusitis; China; guideline; inflammation; biomarkers; epigenesis; phenotype; endotypes; diagnosis; management

\section{INTRODUCTION}

Chronic rhinosinusitis (CRS) is an otorhinolaryngologic condition that is common around the world and affects quality of life $(\mathrm{QoL})$, health care ${ }^{2}$ and productivity. ${ }^{3} \mathrm{CRS}$ often occurs concurrently with lower airway diseases, such as asthma, in Caucasian patients, but not in Chinese patients. ${ }^{4,5} \mathrm{CRS}$ is classified into 2 phenotypes, CRS with nasal polyps (CRSwNP) and CRS without nasal polyps (CRSsNP) ${ }^{6,7}$ The endotypes of CRS differ based on the inflammatory cytokine profiles of the Caucasian and Chinese patients. ${ }^{5}$ Caucasian CRSwNP patients show a greater proportion of T helper (Th) 2 cells and higher levels of eosinophilic infiltrate than Chinese patients. ${ }^{5}$ Recent studies in China on the pathogenesis, phenotyping, endotyping, and different treatments of CRS have resulted in significant new developments that highlight progress in Chinese rhinological research. Consequently, the Chinese Society of Allergy and the Chinese Society of Otolaryngology Head and Neck Surgery convened an expert task force to develop the Chinese guidelines for CRS, founded on evidence-based models. After the initial meeting in October 2017, 2 seminars were held to update the consensus statement in August 2018 and January 2019. The guidelines on CRS (available in English) can be readily accessed by the international scientific community and will benefit clinical practice and research on CRS across the globe.

\section{EPIDEMIOLOGY AND THE BURDEN OF CRS}

The suggestions provided in the European Position Paper on Rhinosinusitis and Nasal Polyps (EP3OS), regarding the definition of symptom-based rhinosinusitis, are used in epidemiological studies. ${ }^{6}$ However, comparisons based on epidemiological studies are undesirable because of insufficient data, variable methods of investigation, and differences in regional, social, and economic circumstances of various countries. ${ }^{8}$ Medical management and surgical interventions cannot effectively control symptoms in CRS patients. The symptoms of CRSwNP and CRSsNP overlap; however, CRSwNP patients have more nasal symptoms and show higher symptom scores than the CRSsNP patients. ${ }^{9} \mathrm{CRSwNP}$ is becoming increasingly prevalent and is particularly difficult to treat using conventional therapies. ${ }^{2}$ 


\section{Yanqing Li (B)}

https://orcid.org/0000-0001-5574-7994

Chengyao Liu iD

https://orcid.org/0000-0002-0056-9032

Feng Liu (iD

https://orcid.org/0000-0003-2866-2340

Meiping Lu (D)

https://orcid.org/0000-0001-8097-614X

Yifan Meng (iD)

https://orcid.org/0000-0003-2988-8763

Jichao Sha (iD)

https://orcid.org/0000-0002-3731-3954

Wenyu she (iD)

https://orcid.org/0000-0001-5632-3552

Lili Shi iD

https://orcid.org/0000-0002-1923-2616

Kuiji Wang (iD

https://orcid.org/0000-0002-0052-6278

Jinmei Xue (iD

https://orcid.org/0000-0002-7428-7812

Luoying Yang (iD)

https://orcid.org/0000-0001-5061-9192

Min Yin (iD

https://orcid.org/0000-0002-6297-0016

Lichuan Zhang (iD)

https://orcid.org/0000-0001-5398-0557

Ming Zheng (iD)

https://orcid.org/0000-0002-8991-6642

Bing Zhou iD

https://orcid.org/0000-0003-2640-7370

Luo Zhang iD

https://orcid.org/0000-0002-0910-9884

Disclosure

There are no financial or other issues that might lead to conflict of interest.
The estimated prevalence of CRS is $10.9 \%$ in Europe, ${ }^{10} 16 \%$ in the United States, ${ }^{11}$ and $5.51 \%$ (EP3OS-defined CRS) in Sao Paulo, Brazil. ${ }^{12}$ A Population Health Survey estimates the prevalence of CRS in Korea to be $6.95 \% .{ }^{13}$ In Canada, $5.7 \%$ of women and $3.4 \%$ of men have CRS. ${ }^{14} \mathrm{CRS}$ is more prevalent than asthma and chronic obstructive pulmonary disease (COPD) according to the vital health statistics. ${ }^{15}$ Due to its high prevalence, CRS imposes enormous health and economic burdens on individuals, families, communities, and on society as a whole. ${ }^{16}$ The health burden of CRS in Asia is huge, especially in developing countries. CRS is common in mainland China with an estimated prevalence of $8 \%$, meaning that approximately 107 million individuals have CRS. ${ }^{17}$ Due to changes in the environment and based on the status of health care, the prevalence and pattern of CRS can vary regionally and change over time.

CRS causes pronounced physical symptoms including a reduced sense of smell, rhinorrhea, nasal blockage, facial pressure or pain, and headache. Although not fatal, these symptoms are persistent and can affect QoL and work by impairing the general health, vitality, and social functioning of CRS patients. These symptoms can also result in stress-associated disorders, which can manifest as depression and anxiety. ${ }^{18-20}$ Patients report that CRS impacts their daily life more severely than do medical examinations. ${ }^{21}$ In Southeast China, patients with CRS visit physicians 4.5 times more, and miss 11.7 more days of work or school per year than individuals without CRS. Patients with CRS are more likely to wake up during the night due to shortness of breath or coughing than individuals without CRS (6.9\% vs. 1.4\% and $14.7 \%$ vs. $4.2 \%$, respectively). ${ }^{22}$ Individuals with self-reported CRS perceive to have an impaired QoL in terms of physical and mental functioning; this particularly affects women, the elderly and those with a higher level of education. These factors as well as clinical care must be considered when assessing the burden of CRS.

Clinical studies have shown that a patient's QoL can be greatly improved by adequately treating CRS. ${ }^{21,23}$ However, few population-based studies show how CRS affects QoL. Studies examining QoL of CRS patients have mostly focused on patients with severe symptoms clinically diagnosed by nasal endoscopies and CT scans. It is still unclear whether, and to what extent, CRS impairs QoL in people with relatively mild symptoms. Moreover, patients without CRS, chosen as negative controls for these studies, may suffer from other disorders that affect their QoL. This selection bias has likely resulted in the effect of CRS on QoL. Furthermore, the impact of CRS on different subpopulations should also be considered.

CRS in combination with asthma is a common but severe airway disease. ${ }^{24} \mathrm{An}$ epidemiological study by the Global Allergy and Asthma Network of Excellence showed a strong association between asthma and CRS (adjusted odds ratio, 3.47) in all age groups. ${ }^{25}$ In contrast, it has been reported that the prevalence of asthma among CRS patients in China is relatively low. ${ }^{26}$ Fan et al. ${ }^{26}$ showed that only $2-3 \%$ of CRS patients in southern China have concurrent asthma. Clinically, nasal polyps with comorbid asthma (NPcA) have gained increased attention due to the severity of this disease and due to the high recurrence of nasal polyps (NP). ${ }^{27,28}$ In Western countries, approximately $32 \%$ of CRSwNP patients have asthma, ${ }^{29,30}$ but the prevalence of NPcA in the Chinese population is unknown. NPcA is highly heterogeneous with respect to clinical, physiological and pathological parameters. A cluster analysis of 110 patients with NPcA by Wu et al. ${ }^{31}$ resulted in the classification of these patients into the following 3 distinct categories: atopic NPcA, smoking NPcA, and NPcA occurring at older age. This classification may contribute to improved management of NPcA. With respect to disease severity and treatment approaches, the clinical features of NPcA occurring 
concurrently with aspirin sensitivity differ from those of NPcA without aspirin sensitivity. ${ }^{32}$ Aspirin desensitization improves disease management and QoL in this patient population. ${ }^{33,34}$

\section{GENETICS AND EPIGENETICS}

Genetic factors working in concert with environmental factors affect the development of CRS. ${ }^{35}$ Formal heritability studies are rare, but genetic studies on CRS have provided crucial insight into the etiology of this condition..$^{36}$ Several studies have reported familial aggregation and significant familial risk of CRS..$^{37-41}$ Mutations in the CFTR gene, which causes cystic fibrosis (CF), are significantly associated with CRS, indicating that genetic variations in immunological molecules in the mucosa of the sinuses contribute to the pathogenesis of CRS. ${ }^{42}$ Using exome sequencing, Zhang et al. ${ }^{43}$ found a novel mutation in DNAH5 (c. $8030 \mathrm{G}$ $>$ A), which may be responsible for CRS and primary ciliary dyskinesia in a Chinese family. Allergic rhinitis and asthma, which show even higher heritability, occur frequently in CRS patients, ${ }^{17,26}$ further indicating the potential role of genetic components in CRS.

Candidate genes and genome-wide association studies (GWAS) have been used in genetic studies of CRS. Currently, over 70 genes are known to be associated with CRS, ${ }^{44}$ but only a limited number of susceptibility genes can be replicated. ${ }^{45-49}$ Only a few single-gene association studies on CRS have been performed in China, and none of the reported susceptibility genes and loci for CRS have been identified in other populations. The susceptibility genes in the Chinese population with CRS are listed in Table 1. Most of these genes code for cytokines and cytokine receptors, proteins involved in the immune response pathways and airway remodeling proteins. Two DNA pool-based GWAS were conducted in Caucasian CRS patients and healthy controls. One study identified a total of 600 SNPs in 445 genes that were statistically significant; additionally it showed that the top 10 CRS-associated genes, including $L A M A 2$ and $L A M B 1$, PARS2 (the mitochondrial function gene), and $A O A H$ showed interactions at the basement membrane (BM) and in the extracellular matrix (ECM) ${ }^{50}$ Another study reported 23 genetic variants associated with Staphylococcus aureus

Table 1. Susceptibility genes for CRS identified in Chinese population studies

\begin{tabular}{|c|c|c|c|}
\hline Gene & SNP & Sample size & Genotyping method \\
\hline$I L-7 \beta$ & $-31 T / C$ & 123 CRS vs. 239 Controls & PCR-RFLP \\
\hline IL-6 & $-572 C / G$ & 123 CRS vs. 239 Controls & PCR-RFLP \\
\hline \multirow[t]{2}{*}{$I L-4$} & $-33 T>C$ & 23 CRS vs. 239 Controls & ARMS-PCR \\
\hline & $-590 C>T$ & & \\
\hline IL-10 & $-1082 A>G$ & 23 CRS vs. 239 Controls & ARMS-PCR \\
\hline$I L-1 R a$ & VNTR (intron 2) & 88 CRS vs. 103 Controls & PCR-RFLP \\
\hline \multirow[t]{3}{*}{$T S L P$} & rs13156068 & 638 CRS vs. 325 Controls & Sequenom MassARRAY \\
\hline & rs764917 & & \\
\hline & rs252706 & & \\
\hline$E B I 3$ & rs428253 & 667 CRS vs. 330 Controls & Sequenom MassARRAY \\
\hline$H L A-D R$ & HLA-DR16 & 30 CRSwNP vs. 81 Controls & PCR-SSP \\
\hline \multirow[t]{2}{*}{$H L A-D Q$} & HLA-DQ8 & 30 CRSwNP vs. 81 Controls & PCR-SSP \\
\hline & HLA-DQ9 & & \\
\hline \multirow[t]{2}{*}{ MMP9 } & rs3918242 & 203CRSwNP vs.730 Controls & TaqMan-MGB \\
\hline & rs2274756 & & PCR-RFLP \\
\hline$R Y B P$ & rs4532099 & 638 CRS vs. 315 Controls & Sequenom MassARRAY \\
\hline$A O A H$ & rs4504543 & 638 CRS vs. 315 Controls & Sequenom MassARRAY \\
\hline
\end{tabular}

CRS, chronic rhinosinusitis; SNP, single-nucleotide polymorphism; CRSwNP, chronic rhinosinusitis with nasal polyps; HLA, human leukocyte antigen; PCR-RFLP, polymerase chain reaction-restriction fragment length polymorphism; ARMS-PCR, amplification refractory mutation system-polymerase chain reaction; VNTR, variable number tandem repeat; PCR-SSP, polymerase chain reaction-sequence specific primer. 
colonization in CRS patients. ${ }^{51}$ Zhang et al. ${ }^{50}$ identified the same CRS susceptibility genes that had been found earlier in a pool-based GWAS in a Caucasian population. Additioally, the study confirmed one SNP locus (rs4504543) in the AOAH gene, indicating that some genetic elements involved in the pathogenesis of CRS are common between Chinese and Caucasian populations ${ }^{48} \mathrm{~A}$ large-scale GWAS on CRS and NP was performed in 2 large European cohorts with 4,366 NP patients, 5,608 CRS patients, and > 700,000 controls. This study indicated that a loss-of-function missense variant of ALOX15, p.Thr560Met shows a significant genome-wide association with NP and CRS. ${ }^{52}$ ALOX15 codes for arachidonate 15-lipoxygenase, which is elevated in NP tissues and plays an important role in inflammatory processes. Although the ExAC database shows that the p. Thr560Met variant of ALOX15 exhibits no polymorphisms in the East Asian population, other functional variants of ALOX15 associated with NP and CRS should be investigated in the Chinese population.

Unlike genetic variations, epigenetic modifications can influence gene and protein expression without changing or modifying the basic DNA sequence, which impacts chronic inflammatory processes and patterns in certain tissues. ${ }^{53,54}$ Hypermethylation in the promoter region of the collagen type XVIII alpha 1 chain was found in CRSwNP tissues obtained from a Chinese patient cohort. ${ }^{55}$ In airway epithelial cells, the overexpression of miR-125b increases type I interferon (IFN) expression by suppressing the EIF4E-binding protein 1, which may play an important role in the development of mucosal eosinophilia in eosinophilic CRSwNP. ${ }^{56}$ Additionally, Ma et al..$^{57}$ reported that microRNAs (miRNAs) could potentially be involved in the regulation of dendritic cell (DC) function and in the core pathogenesis of CRS, highlighting new therapeutic targets in CRS.

\section{MECHANISMS}

\section{General immunity involved in airway diseases}

Unlike other organ systems in the body, the respiratory system is relatively open and consistently exposed to infectious agents, allergens, pollutants and other environmental factors. The diseases of the respiratory system occur in the upper and lower respiratory tracts. The immune system enables the host to resist infection and to clear harmful substances from the body. Immune cells (i.e., airway epithelial cells, DCs, granulocytes, mast cells, macrophages, innate lymphoid cells [ILC], T cells and B cells) and molecules (cytokines, chemokines, immunoglobulins [Igs] and complement factors) may be involved in the pathogeneses of the aforementioned diseases. For example, although CRS develops as a result of dysregulation of the immune response upon exposure to external stimuli, genetic factors should also be considered. The innate immune system is the first barrier in the body's defense system. In CRS patients, the innate immunity provided by the airway epithelium is impaired, leading to an insufficient local innate immune response against microbial agents and antigens that invade and stimulate the mucosal tissues. The abnormal innate immune response also initiates and maintains chronic inflammation by recruiting and activating other innate and adaptive immune cells..$^{58}$

Breakdowns of tight junctions or defective nasal-sinus epithelial cells are typical of CRSwNP. They may be caused by external stimuli and inflammatory mediators, leading to abnormal regulation and declining function of epithelial cells. ${ }^{59}$ Activation of Toll-like receptor (TLR) signaling pathways or epithelial injury may promote expression of thymic stromal lymphopoietin (TSLP), interleukin (IL)-25, and IL-33 by epithelial cells; these 
molecules serve as important connections between innate and acquired immunity. ${ }^{60}$ In CRS patients, the expression of TSLP is significantly increased, ${ }^{61,62}$ and this may promote the differentiation of T cells into Th2 cells $^{63}$ and encourage type 2 ILC (ILC2) to secrete type 2 cytokines, especially IL-5, IL-13 and IL-4. ${ }^{64,65}$ This cascade may explain why TSLP is positively associated with chronic type 2 eosinophilic inflammation which is observed in CRSwNP patients. ${ }^{62,66}$ Expression of IL-25 and its receptor (IL-17RB) is also significantly elevated in CRSwNP patients. In a murine NP model, anti-IL-25 treatment reduced the number of polyps, thickness of the mucosal edema, collagen deposition and infiltration of inflammatory cells, ${ }^{67}$ suggesting that IL-25 might serve as a potential target for CRSwNP. ${ }^{68}$

In addition to activating the DCs and inducing Th2-mediated reactions, TSLP, IL-25 and IL-33 may also contribute to the locally increased numbers and activity of ILC2 cells in CRSwNP. ${ }^{60}$ IL-33 is associated with the secretion of Th1 and Th17 cytokines and the local accumulation of neutrophils in Asian CRSwNP patients. ${ }^{69}$

Increased numbers of ILC2 cells are highly correlated with eosinophilia in blood and local tissues. ${ }^{70,71}$ Type 2 cytokines contribute to the maturation and activation of eosinophils and induce the activation of endothelial cells and other target cells expressing adhesion molecules, chemokines, and different T-cell-associated factors. ${ }^{70,72}$ Different DC subsets and macrophages may be involved in the pathogenesis of the distinct phenotypes and endotypes of CRS, as indicated by the increased number of distinct DC subsets in the $\mathrm{NP}^{43,73}$; this suggests that these subsets may be functionally different from each other. Furthermore, it has been found that the CD11 $\mathrm{c}^{+} \mathrm{DC}$ counts are significantly elevated in the NP of subjects suffering from eosinophilic allergies compared to those in the relevant controls. ${ }^{74}$ Correspondingly, M2 macrophages, which predominate in CRSwNP, attracted DC and Th2 cells by secreting chemokine (C-C motif) ligand (CCL) 18. An increased number of $\mathrm{CD}_{163^{+}}$ M2 macrophages was also observed in eosinophilic NP of atopic subjects. ${ }^{74}$ Conversely, M1 macrophages were predominant in CRSsNP. ${ }^{75}$ Eosinophils play a critical role in CRSwNP, type 2 inflammation and local tissue damage ${ }^{76}$; local basophil and mast cell counts are normally associated with those of the infiltrating eosinophils. ${ }^{77}$

T-helper cell subtypes may contribute to the phenotypes and endotypes of CRS. Th1 cells are normally the predominant $\mathrm{T}$ lymphocytes in CRS patients, especially in those with CRSwNP. Th2 cells are mainly found in the nasal polyp tissues of CRSwNP patients but are nearly absent from the nasal mucosa of the CRSsNP patients. ${ }^{78,79} \mathrm{CRSwNP}$ patients, especially in China, show an infiltration of various inflammatory cells, mainly neutrophils, and Th1 and Th17 cells. ${ }^{80,81}$ Some patients show an assortment of infiltrating cells. For example, Th17/ Th2-type inflammation may exist simultaneously in the same nasal polyp, while neutrophils with relevant biomarkers may also occur in eosinophilic NP. ${ }^{5}$ Th17 cells may participate in the pathogenesis of CRS by secreting IL-17A and IL-21, ${ }^{82,83}$ but the role of the regulatory T cells (Tregs) in CRSwNP tissues remains controversial. ${ }^{84}$

The increase in the number of $B$ cells, plasma cells and lymphoid follicles in the NP of the CRSwNP patients might be due to the upregulated expression of B-cell activating factor (BAFF) in local tissues. Local B cells are activated under certain conditions and can differentiate into memory B cells and/or plasma cells, which produce IgM, IgG, IgA and IgE after undergoing somatic hypermutation and/or class switch recombination. ${ }^{84,86} \mathrm{IgE}$ is a key factor in some CRSwNP patients, ${ }^{87}$ while other types of antibodies may contribute to local inflammation and tissue damage via the activation of classical complement pathways. ${ }^{88}$ 


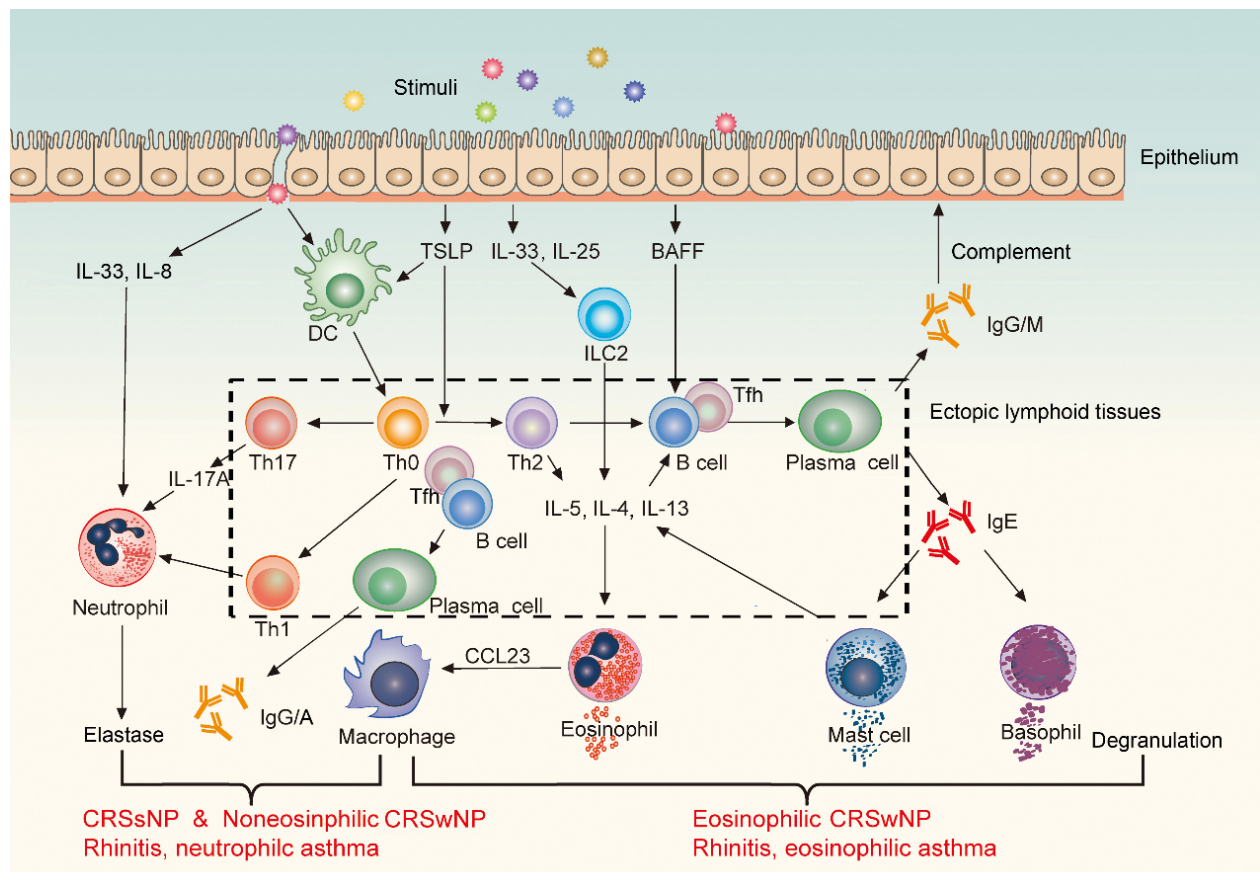

Fig. 1. Potential mechanisms of immune cells and mediators involved in the pathogenesis of airway diseases. IL, interleukin; DC, dendritic cell; TSLP, thymic stromal lymphopoietin; BAFF, B-cell activating factor; Ig, immunoglobulin; Th, T helper; CCL23, chemokine (C-C motif) ligand 23; CRSsNP, chronic rhinosinusitis without nasal polyps; CRSwNP, chronic rhinosinusitis with nasal polyps.

Some autoantibodies, such as antinuclear antibody, anti-double stranded DNA (antidsDNA) antibody and anti-neutrophil cytoplasmic antibody, have been detected in the polyp tissues. ${ }^{89-91}$ The potential mechanisms associated with asthma, rhinitis and CRS are illustrated in Fig. 1.

\section{Microbiology of CRS}

Initially, CRS was thought to be an infectious disease that was caused by viruses, fungi or bacteria. Although CRS is indeed an immune-mediated condition, the local microbial milieu may exacerbate the progression of CRS. ${ }^{92}$

Standard microbial cultures and gene sequencing are the 2 major methods that are used to identify microbes locally. Standard cultures offer defined conditions for microbial growth, and gene sequencing (especially next-generation sequencing) is culture-independent and targets taxonomically-informative regions of the genome. ${ }^{93} \mathrm{~A}$ comparison between the 2 approaches showed that only half of the dominant bacteria and $5 \%$ of the low-abundance bacteria identified with gene sequencing in CRS patients and healthy controls were identified by the standard culture method. Next generation sequencing will further provide detailed information about microbial communities inhabiting the nasal sinus membrane. ${ }^{94}$

\section{Bacteria}

No differences were found between the CRS patients and healthy individuals with respect to bacterial composition, indicating that bacteria existent in the CRS patients were also likely to exist in the healthy individuals. Most studies show an increased bacterial abundance in CRS patients. However, results regarding bacterial diversity in CRS patients compared to that of healthy controls are controversial. ${ }^{95}$ Staphylococcus, Propionibacterium and Corynebacterium were found to be 
the most abundant bacteria in the sinonasal mucosae of both CRS patients and healthy controls; Anaerococcus, Streptococcus, Pseudomonas, Haemophilus and Moraxella were less common. ${ }^{92}$

In the sinonasal mucosae, bacteria exist as free-floating planktonic replicating cells and biofilms. Biofilms are complex, multicellular assemblages comprised of a polysaccharide matrix, which acts as structural basis for microbial clusters and as a barrier to the surrounding environment. Biofilms protect the bacteria living inside from various threats, including host phagocytic cells, antibiotics, and surfactants. ${ }^{96,97} \mathrm{CRS}$ patients with biofilm formation have poor prognosis and postoperative outcomes. ${ }^{98}$

Different bacteria play different roles in the pathophysiology of CRS. S. aureus frequently colonizes the human nose and is more abundant in CRS patients than in healthy controls..$^{99}$ Exotoxins produced by $S$. aureus disrupt the integrity of the epithelial barriers and show anti-inflammatory activity. They affect the complement system, antimicrobial peptide production, adhesion, and chemotactic processes. ${ }^{100,101}$ S. aureus enterotoxins (SEs) can act as super-antigens, stimulating the generation of polyclonal IgE and eosinophilic inflammation. IgE specific to SEs (SE-IgE) occurs in nearly half of all the NP. The presence of specific IgE in response to enterotoxins A and B (SEA and SEB) is positively correlated with the total IgE concentration and eosinophilic inflammation in the nasal tissue. ${ }^{102}$ However, the polyp colonization rate of $S$. aureus in Chinese CRSwNP patients and healthy controls is much lower than that reported in European studies. ${ }^{103}$ Only $20 \%$ of the NP express IL-5 and are predominantly colonized by gram-positive bacteria in Chinese CRSwNP patients. ${ }^{104} \mathrm{Liu}$ et al. ${ }^{105}$ found no significant differences in the bacteriological profiles in the nasal middle meatus among the Chinese CRSwNP and CRSsNP patients and healthy controls. They also showed that the most common bacteria were coagulase-negative Staphylococci, Corynebacterium species, S. aureus, and Haemophilus influenzae. Interestingly, the isolation rates of $S$. aureus are lower in Chinese CRSwNP patients than in their Caucasian counterparts. ${ }^{105}$

Corynebacterium tuberculostearicum was found to be correlated with the severity of CRS, and this was further confirmed in a human cohort and in a study performed in a murine model. ${ }^{106}$ Some bacterial species may play a protective function in CRS patients. Acinetobacter johnsonii exhibits a higher mean relative abundance in healthy individuals and it can release factors that promote IL-10 production, thereby exerting beneficial anti-inflammatory effects in patients with CRS. ${ }^{107}$

Fungi

Fungi widely colonize the sinonasal mucosae of CRS patients and healthy individuals. Amplicon sequencing, used to study fungal organisms in CRS, revealed no major differences in the fungal microbiomes of the controls and the CRS patients. ${ }^{108}$ The results regarding the prevalence are conflicting. Cleland et al. ${ }^{108}$ reported that Malassezia was the most prevalent fungal genera, while Aurora et al. ${ }^{109}$ found Cryptococcus to be the most commonly-detected organism. These variations may have resulted from differences in detection methods, CRS subtypes, disease severity, geography and other comorbidities. ${ }^{110}$

Fungi and bacteria may interact, and the presence of fungi may help bacteria to invade and grow in the sinonasal mucosae of patients with allergic fungal rhinosinusitis (AFRS). For example, adhesion of $S$. aureus to the Candida albicans hyphae may aggravate intramucosal invasion. ${ }^{111}$ Oral, topical and intravenous antifungals are not recommended in CRS, indicating that fungi are unimportant in the pathophysiologic processes of CRS. ${ }^{112}$ 
Viruses

CRS is more severe during seasons that are associated with a high prevalence of viral infection. ${ }^{113}$ Cho et al..$^{114}$ detected multiple respiratory viruses in the lavage samples from CRS patients but not in those from the non-CRS controls, with human rhinovirus showing particularly higher prevalence in CRS patients than in the controls. Liao et al. ${ }^{115}$ tested the scraped epithelial cells from the middle meatus and revealed a higher prevalence of respiratory viruses in the CRSwNP and CRSsNP patients than in the healthy controls although the difference was not statistically significant. Viral infections can increase the incidence of opportunistic secondary bacterial infections which exacerbate CRS ${ }^{16}$ by disrupting epithelial barrier integrity and impairing ciliary function and mucociliary clearance (MCC). ${ }^{117}$ Wang et al. ${ }^{118}$ showed severe infiltrations of $S$. aureus into the nasal mucosa and CRSwNP tissues pre-infected with herpes simplex virus type 1 (HSV1). Nasal polyp tissues collected from the CRSwNP patients—who were infected with HSV1—showed significantly lower production of IFN- $\gamma$ and IL-17 than the inferior turbinate tissues from the healthy controls. ${ }^{19}$

\section{Innate immunity and CRS}

Innate immunity in the sinonasal cavity and pathogen detection by the TLRs expressed on the sinonasal epithelial cells, bitter taste receptors, and sweet taste receptors, are important protective factors. Activation of these receptors elicits innate immune responses, resulting in improved MCC and defensin secretion. ${ }^{58}$ Innate immune effector cells, including dendritic and mast cells, eosinophils, and ILCs, are involved in shaping the CRS pathophysiology and contribute to the secretory phenotype of $\mathrm{T}$ cells and B-cell differentiation. ${ }^{120}$

Eosinophilic and non-eosinophilic CRSwNP also show distinct lesional DC profiles. Only DCs from eosinophilic CRSwNP induced enhanced Th2 responses when cocultured with naive $\mathrm{CD} 4^{+} \mathrm{T}$ cells ${ }^{43}$ In innate immunity, the expression of the antimicrobial protein, nasal epithelium clone 1 in the short palate and lungs (SPLUNC1) is differentially impaired in subsets of eosinophilic and non-eosinophilic CRSwNP. Eosinophilic CRSwNP shows significantly decreased SPLUNC1 expression. ${ }^{121}$ TSLP-which is similar to IL-7 and is produced by epithelial and keratinized cells ${ }^{122}$-is an important initiator of the Th2-cell response. TSLP activates dendritic and other antigen-presenting cells, thereby driving the differentiation of $\mathrm{CD} 4^{+} \mathrm{T}$ cells towards the Th phenotype. ${ }^{123}$ TSLP and TSLP receptors show significantly higher expression in the eosinophilic CRSwNP compared to that in the non-eosinophilic CRSwNP. ${ }^{124}$

Immune and epithelial cells in the sinonasal mucosa interact with the inhaled environmental stimuli and the nasal bacterial microbiome, thereby forming a dynamic immune barrier that is altered in CRS. Defects in innate immunity combined with chronic activation of various inflammatory cells are responsible for CRS pathogenesis. Epithelial injury in the nasal mucosa may allow pathogens, proteases, or antigens to enter the lamina. These irritants, together with IL-25, IL-33 and TSLP secreted during epithelial injury, initiate, recruit and activate antigen-specific T and B cells. ${ }^{72}$

\section{T-cell immunity in CRS}

T-cell-associated immunity, especially $\mathrm{CD} 4^{+} \mathrm{Th}$ cells, which orchestrate local mucosal immune responses, may play an important role in CRS pathogenesis. Dysregulation of the Th1/Th2 balance may cause a Th2-biased response, which induces the formation of NP. ${ }^{125128} \mathrm{CRSsNP}$ is characterized predominantly by a Th1-mediated neutrophilic milieu whereas CRSwNP is characterized by Th2-biased eosinophilic inflammation in Caucasian patients. ${ }^{129,130}$ 
Derycke et al. $^{79}$ found more $\mathrm{CD}^{+} \mathrm{T}$ cells in the NP tissues than in the CRSsNP or control nasal tissues but observed no significant differences between the CRSsNP and the control tissues. They found that effector $\mathrm{T}$ cells predominantly showed a Th1 phenotype in CRSwNP and CRSsNP and in the control mucosal tissues. However, Th2 cells $\left(\mathrm{CD}^{+} \mathrm{CD}^{+}\right.$cells producing IL-4 or IL-5) were only detected in CRSwNP.

Th17 cells are a novel Th-cell subset that express IL-17 and are involved in T-cell-mediated immunity in CRS. Cao et al..$^{82}$ demonstrated an upregulated Th17 response in Asian patients with CRSsNP or CRSwNP. Derycke et al. ${ }^{131}$ found that Th17 cells can modulate neutrophil survival by secreting IL-17A in Caucasian patients with non-CF and CRSwNP. IL-17A $\mathrm{A}^{+}$-cell numbers were positively associated with those of eosinophils in the Japanese CRS patients. ${ }^{132}$ Jiang et al. ${ }^{133}$ showed enhanced Th17 responses in Chinese CRSwNP patients. Saito et al..$^{83}$ showed that IL-17 $\mathrm{A}^{+}$-cells are correlated with high eosinophil numbers but not with the high neutrophil counts in Japanese patients with asthma-associated CRSwNP.

Several studies have presented conflicting findings on the role of Tregs in CRS pathogenesis. Two separate studies have found that the expression of FoxP3, the master transcriptional regulator of Tregs, is decreased at the messenger RNA (mRNA) and protein level in CRSwNP as is the expression of the regulatory cytokines IL-10 and transforming growth factor (TGF)- $\beta$, indicating a Treg deficiency or dysfunction in CRSwNP tissues. ${ }^{81,129} \mathrm{Wu}$ et al. $^{134}$ found decreased expression of FoxP3 in the NP tissues compared to that in the healthy uncinate process tissues. They found a molecular mechanism regulating the inhibitory function of Tregs via the phosphorylation motif(Ser270/274) of Foxp3, which is recognized by the proinflammatory kinase, GSK-3ß. Ma et al. ${ }^{135}$ found decreased percentage of FoxP3 ${ }^{+} \mathrm{CD} 8^{+}$Tregs in the eosinophilic and non-eosinophilic NP. Conversely, Miljkovic et al..$^{136}$ found that Tregs $\left(\mathrm{CD} 45^{+} \mathrm{CD} 4^{+} \mathrm{CD} 25^{+} \mathrm{CD} 127^{\text {low }}\right)$ are significantly elevated in the CRSwNP nasal tissues compared to those in the CRSsNP tissues. Overall, the frequencies of Tregs $\left(\mathrm{CD3}^{+} \mathrm{CD}^{+} \mathrm{CD}^{2} 5^{+} \mathrm{FoxP3}^{+}\right)$were significantly higher in the $\mathrm{CRS}$ tissues than in the control tissues, while $\mathrm{CD} 8^{+}$Treg $\left(\mathrm{CD}^{+} \mathrm{CD}^{+} \mathrm{CD}^{2} 5^{+} \mathrm{FoxP}^{+}\right)$levels were significantly reduced in the CRSwNP. ${ }^{137}$ In summary, although Tregs play an important role in inflammatory diseases, it is essential that the role of Tregs in CRS be investigated worldwide.

\section{B-cell immunity in CRS}

As key components of adaptive immune responses, B cells produce antibodies, function as antigen-presenting or regulatory cells and can contribute to the pathogenesis of inflammatory disorders, including CRS. Although B cells are likely to be important in CRS, their role in airway mucosa is unclear and should be determined in future studies.

B cells accumulate in the lamina propria of NPs. ${ }^{85}$ The levels of total IgE, SE-IgE, and IgEpositive cells, are increased in CRSwNP samples.$^{87}$ Furthermore, the levels of the Ig isotypes, IgM, IgG, IgA and IgE, are elevated in the CRSwNP nasal mucosa. Ig isotypes with the exception of IgE, show normal expression in the sera of CRSwNP patients, indicating that antibodies in the NPs are produced by local immune cells. ${ }^{13}$ Whether B-cell responses in CRSwNP nasal mucosa are antigen specific, superantigen-stimulated, or an expansion of natural antibody responses, remains to be determined. ${ }^{139}$ IgE may be involved in the pathogenesis of CRSwNP through activation of eosinophils, mast cells, and basophils via Fc receptors. ${ }^{84,85}$ The antigen specificity of antibodies and their roles in CRS are unclear. ${ }^{84}$ Further, it is also unknown whether these B cells enter the nasal tissue as naïve cells and later become activated, or whether they enter the nasal tissue as memory cells and get primed within the tissue. 
In Western countries, CRSwNP manifests in the form of a local Th2-mediated inflammation with increased IgE levels. IgE induces allergic inflammation by activating the mast cells and basophils. Germinal center (GC)-like structures are detected in CRSwNP. The type 2 cytokine, IL-13 is responsible for the B-lineage cell responses in eosinophilic CRSwNP. IL-13 can stimulate IgE class-switch, recombination, and IgE production in B cells. ${ }^{10} \mathrm{BAFF}$, a important factor for B-cell maturation and survival, can induce T-cell dependent or independent Ig class switching and production, resulting in increased CD20 expression. Concentrations of BAFF, IgE and IL-5, are increased in eosinophilic nasal polyp tissues, and BAFF protein levels are associated with those of IgE and IL-5. ${ }^{141}$ Previous studies have suggested that the levels of Th17-associated mediators (myeloperoxidase [MPO], IL-8, IL-17A and IL-23), BAFF, and Th1 cytokine (IFN- $\gamma$ ), were upregulated in refractory CRSwNP compared to that in the controls and primary NP regardless of tissue eosinophilia or asthmatic comorbidity. ${ }^{142}$

BAFF is a pathogenic factor in autoimmune diseases. The levels of IgG anti-dsDNA and anti-BP-180 antibodies are increased in CRSwNP nasal tissues, suggesting that these autoantibodies are involved in the pathogenesis of CRSwNP. ${ }^{89}$ Locally increased B-cell accumulation and IgE responses occur in CRSwNP with over $30 \%$ of B and plasma cells in the NP re-expressing RAG1 and RAG2 that are required for receptor revision, class switching to IgE, and B-cell differentiation into IgE-secreting plasma cells. ${ }^{86,143} \mathrm{~B}$ cells and activated plasma cells may be recruited by the B cell chemotactic factors C-X-C motif chemokine ligand (CXCL) 13 and CXCL12, which are elevated in CRSwNP. ${ }^{144}$

\section{Eosinophils in CRS}

Eosinophils, which are important granulocytes and immune-system components, develop during hematopoiesis in the bone marrow and then migrate into the blood where they respond primarily to invasion of multicellular parasites. Eosinophils are important for modulating allergy and asthma. In healthy individuals, eosinophils make up approximately $1 \%-3 \%$ of white blood cells. In some CRS patients, eosinophilia is increased and is independent of concomitant allergic rhinitis and atopy. Based on the extent of tissue eosinophilia, CRSwNP is classified into eosinophilic and non-eosinophilic subtypes. These subtypes, which are characterized by their distinct clinical features, computed tomography (CT) scans, and different immunopathologic mechanisms, are associated with different prognoses and therapeutic strategies (details have been provided in section 5.1, eosinophilic CRS [ECRS] and non-ECRS).

Tissue eosinophilia is modulated by miRNAs. Eosinophilic CRSwNP shows distinct miRNA expression profiles in Chinese adults. MiR-125b is specifically upregulated in eosinophilic CRSwNP and may enhance type I IFN expression thereby contributing to tissue eosinophilia. ${ }^{56}$

Osteopontin (OPN), also known as early T lymphocyte activation 1, is a phosphorylated acidic glycoprotein produced by various immune cells. ${ }^{145} \mathrm{~A}$ study using an in vitro dispersed NP cell culture system showed that recombinant human OPN promotes eosinophil migration and the production of eosinophilic cationic protein (ECP). ${ }^{146}$

High mobility group box 1 (HMGB1), a non-histone chromatin-binding nuclear protein, is essential for DNA recombination, repair, and transcription, and for cellular differentiation and signaling. ${ }^{147}$ In the extracellular microenvironment, HMGB1 is involved in the recruitment of inflammatory cells. ${ }^{148}$ Expression of HMGB1 protein and mRNA is higher in eosinophilic CRSwNP than that in the controls. ${ }^{149}$ 


\section{Neutrophils in CRS}

Neutrophils are terminal effector cells in tissue destruction and antibacterial defenses. They are also immunocompetent cells that upregulate the inflammatory response by secreting cytokines, including IL- $1 \alpha,-1 \beta,-6$ and -8 , IFN- $\alpha$, and tumor necrosis factor (TNF) ${ }^{150}$ Subtypes of polarized neutrophils include classical, proinflammatory $\mathrm{N} 1$, and anti-inflammatory or tumorigenic $\mathrm{N} 2$ neutrophils. ${ }^{151}$ The roles of the $\mathrm{N} 1$ and $\mathrm{N} 2$ neutrophils in humans have not yet been detailed, especially in CRS.

Compared to CRSwNP, CRSsNP is more neutrophilic and shows a type 1- and type-17dominant cytokine profile. ${ }^{5}$ Biofilm-positive CRSsNP patients also exhibit higher levels of neutrophils. ${ }^{152,153}$ Neutrophils are major sources of TGF- $\beta 2$ in CRS, the expression of which is upregulated in CRSsNP and non-eosinophilic CRSwNP. Thus, neutrophils play an important role during the fibrotic events in CRSsNP and non-eosinophilic CRSwNP. ${ }^{130}$ They are also major sources of oncostatin M (OSM) in individuals with CRSwNP and severe asthma. OSM is elevated in CRSwNP and may contribute to the disruption of the epithelial barrier. ${ }^{154}$ Aging may affect neutrophil responsiveness and survival. Age-related decline in neutrophilmediated inflammation occurs in non-eosinophilic CRSwNP and may favorably influence postoperative results in elderly patients. ${ }^{155}$ Elastase-positive neutrophils may be a cellular biomarker in refractory CRSwNP. ${ }^{156}$

The recruitment of neutrophils from the circulation into the extravascular spaces first involves transendothelial migration of the neutrophils into the inflammatory sinus mucosa. Then, neutrophils migrate out of the mucosa and into the sinus effusion. Mucosal epithelial cells and IL-8 are essential for neutrophil recruitment in CRS. ${ }^{157,158}$ Growth-related oncogene-alpha, granulocyte chemotactic protein-2, and epithelial cell-derived neutrophil attractant-78 are also implicated in neutrophil chemotaxis in CRS, while the roles of CXCL1, CXCL2 and IL-1 $\beta$ which are also involved in neutrophil chemotaxis, remain undetermined. ${ }^{158,159}$

Composed of several proinflammatory cytokines, including IL-1 $\beta$, IL-36 $\gamma$ and IL-33, IL-1 cytokine family participate in the regulation of neutrophilic inflammation in CRS. ${ }^{160}$ Recently, Wang et al. ${ }^{161}$ reported that the expression of the IL-36 family is upregulated in CRSsNP and CRSwNP. Epithelial cell-derived IL-36 $\gamma$ can be activated by neutrophil-secreted elastase. Neutrophils are the major cell type expressing IL-36R in CRS. ${ }^{161}$ Upon activation by cleaved IL36, neutrophils secrete IL-17A and -8 thereby exacerbating neutrophilic inflammation in CRS. ${ }^{161}$

\section{Remodeling in CRS}

Remodeling refers to permanent or transient changes in tissue architecture, including structural changes in the epithelium and production of the ECM. ${ }^{162}$ Tissue remodeling in CRS may occur concurrently with or after inflammation.

\section{Classification of tissue remodeling in different CRS types}

In addition to the persistent and exaggerated inflammation of the sinonasal mucosa, CRS is also characterized by marked tissue remodeling, including epithelial damage and metaplasia, BM thickening, fibrosis, goblet cell and mucus gland hyperplasia, and/or edema. ${ }^{130,163,164}$ Hellquist's classification lists 4 types of tissue remodeling that occur in CRS: edematous, fibrotic, glandular and atypical. ${ }^{165}$ Increased fibrosis is observed in CRSsNP whereas CRSwNP involves tissue edema with albumin deposition and pseudocyst formation. ${ }^{166,167}$ Both CRSsNP and CRSwNP involve goblet-cell hyperplasia in the epithelium. ${ }^{84}$ 
Mechanisms of tissue remodeling in CRS

Tissue remodeling is a dynamic process involving growth factor-induced ECM production and the degradation of ECM mediated by proteases and protease inhibitors. ${ }^{164}$ TGF- $\beta$ and matrix metalloproteinases (MMPs) are both critical factors involved in these processes. ${ }^{168}$ The proteins and cytokines involved in CRS-associated tissue remodeling are listed in Table 2.

In CRSsNP, fibrosis is mainly associated with high levels of TGF- $\beta 1$ or TGF- $\beta 2$. Upregulated expression of receptors and signal transducers in CRSsNP induces the activation of the TGF- $\beta$ signaling pathway ${ }^{169}$ However, the expression levels of TGF- $\beta 1$ in CRSwNP are debated (Table 2).

Edematous CRS, commonly observed in CRSwNP and eosinophilic CRSwNP, may result from an imbalance between the expression of MMPs and tissue inhibitor of metalloproteinases (TIMPs) (Table 2). ${ }^{16,170,171}$ Reduced TIMP-1 and -4 expression may disinhibit the activities of MMP 2, 7 and 9, thereby resulting in the generation of the extensive edemas observed in CRSwNP. ${ }^{130}$ Periostin, an important tissue-remodeling molecule, is also associated with the basement-membrane thickening and fibrosis in CRS. ${ }^{172}$ Activation of the coagulation system and increased generation of thrombin and coagulation factor XIII-A lead to the excessive production and cross-linking of fibrin and edema in CRSwNP. ${ }^{173,174}$

\section{Correlation between tissue remodeling and inflammation in CRS}

Tissue remodeling is associated with the inflammation patterns in Chinese CRS patients. Eosinophilic and neutrophilic inflammation is positively correlated with the severity of edema and fibrosis, respectively, in CRS. Neutrophils are the major sources of TGF- $\beta 2$, which is upregulated in CRSsNP and non-eosinophilic CRSwNP, relative to that of the control tissues and eosinophilic CRSwNP. ${ }^{130}$ Eosinophilic NPs were characterized by diffuse ethmoidal and olfactory involvement, whereas non-eosinophilic NPs showed more localized patterns and maxillary sinus involvement. In addition, high ethmoidal/maxillary CT scores were positively correlated with the levels of Th2 inflammatory markers, including IL-4, IL-5, periostin mRNA expression and total IgE levels in the NPs, whereas the levels of the Th1 cytokines and IFN- $\gamma$, were inversely correlated. ${ }^{175}$

Epithelial exfoliation and BM thickness are strongly correlated with the number of infiltrating eosinophils ${ }^{176}$ and IL-17A-positive cells ${ }^{83}$ in CRS. Conversely, tissue remodeling may promote inflammation. MMP-2 and - 9 and TGF- $\beta 1$ facilitate eosinophil and mast cell migration into the NP. ${ }^{177}$ However, airway remodeling can occur early in life ${ }^{178}$ without obvious inflammation, ${ }^{179}$ challenging the view that remodeling is dependent on prior development of inflammation.

\section{Epithelial to mesenchymal transition (EMT) in CRS}

The epithelium provides an effective barrier between the airway and subepithelium. This barrier supports epithelial cells, tight junctions, and adherens junctions, which ensure a strong cell-to-cell contact. ${ }^{180}$ If epithelial cohesion and integrity are destroyed by injury, inflammation or infection, the sinonasal mucosa can be invaded by pathogens and environmental antigens, resulting in the development of CRS. ${ }^{59}$

EMT is a process in which epithelial cells lose their cell-to-cell interactions and polarized character, eventually turning into spindle-shaped migratory mesenchymal cells. This process is crucial for wound repair, organ development, and tumor progression. ${ }^{181} \mathrm{EMT}$ is characterized by the downregulated expression of epithelial marker proteins (including E-cadherin, ZO-1, claudin and occludin) and upregulated expression of mesenchymal-associated markers 


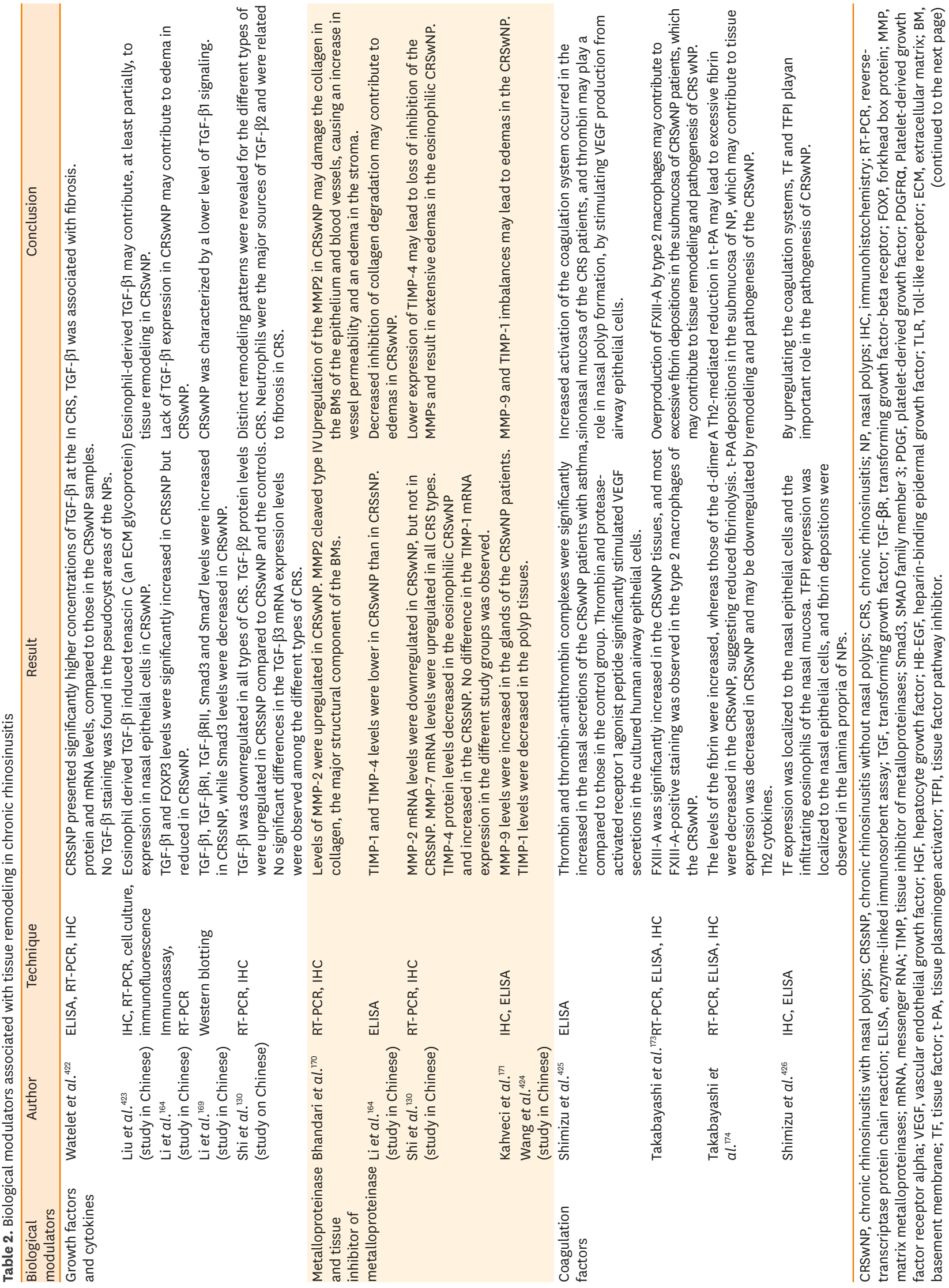




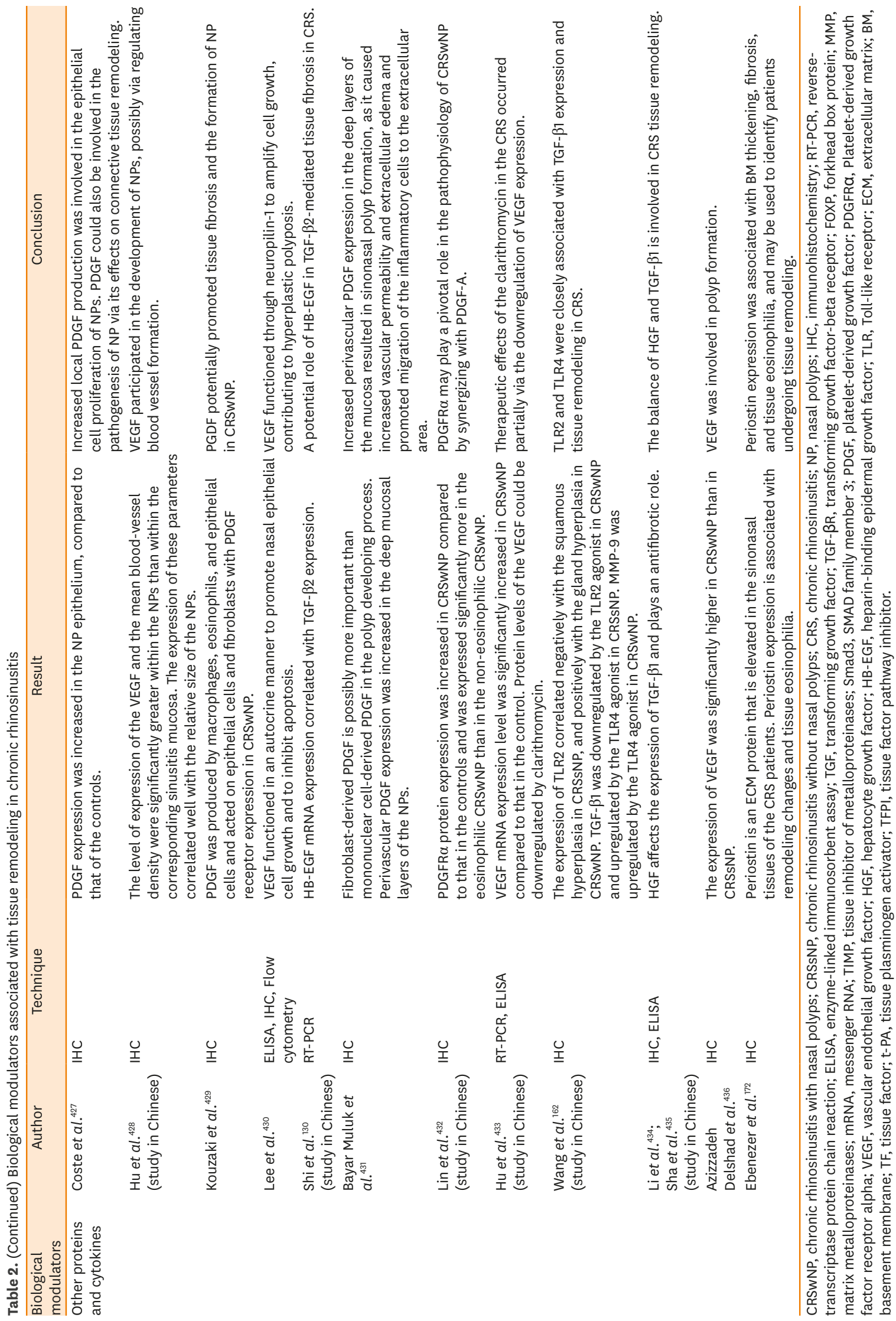


(including periostin, vimentin, MMP2, MMP9 and $\alpha$-smooth muscle actin [ $\alpha \mathrm{SMA}])^{72}$ It is implicated in CRS. ${ }^{182}$ The process of tissue remodeling, which induces epithelial loss and differentiation of fibroblasts into myofibroblasts, is associated with the pathogenesis of CRSwNP. ${ }^{164}$ The loss of E-cadherin expression is a fundamental event in EMT. ${ }^{183}$ Meng et al. ${ }^{163}$ found that increased TGF- $\beta$ expression activates myofibroblasts to express $\alpha$ SMA and vimentin and that the expression of ZO-1, occludin and E-cadherin was reduced in mature polyps. EMT is particularly prevalent in the stalks of early-stage polyps, indicating that polyp stalks are an important site for EMT events. ${ }^{163}$ Hypoxia can induce EMT, and expression of hypoxia-inducible factor-1 $\alpha$ is correlated with E-cadherin loss and $\alpha \mathrm{SMA}$ expression. It is likely that hypoxiainduced EMT contributes to nasal polyp formation. ${ }^{184}$ Although the exact mechanisms by which EMT plays a role in CRS are unclear, the role of inducible factors (including TGF- $\beta$, epidermal growth factor family, vascular endothelial growth factor and fibroblast growth factor) and EMTinducing signaling pathways (including Notch, Wnt, tyrosine kinase receptor and SMAD) is well-documented in COPD and asthma and should therefore be examined in CRS. ${ }^{185}$

\section{Osteitis in CRS}

In 1998, Kennedy et al. ${ }^{186}$ examined 43 ethmoid bone samples obtained from endoscopic surgeries and developed the concept of "bone remodeling" to explain the phenomenon of osteitis. Osteitis occurs in CRS and involves the formation and destruction of active bones along with inflammatory cell infiltration of the bone surface. ${ }^{186}$

The mechanisms of osteitis in CRS are unclear. Bone is a dynamic tissue that is constantly formed and resorbed in response to changes in mechanical loading, altered serum calcium levels, and a wide range of paracrine and endocrine factors. The dynamic nature of the skeleton is maintained by remodeling, and this involves the coordinated activities of osteoclasts (cells that destroy bone) and osteoblasts (cells that form bone), as well as osteocytes within the bone matrix and osteoblast-derived lining cells that cover the bone surface. Cytokines such as nuclear factor- $\mathrm{KB}$ (NF- $\mathrm{KB}),{ }^{187,188}$ colony stimulating factor (CSF)-1, TNF, IL-6, IL-11, IL-13, ${ }^{189} \mathrm{IL}-15$, IL-17 ${ }^{190}$ and macrophage CSF may be involved in the initiation and regulation of bone remodeling. ${ }^{191,192} \mathrm{~A}$ significant positive correlation between IL-13 and mineralization was observed in vitro. ${ }^{189}$ Moreover, elevation of IL-13 and IL-17A in CRS with neo-osteogenesis was related to osteoblast differentiation by inducing Runt-related transcription factor $2 .{ }^{190}$ Osteitis is activated by the TGF- $\beta /$ Smad signaling pathway in CRSwNP, indicating that eosinophils are important for bone remodeling. ${ }^{193}$

Osteitis in CRS is defined as, inflammatory changes in the marrow-less bone, leading to disruptions in the lamellar bone and the formation of new woven bone. ${ }^{194}$ Histopathological diagnosis is considered the "gold standard" for diagnosing osteitis. The diagnostic criteria include new woven bone, periosteal thickening, bone absorption, and fibrosis. ${ }^{186,194499}$ However, imaging is more practical for the diagnosis of osteitis in CRS than histopathology. Presently, CT is used to diagnose and evaluate sinus osteitis. Biedlingmaier et al. ${ }^{198}$ used CT to evaluate and predict bone remodeling using decreased bone density, destruction of the trabeculae and bone cortex, and bone sclerosis.

For evaluating osteitis, Georgalas et al. ${ }^{199}$ recommended using a global assessment tool and developed the Global Osteitis Score System. This evaluation system consists of a scale for evaluating the thickness of nasal bones and can be used to determine the severity and scope of osteitis. ${ }^{199}$ Measuring the Hounsfield units in CT is even more accurate than measuring the bone density when evaluating osteitis in CRS. ${ }^{200}$ 


\section{ENDOTYPES OF CRS}

CRSwNP and CRSsNP are the 2 phenotypes of CRS based on the presence or absence of NP. ${ }^{6,201}$ Discriminating between the 2 phenotypes is relatively straightforward and is done via nasal endoscopic examination and through imaging techniques such as CT scanning. The therapies available for CRS are scant and include nasal and/or oral corticosteroids, antibiotics (macrolides and doxycycline), and surgery (if the drug therapies prove unsuccessful). ${ }^{6,202,203}$ To reflect the pathomechanisms of CRS more comprehensively and to establish a more precise therapeutic strategy, it is necessary to define the endotypes of CRS. Distinct CRS clusters based on their immunological mechanisms, are important for the development of individualized treatment strategies for CRS patients. The determination of CRS endotypes will help in providing personalized treatments for this patient population. ${ }^{87,204,205}$

\section{ECRS and non-ECRS}

CRS is a heterogeneous entity showing different inflammatory endotypes. Based on the results of nasal endoscopy and CT scanning, the current guidelines recommend classifying CRS as involving or not involving polyps. ${ }^{6}$ However, these clinically observable phenotypes do not adequately reflect the diversity of CRS, ${ }^{206,207}$ and cellular endotypes are more useful for determining the mechanisms of inflammation.

Mucosal eosinophilia is a common histological feature of NP. The inflammatory patterns of CRS are designated as eosinophilic and neutrophilic (non-eosinophilic) based on the predominant inflammatory-cell type. ${ }^{208}$

Statistically, patients with mucosal eosinophilia are defined as those who fall outside the normal range obtained using healthy sinonasal mucosa. ${ }^{209}$ Using this method, Cao et al. ${ }^{82}$ used a cutoff value of $\geq 10 \%(4.77 \%+(2 \times 2.47 \%)=9.71 \%)$ to determine the proportion of tissue eosinophils among the total inflammatory cells in the Chinese patients. The proportion of mucosal eosinophilia in CRS is $68 \%$ in Beijing and $46 \%$ in Wuhan. ${ }^{82}$

This cutoff value can be used to define tissue eosinophilia. However, tissue eosinophilia does not equate with eosinophilic CRSwNP. To determine eosinophilic CRSwNP, criteria should be fulfilled by examining the CRS tissue samples. To date, an international consensus has not been reached regarding the definition of ECRS perhaps in part because tissue eosinophilia in CRS is known to vary by geographical region.

Eosinophilic and non-eosinophilic CRSwNP have different clinical characteristics. Compared to non-eosinophilic CRSwNP, eosinophilic CRSwNP is more prevalent in men and is associated with smoking, atopy, and a higher absolute count of peripheral blood eosinophils and IgE levels. Peripheral eosinophils are independently and significantly associated with eosinophilic CRSwNP. ${ }^{210}$ Zuo et al..$^{211}$ showed that a smell-loss score, ethmoid osteitis index, and the number and ratio of blood eosinophils, can be used as surrogate markers for the differential diagnosis of ECRS.

Eosinophilic and non-eosinophilic CRSwNP show distinct tissue remodeling patterns. Although Chinese patients with non-eosinophilic and eosinophilic CRSwNP present with edema in the lamina propria, eosinophilic CRSwNP is more edematous and less fibrotic compared to the non-eosinophilic CRSwNP. Eosinophilic CRSwNP shows decreased collagen deposition and increased severity of edema compared to that in the non-eosinophilic 
CRSwNP and CRSsNP. ${ }^{130}$ Glandular hyperplasia occurs more in non-eosinophilic CRSwNP and CRSsNP, than in eosinophilic CRSwNP. ${ }^{82,131,212}$ Atypical CRS, characterized by large and pleomorphic histiocytes, has been rarely found in Chinese CRS patients.

Eosinophilic and non-eosinophilic CRSwNP exhibit elevated Th1 and Th17 cell counts in the local microenvironment, while only eosinophilic CRSwNP shows increased Th2 cell counts. Chinese patients with eosinophilic CRSwNP show increased total IgE levels compared to those of patients with non-eosinophilic CRSwNP. Local IgE, specific for common aeroallergens, is more frequently found in the eosinophilic CRSwNP than in the noneosinophilic CRSwNP. ${ }^{213}$

Although CRSwNP in Western countries is mostly eosinophilic, ${ }^{5,81}$ a significant percentage of CRSwNPs in Asian countries are non-eosinophilic, including China, ${ }^{82}$ Korea, ${ }^{214}$ Japan, ${ }^{215}$ and Malaysia. ${ }^{216}$ In China, neutrophil numbers are decreased further in the eosinophilic CRSwNP than in the non-eosinophilic CRSwNP and CRSsNP. ${ }^{130}$ Genetic factors or genetic/ environmental interactions, may play a role in eosinophilic infiltration as evidenced by the reduced eosinophilia in second-generation Asian CRSwNP patients compared to that in the Caucasian CRSwNP patients. ${ }^{217}$ The inflammatory patterns have evolved over time. The prevalence of eosinophilic CRSwNP in Asian countries, including Thailand, Korea, and China, has increased remarkably in the past 10 to 20 years, indicating that environmental factors are involved in the pathogenesis of CRSwNP. ${ }^{214,218-221}$

In the previous decade, studies on CRS inflammatory patterns were mostly conducted in patients of European descent. Several recent studies have shown the immunological differences between patients of European descent and Chinese patients. Zhang et al..$^{222}$ found fewer activated eosinophils and lower IgE levels in the NPs of patients from South China, compared to those of patients of European descent. They further showed that tissues from the CRSwNP patients of European descent exhibited significantly high levels of the Th2 cytokine IL-5 and Th2 transcription factor GATA binding protein 3 (GATA-3), and higher levels of eosinophilic inflammation $\left(\mathrm{ECP} / \mathrm{MPO}^{77}\right.$ ratio > 1) compared to those of the controls. These findings were obtained by comparing a Th1/Th17 cell pattern with neutrophilic inflammation (ECP/MPO ratio < 1) in tissues obtained from Chinese CRSwNP patients and healthy controls. ${ }^{81}$ Cao et al..$^{82}$ found that CRSsNP patients from south China had higher levels of IFN- $\gamma$ expression whereas only a subpopulation of patients with eosinophilic CRSwNP showed enhanced expression of GATA-3 and IL-5. These findings indicate immunological heterogeneity among different regions within the same disease phenotype and show why CRS phenotyping does not reflect detailed differences in pathogenic mechanisms. These results also highlight the importance of delineating the CRS endotypes, which can reveal pathogenic patterns based on the underlying mechanisms.

\section{Cluster analysis of CRS endotypes}

Cluster analysis is an unsupervised learning method that can integrate multiple variables to identify unique patient categories. It can be used to categorize heterogeneous disorders into disease subtypes and has recently been employed to identify various inflammatory diseases, such as asthma, ${ }^{223} \mathrm{COPD},{ }^{224}$ and obstructive sleep apnea. ${ }^{225}$ Distinct CRS clusters with diverse inflammatory mechanisms can be used to develop personalized treatment strategies for CRS patients. Nakayama et al. ${ }^{226}$ identified 4 distinct clinical CRS phenotypes based on the presence of NPs and mucosal eosinophil counts; however, these clusters were not correlated with treatment choices or therapeutic outcomes. Lou et al. ${ }^{227}$ used unsupervised hierarchical cluster analysis 

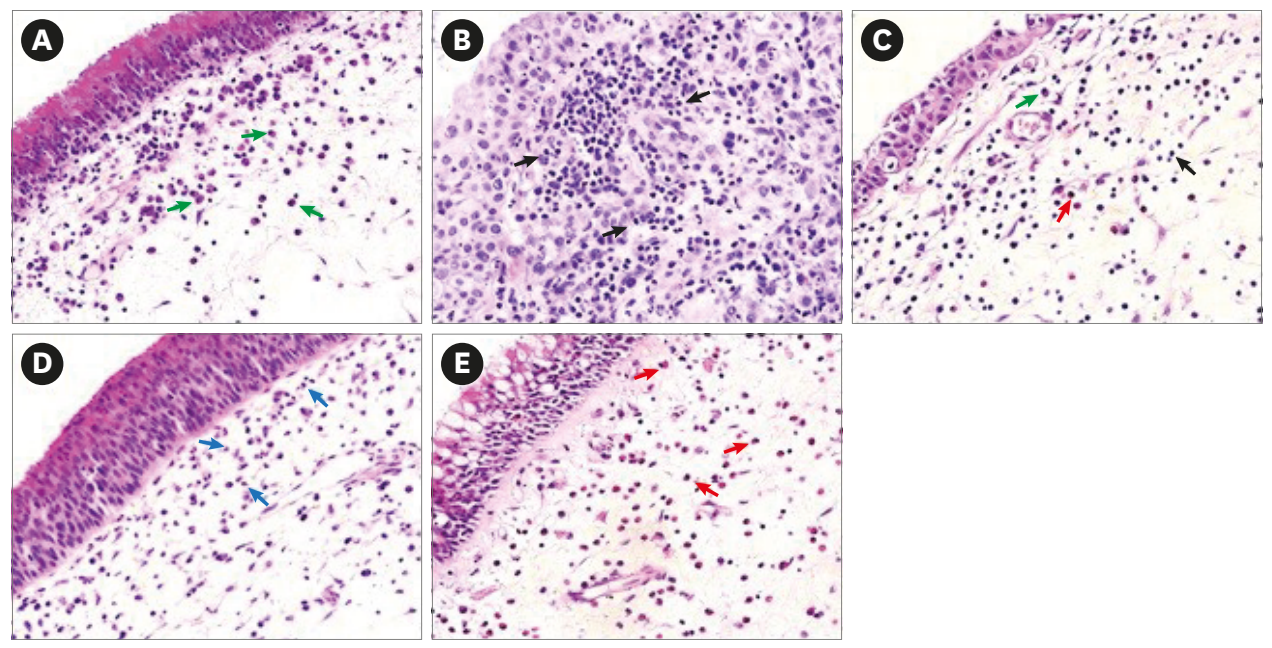

Fig. 2. Representative hematoxylin and eosin staining of nasal polyps in 5 inflammatory phenotypes (400x magnification). (A) Cluster 1, the plasma cell-dominant group. (B) Cluster 2, the lymphocyte-dominant group. (C) Cluster 3, the mixed group. (D) Cluster 4, the neutrophil-dominant group. (E) Cluster 5, the eosinophil-dominant group. Plasma cell, green arrow; lymphocyte, black arrow; neutrophil, blue arrow; eosinophil, red arrow.

and translated the theoretical stratification into a clinically meaningful stratification. This approach generated 5 distinct clusters (Fig. 2) in a retrospective cohort of 366 Chinese CRSwNP patients thereby providing relevant information on disease recurrence. Plasma cell-dominant and lymphocyte-dominant CRSwNP, showed polyp recurrence in less than $7 \%$ of the patients. The clusters indicated that a mixed inflammatory pattern or inflammation characterized by a neutrophil infiltration would indicate poor prognosis with polyp recurrence in $75 \%$ and $46.4 \%$ of the patients, respectively. Notably, CRSwNP characterized by extensive tissue eosinophilia (tissue eosinophil counts $\geq 54.5 \%$ ) showed the highest polyp recurrence rate of $98.5 \%$.

Using cluster analysis, Tomassen et al..$^{5}$ described 3 endotypes of CRSwNP and CRSsNP in the CRS samples obtained from 11 European centers. These endotypes showed different expression patterns of Th cytokines, inflammatory biomarkers, and IgE. Based on these findings, CRS can be categorized into, non-type 2 inflammation, and moderate and severe type 2 inflammation, with increased occurrence of NPs and asthma as comorbidity. ${ }^{5}$ Wang et al. ${ }^{228}$ evaluated the Th cytokine and marker profiles in the CRS patients from Asia (China and Japan), Europe (Benelux and Germany) and Australia. They demonstrated a remarkable diversity in the Th cytokine signatures between these geographical regions and showed that tissues from the European and Australian CRSwNP patients were characterized by a stronger expression of type 2 inflammation than those from the Asian patients. Conversely, in Asia, the expression patterns were shown to vary from low type 2 expression in Chengdu/China to moderate expression in Beijing and Japan. Accordingly, the percentage of eosinophilic inflammation (ECP/MPO ratio > 1) and SE-IgE levels in the European, Australian and Japanese CRSwNP patients were higher than those in patients from Beijing and Chengdu in China. These differences were reflected in the tissues obtained from the CRSsNP patients. Recently, Liao et al. ${ }^{229}$ described 7 clusters of CRS patients in central China, with 28 clinical variables and 39 mucosal cellular and molecular variables. The 7 clusters were classified into 3 endotypes: (1)type 2 inflammation with higher levels of Th2 cytokines such as IL-5 and -13 , and with severe eosinophilic infiltration; (2)mixed type 1 and 3 inflammation with higher levels of Th1 (IL-12 and IFN- $\gamma$ ) and Th17 (IL-17) cytokines, and moderate levels of IL-5 (Th2 cytokine); and (3)non-type 1/type 2/type 3 inflammation with lower expression of Th1, Th2, 
and Th17 cytokines. ${ }^{229} \mathrm{~A}$ recent study of CRS patients in America identified 6 clusters and suggested that a severe type 2 endotype and a mild type 2 endotype with pro-inflammatory signatures were both present in $15 \%$ of the subjects. However, $70 \%$ of the patients were characterised by disease with a low overall inflammatory burden but without distinct Th1-, Th2- or Th17-associated signatures. ${ }^{230}$ Table 3 summaries the endotypes from the different regions from the studies referenced above. Kim et al. ${ }^{231}$ evaluated the expression of Th cytokines, chemokines and transcriptional factors based on the classification of ECRS (non, mild, moderate and severe ECRS) and found that the upregulation trend of type 2 cytokines (IL-5, IL-13, CCL24 and etc.) and the downregulation trend of type 3 cytokines (IL-17 and IL-22) and the type 1 cytokine (IFN- $\gamma$ ) were associated with an increased prevalence of phenotypes such as asthma and atopy from control to severe ECRS.

These studies have shown that it is possible to identify CRS endotypes via the key factors that regulate immunity and inflammation in CRS such as Th cytokines and IgE levels. Monoclonal antibodies (mAbs) against type 2 inflammatory factors, such as IL-5, IL-4R $\alpha$, IgE and GATA-3 specific DNAzyme, can inhibit type 2 and eosinophilic inflammation and are used to treat conditions associated with airway inflammation such as CRSwNP and asthma. ${ }^{87,204,205,232,233}$ However, these biotherapies target type 2 inflammation and further studies are needed to target the non-type 2 immunity and other factors in CRS. ${ }^{234-236}$

Precision medicine, which targets key biomarkers, is used for the management of cancer and inflammation, ${ }^{237}$ could be used to manage upper airway diseases such as CRS and rhinitis based on their endotypes..$^{60,238,239}$ Moving forward, it is important to determine the mechanisms of CRS and to identify the key regulatory markers with respect to the CRS endotypes.

\section{DIAGNOSIS}

\section{Symptoms}

CRS (with or without polyps) is defined as an inflammation of the nasal cavity and paranasal sinuses. The symptoms can be categorized into main and secondary symptoms and are important for the diagnosis of CRS. The main symptoms include nasal blockage/obstruction/congestion and

Table 3. Endotypes based on cytokine profiles in different regions

\begin{tabular}{|c|c|c|c|c|c|}
\hline Authors & Regions & Analysis & Parameters & Endotypes & Clinical outcomes \\
\hline Tomassen et al. ${ }^{5}$ & Multicenters in Europe & $\begin{array}{l}\text { Cluster analysis with } \\
2 \text { CRS phenotypes } \\
\text { together }\end{array}$ & $\begin{array}{l}\text { Mucosal Th cytokines, } \\
\text { eosinophilic/ } \\
\text { neutrophilic markers } \\
\text { and IgE }\end{array}$ & $\begin{array}{l}\text { Severe type } 2 \text {, moderate type } 2 \text { and } \\
\text { non-type } 2\end{array}$ & $\begin{array}{l}\text { More CRSwNP and asthma } \\
\text { in moderate and severe } \\
\text { type } 2\end{array}$ \\
\hline \multirow[t]{2}{*}{ Wang et $a l^{228}$} & $\begin{array}{l}\text { Benelux, Germany, } \\
\text { Beijing and Chengdu } \\
\text { of China, Japan and } \\
\text { Australia }\end{array}$ & $\begin{array}{l}\text { Descriptive study for } \\
\text { CRSWNP and CRSSNP } \\
\text { respectively }\end{array}$ & Mucosal Th cytokines & $\begin{array}{l}\text { CRSwMP: type } 2 \text { dominance in } \\
\text { Europe/Australia/Japan, mixed type } \\
1,2 \text { and } 3 \text { in Beijing and non-type 1, } 2 \text {, } \\
3 \text { in Chengdu }\end{array}$ & $\begin{array}{l}\text { Different endotypes driven } \\
\text { therapeutic strategy }\end{array}$ \\
\hline & & & & $\begin{array}{l}\text { CRSsNP: mixed type 1, } 2 \text { and } 3 \text { in } \\
\text { Benelux, Germany, Australia and } \\
\text { Beijing, non-type 1, 2, } 3 \text { in Chengdu }\end{array}$ & \\
\hline Liao et al. ${ }^{229}$ & Middle region of China & $\begin{array}{l}\text { Cluster analysis with } \\
2 \text { CRS phenotypes } \\
\text { together }\end{array}$ & $\begin{array}{l}\text { Clinical variables and } \\
\text { mucosal cellular and } \\
\text { molecular variables }\end{array}$ & $\begin{array}{l}\text { Type } 2 \text {, mixed type } 1 \text { and } 3 \text { with } \\
\text { moderate type } 2 \text {, non-type 1, 2, } 3\end{array}$ & $\begin{array}{l}\text { Distinct endotypes of CRS } \\
\text { display differences in clinical } \\
\text { response to treatments }\end{array}$ \\
\hline Turner et $a l .{ }^{230}$ & America & $\begin{array}{l}\text { Cluster analysis with } \\
2 \text { CRS phenotypes } \\
\text { together }\end{array}$ & Mucosal Th cytokines & $\begin{array}{l}\text { Severe type } 2 \text {, mild type } 2 \text { and non- } \\
\text { type1, } 2,3\end{array}$ & $\begin{array}{l}\text { Diverse endotypes differ } \\
\text { substantially with different } \\
\text { phenotypes and disease } \\
\text { behavior }\end{array}$ \\
\hline
\end{tabular}

CRS, chronic rhinosinusitis; CRSwNP, chronic rhinosinusitis with nasal polyps; CRSsNP, chronic rhinosinusitis without nasal polyps. 
nasal discharge (anterior/posterior nasal drip) while the secondary symptoms involve facial pain/ pressure and the reduction or loss of smell. Two or more symptoms, one of which must belong to the main category, are required to be manifested for a condition to be diagnosed as CRS.

Nasal obstruction is commonly reported in CRS. Nasal discharge may be anterior or posterior and may present as thick purulent secretions or watery discharge. The incidence of facial pain in CRS patients is variable. NPs, mucosal edema and excessive nasal secretions can physically prevent odorants from reaching the olfactory cleft. Therefore, olfactory disturbance is common. Additional minor symptoms include dizziness, ear pressure, sore and/or itchy throat, cough, and sleep impairment.

Symptom severity in CRS patients can be estimated using a visual analogue scale (VAS) score on a measurable continuum $(0-10 \mathrm{~cm})$ or as a grade (no symptoms, mild, moderate or severe symptoms). For example, mild disease is defined by a VAS score of $0-3$, moderate as $>3-7$, and severe as $\geq 7.240$

\section{Physical examination}

Physical examination performed using anterior rhinoscopy or nasal endoscopy in combination with symptom assessment can be used to diagnose CRS. Anterior rhinoscopy is the first step in examining patients with chronic sinusitis; however, its use is restricted by the limited illumination and access into the nasal cavity. Nasal endoscopy offers better illumination and visualization compared to that of anterior rhinoscopy and permits a complete examination of the nasal cavities, sinuses, and nasopharynx. It is convenient for observing polyps, edema, discharge, crusting and scarring in the nasal cavities of CRS patients. However, in post-surgical CRS patients, nasal endoscopy does not necessarily correlate with symptoms. ${ }^{241}$

\section{Radiology}

CT is an important auxiliary method for diagnosing CRS, particularly for identifying cells around the frontal recess. ${ }^{242}$ The characteristics of CRS that are detectable via CT include unilateral or bilateral mucoperiosteal thickening, soft tissue masses, sinus expansion, and osteitis of bony architecture in the affected sinuses. ${ }^{243}$ In our previous study, we observed intrasinus hyperattenuating masses on CT scans, ${ }^{244}$ and these features are more prominent in images of the soft tissues. The sinuses were mostly affected bilaterally. CT is increasingly used to assist with endoscopic sinus surgery (ESS), and ESS is often performed based on CT characteristics of CRS. Bone structure and markers identified on CT scans are used as landmarks in ESS. Identifying important structural and anatomical abnormalities pre-surgery will help ensure safety during surgery. Certain features of the soft tissue masses on CT scans can help in differentiating CRS (especially with NPs) from other nasal diseases (such as benign nasal tumors or sinus cysts). Nasal imaging navigator technology is also based on CT. In 1997, Lund et al. ${ }^{245}$ proposed the Lund-Mackay CT scoring system which is widely used in rhinology. The score ranges from $0-24$ based on the opacification of 10 bilateral sinuses ( 0 $=$ normal $; 1=$ partial opacification; $2=$ total opacification) and ostiomeatal complex (OMC) $(0=$ normal; 2 = total opacification $)$. This scoring system allows physicians to quantitatively assess the severity of CRS symptoms and to correlate it with the extent of disease. The LundMackay CT scoring system is simple to use and makes nasal endoscopy more predictable. ${ }^{245}$

Recent studies have examined the phenotypes of eosinophilic and non-ECRS. These 2 phenotypes show a heterogeneous opacification pattern. Ishitoya et al. ${ }^{246}$ demonstrated that Japanese patients with ECRS showed ethmoid sinus-dominant opacification while those with 
non-ECRS showed maxillary sinus-dominant opacification. Once CRS becomes more severe, both phenotypes show a pan-sinusitis pattern. ${ }^{246} \mathrm{~A}$ study in China showed that a ratio of ethmoid to maxillary sinuses that was equal to or greater than 2.59 on the Lund-Mackay CT scoring system could be used to pre-diagnose eosinophilic or non-ECRS. ${ }^{247}$

Magnetic resonance imaging (MRI) shows that mucosal edema and mucus accumulation are the main pathological changes in CRS. T2-weighted images show extended hyperintense signaling in the affected sinuses, which represent the inflamed mucosa. In ECRS, differences in the signal intensity are sometimes observed on $\mathrm{T} 2$-weighted images; these are caused by variations in the concentrations or the water-free content of the sinus secretions. ${ }^{248} \mathrm{MRI}$ is not routinely used to examine CRS patients unless the unilateral sinus is affected.

\section{Nasal cytology in CRS}

Nasal cytological testing is used to assess inflammation in nasal cavities and sinuses. Samples are obtained by nasal swabbing, brushing or lavage. Liquid-based cytology can exclude the mucus in nasal secretions, providing a cleaner background for observation. ${ }^{249}$

Nasal cytological testing is non-invasive, simple to perform and convenient for evaluating different types of inflammation in the nasal mucosa. Both total inflammatory cell counts and individual inflammatory cell types in the secretions are closely correlated with those in the mucosa of the inferior nasal turbinate. The sensitivity and specificity of cytological testing during inflammation of the nasal mucosa is 94.1 and $76.9 \%$, respectively. ${ }^{249}$

Nasal cytology is also important in the diagnosis and treatment of patients with NPs. Eosinophil numbers in nasal secretions and polyp tissues are significantly correlated..$^{250} \mathrm{Nasal}$ cytology helps to differentiate whether or not NPs are accompanied by allergic rhinitis. ${ }^{251}$

Cytological testing is not fully accepted for diagnosing CRSwNPs. In children with rhinosinusitis, inflammatory cell numbers are higher, and the ratio between ciliated and goblet cells is reversed compared to that in the controls. ${ }^{252}$ Nasal cytological testing is unsuitable for assessing inflammation in sinusitis as indicated by a low sensitivity of $63.4 \%$ and by the lack of a significant correlation between the total and individual inflammatory cell counts in the paranasal sinus mucosa. ${ }^{249}$

\section{DIFFERENTIAL DIAGNOSIS}

\section{AFRS}

Whether AFRS is truly a unique disease is debatable. ${ }^{6}$ AFRS is not clinically distinct from eosinophilic mucus CRS ${ }^{253}$ and may eventually be renamed as eosinophilic fungal CRS. Nevertheless, in 1994, AFRS was defined using the classic Bent-Kuhn criteria as follows ${ }^{254}$ : (1) nasal polyposis, (2) type I hypersensitivity, (3) eosinophilic mucin without fungal invasion into the sinus and bone tissue, (4) fungi detectable by staining and (5) characteristic radiological findings. These criteria can be used to distinguish between AFRS and CRS.

AFRS is predominantly observed in adolescents and young adults ${ }^{255}$ and is more common in geographical areas that have high humidity. ${ }^{256}$ Patients with AFRS are usually atopic to various fungi, show IgE sensitization, and tend to have concomitant asthma and recurrent rhinosinusitis/NPs, and undergo recurrent surgeries. The symptoms of AFRS are similar to 
those of CRS, including recurrent nasal obstruction, rhinorrhea, and postnasal drainage. The mucin produced in AFRS has a thick, "peanut butter-like" appearance, and is brown and occasionally bloody with crusty casts. This mucin expands, resulting in facial asymmetry and proptosis. Treatment with antihistamines and nasal corticosteroid sprays is often inadequate. ${ }^{257}$

Sensitization can be assessed via laboratory testing. Total IgE titers are typically higher in AFRS than in CRS. ${ }^{258}$ Moreover, AFRS exhibits a unique appearance on radiological images. The accumulation of iron, manganese and other elements in the mucus allows for the detection of sinus opacification and calcification via CT. ${ }^{259}$ There is also a sheet area of high-attenuation, having an appearance of "ground glass" within the sinuses. ${ }^{260} \mathrm{Often}$, bone thinning and erosion are observed as an expansive lesion, secondary to the accumulation and expansion of the mucus. Bony invasions are generally not present. ${ }^{261} \mathrm{~A}$ mixed or highintensity signal on T1-weighted sequences can be observed using MRI, whereas a signal void or low signal intensity is observed on the T2-weighted sequences.

AFRS is only diagnosed after ESS $^{262}$ because histopathology is required for the diagnosis of the condition. Pathologically, eosinophilic mucus rich in inflammatory debris and CharcotLeyden crystals is the hallmark of AFRS. The causative fungi are identified via histological evaluation using Gomori methenamine silver staining and fungal cultures.

Nevertheless, these criteria are not specific to AFRS. Several studies have detected fungus in CRS patients and controls ${ }^{263-265}$ thereby questioning the IgE-mediated pathophysiology of fungal allergy in AFRS.

\section{Aspirin-exacerbated respiratory disease (AERD)}

CRSwNP may be accompanied by asthma and aspirin intolerance in a syndrome called AERD. It is a clinical triad of nasal polyposis, asthma, and respiratory hypersensitivity to NSAIDs, specifically aspirin. Samter and Beers ${ }^{266}$ further described it in 1968. Therefore, AERD was previously called and "Samter's Triad."

AERD occurs in $9 \%-10 \%$ of patients with nasal polyposis. ${ }^{267} \mathrm{~A}$ cohort study in China revealed that the prevalence of AERD is much lower in Chinese CRS patients $(0.57 \%)$ than in individuals of European descent. ${ }^{268}$ The average age of onset is 34 years, and women are more prone to develop AERD than men; AERD is very rare in children. ${ }^{269}$

AERD is a discrete disorder that occurs within another distinct disease and is therefore different from most other medical conditions. ${ }^{270}$ Thus, this syndrome is often missed unless evaluations for asthma and aspirin hypersensitivity are performed in patients with nasal polyposis.

The mechanisms underlying AERD are unclear, but they are hypothesized to involve the inhibition of cyclooxygenase 1 (COX-1). Respiratory reactions occurring within 0.5-2 hours of the ingestion of a COX-1 inhibitor are the most prominent and definitive features distinguishing patients with AERD from those with CRSwNP. ${ }^{271}$ Thus, it is crucial to obtain the medical history of CRSwNP patients, especially for those with anosmia and/or recurrent $\mathrm{NP}$, to establish whether they have aspirin intolerance. An aspirin provocation test can be used to confirm the diagnosis.

Aspirin desensitization is the most beneficial therapy for AERD patients. Other therapies, including the avoidance of aspirin and other NSAIDs, are ineffective. Functional ESS (FESS) 
can be useful for AERD patients, but NP regrow rapidly after surgery. Moreover, additional studies are required to demonstrate the differences between Chinese and Caucasian populations with respect to AERD.

\section{IgG4-related CRS}

IgG4-related CRS has recently been proposed as a new clinical entity ${ }^{272}$ although its characteristics have not been widely investigated. Currently, IgG4-related CRS is mainly diagnosed using the criteria that are used for the IgG4-related disease (IgG4-RD), a systemic, immune-mediated condition that affects various organs. ${ }^{27,274}$ The 2011 Boston criteria proposed that the histological diagnosis of IgG4-RD be based on the presence of characteristic morphological features, including lymphoplasmacellular inflammation, storiform fibrosis, obliterative phlebitis, prominent IgG4-positive plasma cells, and an IgG4-/IgG-positive ratio of $>40 \%{ }^{275}$ Conversely, the development of IgG4-RD in the nasal cavity and paranasal sinuses is relatively rare, and published data on IgG4-RD in these sites is both limited and controversial. Moteki et al..$^{272}$ first described IgG4-related CRS in 2011. They assessed serum IgG4 levels and performed immunohistochemical labeling for IgG4 in nasal mucosal tissues from patients with IgG4-related CRS and common CRS. Their results indicated that increased serum IgG4 levels, but not positive staining for IgG4 in the nasal mucosa, was a diagnostic factor for IgG4-RD. Piao et al. ${ }^{276}$ have shown that increased concentration of serum IgG4 and infiltration of IgG4-positive plasma cells into the nasal mucosa of patients with Mikulicz's disease occurs more in IgG4-related CRS (MD-CRS) than in $\mathrm{MD}$ or common CRS alone. They further suggested that IgG4-positive plasma cells should be assessed histopathologically when establishing a differential diagnosis of IgG4-related CRS. A comprehensive evaluation of the clinical symptoms, serum IgG4 levels, and infiltration of IgG4positive plasma cells can provide an accurate diagnosis of IgG4-related CRS. ${ }^{277}$

\section{Benign tumors}

In this section, we have summarized and reviewed the differential diagnoses of benign and malignant tumors that mimic CRS and CRSwNP. These benign and malignant tumors can appear in any area of the nose, and therefore, it is crucial to perform imaging before the initiation of any intervention; for the best results, imaging should involve biopsy.

\section{Epithelial tumors}

Inverted papilloma, the most common benign tumor occurring within the middle meatus, may extend into the nasal cavity and sinuses. The clinical features include bloody nasal discharge, unilateral lesions, dendritic protrusions and limited growth. Endoscopic surgery is an effective approach for removing nasal inverted papillomas with minimal invasiveness, but this tumor shows high recurrence. Pathological examination of the surgical margins can be used to partially predict the prognosis. ${ }^{278}$ Salivary gland tumors and pleomorphic adenomas may occur concurrently within the nose and sinuses, but such occurrences are uncommon. ${ }^{279}$

\section{Mesenchymal tumors}

Fibroma and angiofibroma occur almost exclusively in adolescents presenting with nasal obstruction and epistaxis. ${ }^{280}$ Less common mesenchymal tumors include schwannomas, ${ }^{281}$ neurofibromas, ${ }^{282}$ meningiomas, ${ }^{283}$ leiomyomas, ${ }^{284}$ angioleiomyomas ${ }^{285}$ and other benign nasal tumors that can be identified via histological evaluation and imaging of biopsy samples.

\section{Malignant tumors}

Malignant tumors, such as squamous cell carcinoma or mucinous adenocarcinoma, can mimic CRS within the nose and sinuses. The early clinical signs and symptoms of sinonasal 
malignant tumors include unilateral and progressive nasal congestion, bloody discharge, and nasal discharge with malodorous pus; these may be accompanied by headache, epiphora and dysosmia. A definite diagnosis is made by pathological biopsy. Squamous cell carcinoma ${ }^{286}$ is the most common malignant tumor of the sinonasal region, but mesenchymal tumors must also be suspected until proven otherwise.

\section{MANAGEMENT}

\section{Medical treatment Corticosteroids}

Glucocorticoids have anti-inflammatory and immune suppression effects, and are consequently, the most important drugs against $\mathrm{CRS}^{287}$; they can be used both orally and topically. Short-term treatment with oral steroids, called "medical polypectomy," 288,289 significantly reduces polyp size and alleviates symptoms. However, the effects of oral steroids on CRSwNP are not maintained for a long time. This is exemplified by oral methylprednisolone. Its effect on polyp size peak at week 3 , but after 2 months, polyps recur. ${ }^{202}$ Oral steroids can also generate adverse effects including inhibition of adrenal axis function, slowed growth, osteoporosis and gastrointestinal discomforts. Contraindications should be evaluated before starting treatment with oral steroids, and potential side effects must be monitored during therapy. In CRSsNP, short-term treatment with systemic steroids has gradually reduced and replaced with treatment with topical steroids. The frequent use of systemic steroids is not recommended because of the potential adverse effects. There are no recommendations for oral corticosteroid use in CRSsNP, because currently there are no clinical data to confirm their efficacy and because of the potential side effects of a systemic steroid therapy. ${ }^{290}$

To the best of our knowledge, numerous randomized controlled trials (RCTs) have reached a consensus on using nasal steroids for CRS (designated by grade A recommendation) has been reached via, ${ }^{287,290,291}$ and nasal steroid sprays are commonly used in clinical practice. Local side effects of steroid nasal sprays include epistaxis, dry nose, septal perforation, and nasal cauterization and irritation, but these occur at low rates. In clinical trials, corticosteroid-treated groups and control groups show no significant differences with respect to the adverse events, and the systemic side effects of the nasal corticosteroids remain debatable. ${ }^{292}$ Early studies have suggested that beclomethasone propionate, a corticosteroid nasal spray, affects growth, and that this may be related to its high bioavailability. ${ }^{292}$ Fluticasone furoate and triamcinolone acetonide have been reported to cause a small, but not statistically or clinically significant, decrease in growth. ${ }^{293}$ However, fluticasone propionate may suppress the hypothalamic pituitary-adrenal axis. ${ }^{293}$ There is no evidence that nasal steroids increase the risk of developing cataracts, glaucoma, or elevated intraocular pressure.

Nasal corticosteroids cannot rapidly alleviate symptoms and reduce mucosal inflammation, and should, therefore, be used for $>12$ weeks to maintain efficacy. Steroid drops, irrigation, and inhalation are also used in clinical practice. Intranasal nebulization with a budesonide suspension for 2 weeks alleviates nasal symptoms, reduces polyp size, and downregulates inflammatory factors and tissue remodeling in eosinophilic CRSwNP with no significant effects on the function of the adrenal cortex and no serious side effects.

Intranasal nebulization with budesonide $1 \mathrm{mg}$ BID, which differs from nasal steroid sprays and oral pills, is a safe and effective way to treat patients with NPs and can be used as a 
conventional perioperative therapy against NPs. ${ }^{294}$ No systemic side effects have been observed in asthma patients treated with nasal sprays and inhaled steroids. ${ }^{292}$ Nasal irrigation with budesonide was once assessed for use in CRS, ${ }^{295}$ but long-term safety and efficacy of this application needs further study.

Due to the heterogeneity of CRS, patients with different endotypes show different responses to drugs. ${ }^{227}$ Some patients show a poor or lack of response to standard steroid therapies ${ }^{287}$; this is known as glucocorticoid resistance. The mechanism of glucocorticoid resistance in CRS is unclear. Increased expression of phosphorylated glucocorticoid receptor (GR) $\alpha$ or that of its competitive receptor GR $\beta$ would interfere with the anti-inflammatory effects of glucocorticoids. Downregulation of GR expression, which occurs post glucocorticoid treatment may cause secondary glucocorticoid resistance. ${ }^{287}$ Unlike eosinophilic CRSwNP, CRSwNP with increased neutrophilic inflammation is less responsive to glucocorticoid treatment, ${ }^{296}$ indicating that different CRSwNP endotypes show different responses to glucocorticoids.

Recent studies show that mucin $1^{297}$ deficiency and overexpression of mucin $4^{298}$ are associated with glucocorticoid resistance in CRS. Determining the mechanisms of glucocorticoid resistance is important for developing future precision therapies.

\section{Macrolides}

Macrolides are antibiotics containing a 14-, 15- or 16-membered macrocyclic lactone ring. Orally administered macrolides show good bioavailability and tissue penetration. They are active against most gram-positive bacteria, some gram-negative bacteria, mycobacteria, chlamydia, Legionella spp., and mycoplasma..$^{299,300}$ In 1990, Suzuki et al. ${ }^{301}$ found that longterm low-dose erythromycin therapy in patients with diffuse pan-bronchiolitis improved the 10-year survival rate and relieved CRS symptoms; this promoted the use of macrolides as new treatment options in CRS. Macrolide activity against CRS involves anti-inflammatory and immunomodulatory mechanisms including the inhibition of NF- $\mathrm{\kappa B}$, pro-inflammatory cytokines (IL-8, IL-5, IL-6 and IL-1) and oxygen radicals, expression of granulocyte adhesion factor; enhancement of mucociliary activity; and decreasing the formation of bacterial biofilms. ${ }^{302-306}$ In 2007, macrolide therapy received an A-class recommendation form the EP3OS for the treatment of CRSsNP. ${ }^{307}$ However, macrolides show no effects in patients with high levels of IgE or those with NPs or asthma. Additionally, long-term treatment with macrolides may result in bacterial resistance. Based on the data by Wallwork et al. ${ }^{308}$ and Videler et al. ${ }^{309}$ the EP3OS recommendation was downgraded from A to C in 2012. ${ }^{6}$

Macrolides and nasal steroids exert similar clinical effects in CRSsNP patients; both can alleviate subjective or objective symptoms and improve endoscopic scores. ${ }^{310}$ The CRSsNP phenotype in Chinese adults differs from that in patients of European descent. The cytokine profile of the Chinese CRSsNP is Th1-dominant with non-eosinophilic inflammation ${ }^{82}$; macrolide-based treatments are more effective for this endotype. Therefore, long-term, low-dose macrolide therapy is recommended for CRSsNP patients with neutrophilic inflammatory patterns and low IgE levels. ${ }^{308,311}$ Oral or nasal steroids and surgery remain the preferred therapy for CRSwNP patients. Long-term, low-dose macrolide therapy postsurgery can improve the subjective or objective symptom score, shrink polyp size, and delay polyp recurrence..$^{312-314}$ Lou et al..$^{227}$ identified 5 clusters of NP including plasma cell-dominant, lymphocyte-dominant, mixed inflammatory-cell type, neutrophil-dominant, and eosinophildominant. Some CRSwNP patients are not sensitive to steroid therapy; this may be due 
to the presence of different NP phenotypes. Long-term, low-dose macrolide therapy is recommended for treating corticosteroid-resistant CRSwNP patients, neutrophil-dominant NPs, the persistent edema of nasal mucosa, and purulent nasal discharge. ${ }^{315,316}$ In a previous meta-analysis conducted using a non-RCT study, ${ }^{317}$ we found significant differences between the endoscopic scores of the control group and those of the groups treated with macrolides for 8 weeks (standardized mean difference [SMD], $-0.77 ; 95 \%$ confidence interval [CI], -1.07 , $-0.46 ; P<0.00001$ ) and 12 weeks (SMD, $-1.04 ; 95 \% \mathrm{CI},-1.97,-0.82 ; P<0.00001)$. In 2 nonRCT studies, the CT scans revealed a significant improvement after 12 weeks of treatment with macrolides (mean difference, $-5.81 ; 95 \% \mathrm{CI},-8.10,-3.52 ; P<0.00001$ ). Additionally, Asian and non-Asian subgroups were assessed in 5 RCT studies using a Sino-Nasal Outcome Test (SNOT) after 12 weeks of macrolide therapy; the treated and control Asian subgroups showed significant differences (SMD, $-0.51 ; 95 \% \mathrm{CI},-0.99,-0.02 ; P=0.04$ ) while no differences were observed between the control and treated non-Asian subgroup (SMD, -0.01; $95 \% \mathrm{CI},-0.65,0.63 ; P=0.98)$.

Clarithromycin, azithromycin, and roxithromycin are some of the widely used macrolides. Compared to the doses used for acute infections, the daily dose of macrolides during the treatment of CRS is halved, and the treatment period lasts generally 12 weeks. Long-term, low-dose macrolide therapy is considered safe. ${ }^{6}$ However, inclusion and exclusion criteria require careful consideration as do the possible adverse events, including bacterial resistance, cardiovascular effects, gastrointestinal reactions, hearing loss, allergies, and liver damage.

\section{Antimicrobial therapy for CRS}

No clinically controlled trial has examined the effect of antibiotics vs. placebo in the treatment of CRSsNP. Published clinical trials have shown no significant differences between the effects of the various antibiotics tested (mostly cefuroxime, amoxicillin-clavulanic and ciprofloxacin). ${ }^{318,319}$ Several RCTs have reported that doxycycline can alleviate certain symptoms of CRSwNP. ${ }^{217}$ Currently, there is no evidence supporting the use of CRS (CRSsNP and CRSwNP) patients with antibiotic therapy in CRSsNP or CRSwNP. ${ }^{320}$ Studies have shown that bacterial infection is not a determining factor in CRS pathogenesis. ${ }^{72}$ However, antibiotics are recommended for conditions similar to acute bacterial rhinosinusitis, exacerbated CRS with evidence of bacterial infection, and orbital and intracranial complications that occur in CRS. Clinically, empirical therapy uses broad-spectrum antibiotics (mostly amoxicillin-clavulanate potassium, and new generation cephalosporin and quinolone) to target gram-positive, gram-negative, and anaerobic organisms, while EP3OS recommends culture-directed therapy with susceptibility testing using the commonly prescribed dosages and a treatment duration of $<2$ weeks. Although fungi can contribute to the pathogenesis of ECRS, clinical trials indicate that antifungal therapy is not beneficial and may potentially result in severe adverse effects. Therefore, antifungal therapy is not recommended for CRS. ${ }^{321}$

\section{Other medical treatments}

1) Leukotriene receptor antagonists (LTRAs)

In the pathophysiology of allergic diseases, cysteinyl leukotrienes (CysLTs) act as modulators and mediators via distinct receptors (CysLTRs) while antileukotrienes are important in therapies against allergic rhinitis and asthma. ${ }^{3,322}$ CysLTs play more important roles in ECRS than in non-ECRS, ${ }^{323,324}$ and LTRAs have been shown to be effective in treating ECRS. ${ }^{325,326}$ CysLTs and CysLTRs are significantly enhanced in CRSwNP patients, particularly in those with IL- $5^{+}$NPs compared to those in CRSsNP patients and the healthy controls. LTRAs, such 
as montelukast, can downregulate cytokine and mucin expression in polyp explants, and thereby alleviate the symptoms of recalcitrant CRSwNP. ${ }^{327}$

Intranasal corticosteroids (INCSs) is an effective drug against CRSwNP, but it cannot inhibit all the cytokines and inflammatory transmitters involved in the formation of the NP. INCSs show a limited impact on leukotriene-mediated airway inflammation, but supplementation with LTRAs can improve clinical outcomes ${ }^{327-331}$ and is an ideal complementary-treatment strategy. A meta-analysis showed that LTRAs are superior to placebos with respect to the alleviation of CRS symptoms. ${ }^{332}$ Compared to the placebo, LTRA significantly improved the symptoms, polyp size, and immunologic parameters, including eosinophilia, in the CRSwNP patients. Postoperatively, LTRAs are also effective when combined with INCSs and can reduce facial pain/headache, nasal itching, sneezing, postnasal drip, and olfactory impairments. Combinatorial therapies with LTRA and INCSs can reduce the symptoms but not the general severity of CRSwNP, and they do not have any effect on asthma, AERD, or atopy. It seems that LTRAs may provide additional benefits to INCS for symptom management but not for reducing its general severity. Meanwhile, the outcomes seem to be unaffected with regards to the generalized status of asthma, AERD, and atopy.

ESS does not reverse the progression of mucosal inflammation; therefore, a local or systemic therapy is used instead. A clinical study evaluated the effects of montelukast $(10 \mathrm{mg})$ and mometasone furoate nasal spray $(400 \mu \mathrm{g})$ on the postoperative course of nasal polyposis. ${ }^{333} \mathrm{The}$ SNOT-22 scores were reduced in both groups at the 6-month follow-up with the mometasone furoate group showing a marginal advantage with respect to the recurrence rate. Another prospective, randomized, open-label trial was used to evaluate the effectiveness of using montelukast as an adjunct to the INCS-based therapy after ESS for the CRSwNP patients. ${ }^{334}$ INCS was assessed as a monotherapy and in combination with montelukast for 1 year. The results indicated that the subjective and objective scores were significantly reduced in both INCS monotherapy and INCSs in combination with montelukast groups with no significant differences. More RCT studies are required to evaluate LTRAs in the treatment of CRS.

2) Antihistamines

Antihistamines bind to $\mathrm{H} 1$ receptors are used to treat allergic diseases. Second-generation oral and intranasal H1-antihistamines are recommended as the first-line of treatment for allergic rhinitis because they show weaker sedative effects and stronger anti-inflammatory effects than first-generation H1-antihistamines. ${ }^{335}$ The second-generation oral H1-antihistamine, desloratadine inhibits eosinophilic inflammation in NPs; these effects of desloratadine may be augmented by mometasone furoate. ${ }^{336}$ To date, no RCTs have evaluated H1-antihistamine therapy in adults or children with CRS. Current data are insufficient to determine whether oral or intranasal H1-antihistamines can be used to treat CRS patients without allergic rhinitis.

\section{3) Mucolytics}

Mucolytics are used for the treatment of rhinosinusitis as they have mucolytic, secretolytic, anti-inflammatory, antibacterial, antiviral, and immunological activities. ${ }^{37-339}$ The herbal dry extract, BNO 1011 is based on a combination of 5 herbs that can significantly improve radiographic, histological, and MCC parameters in a rabbit model of CRS. ${ }^{142}$ Daily treatment with BNO 1016 (Sinupret extract, a combination of 5 botanical drugs) for 12 weeks has been shown to be clinically safe and effective. ${ }^{340}$ However, a systematic review reported limited evidence regarding whether the herbal medicinal products, including Sinupret, are beneficial for the treatment of rhinosinusitis, particularly CRS. ${ }^{341}$ Web-based nationwide surveys show 
that oral mucolytics are commonly used by a majority of Chinese otolaryngologists $(69 \%)$ for postoperative treatment of CRS. ${ }^{342}$ However, more evidence-based studies are needed to further evaluate this approach.

4) Decongestants

Nasal obstruction is common in CRS. The main function of decongestants is to shrink blood vessels and reduce the volume of the inferior and middle turbinates. ${ }^{343}$ Before the use of INCSs, decongestants were used to reduce nasal edema and expand the nasal cavity ${ }^{344}$ and thereby improve the distribution and efficacy of the INCS. Combinatorial therapy with INCS and oxymetazoline for 6 weeks was more effective than INCS monotherapy at alleviating nasal obstructions and disturbances in smell, improving MCC, and reducing polyp size in CRSwNP. ${ }^{345}$ Decongestants can be further subdivided into intranasal (spray or drops) and oral medications. Generally, short-term treatments (usually $<7$ days) with nasal decongestants will help avoid the rebound effects that cause rhinitis medicamentosa. However, the current evidence does not support the use of oral decongestants in CRS.

5) Bacterial lysates

Bacterial lysates stimulate non-specific defense mechanisms and general immunity, leading to increased immunoprotection. Oral bacterial lysates can minimize the risk of recurrent respiratory infections in children and adults and reduce the severity of airwayrelated symptoms and the number of infections requiring antibiotic treatment. ${ }^{346} \mathrm{OM}-85$ BV (Broncho-Vaxom), an orally applicable bacterial lysate, possesses ciliostimulatory and immunogenic properties that may be partially responsible for its efficacy as a therapeutic agent for respiratory disorders. ${ }^{347}$ The effects of OM- $85 \mathrm{BV}$ as an adjunctive treatment in CRS have been demonstrated in mice. ${ }^{348}$ Additionally, a multi-centric, placebo-controlled, double-blind clinical study indicated that the oral administration of OM-85 BV can be used as an adjunct to standard therapies in adults for CRS. ${ }^{349}$ Bacterial lysates used during CRS remission in children can provide long-term prophylaxis, and effectively decrease the frequency of rhinosinusitis attacks. ${ }^{350}$ Generally, oral bacterial lysates are adjunctive drugs that are cost-effective and show good safety and few adverse reactions. However, further clinical trials are needed to evaluate this class drug.

\section{Nasal irrigation}

Nasal irrigation or nasal washing/douching/lavage is a simple, inexpensive, and well-tolerated procedure that has been used by otolaryngologists for treating rhinitis and sinusitis, for over a century. ${ }^{351}$ Nasal irrigation can increase MCC, alleviate mucosal swelling, dislodge thick secretions, remove local inflammatory mediators, allergens, and infective debris, reduce postoperative crusting, and moisten the sinonasal cavities. Because of its confirmed effectiveness and safety, nasal irrigation is recommended as a supplementary therapy in CRS. Various solutions consisting of solo isotonic and hypertonic saline, dead-sea salts, or those including topical corticosteroids, antibiotics, or natural substances are used for nasal irrigation. ${ }^{352-354}$ Compared to the common methods of nasal delivery, high-volume nasal irrigation is better able to deliver and maximally distribute topical medications to the sinus mucosa. ${ }^{355}$

In 2007, a study published on the Cochrane library demonstrated that irrigation with nasal saline is well-tolerated and alleviates the symptoms of CRS to a greater degree than the placebo, thereby improving QoL as assessed by using the disease-specific QoL (DSQOL) questionnaire. ${ }^{356} \mathrm{~A}$ recent review in the Cochrane library demonstrated improvement in DSQOL of CRS patients after a minimum of 3 months of high-volume nasal irrigation with hypertonic 
saline compared with that of the placebo; however, $23 \%$ of the treated individuals experienced adverse reactions including epistaxis. ${ }^{357} \mathrm{~A}$ twice daily regimen of nasal irrigation with a solution of $0.05 \%$ mupirocin and Ringers salts markedly reduced the VAS, DSQOL, and endoscopic findings in the most recalcitrant CRS patients. ${ }^{358}$ Although this clinical application is off-label, the efficiency and safety of nasal irrigation with corticosteroids is being evaluated. ${ }^{353}$ In 2009 , the first study on high-volume nasal irrigation with budesonide reported that $75 \%$ of the CRS patients subjected to the treatment showed significant improvements in their VAS and endoscopic scores. ${ }^{295}$ No adrenal suppression was detected after $1 \mathrm{mg}$ of budesonide in $120 \mathrm{ml}$ of saline was administered twice daily for 60 days. ${ }^{359}$

Nasal irrigation plays a crucial adjunctive role in post-ESS care. At present, nasal irrigation using a saline solution is considered to be effective for preventing purulent rhinorrhea, granulation, and polyp recurrence after ESS. ${ }^{360}$ Nasal irrigation with budesonide is also an effective postoperative therapy for patients with NP and asthma as evidenced by decreased DSQOL and Lund-Kennedy scores and reduced intake of oral steroids. ${ }^{361}$ Furthermore, $83 \%$ of the difficult-to-treat CRS patients exhibited satisfactory alleviation of their subjective symptoms, and $75 \%$ of the patients showed improvement in DSQOL and endoscopic scores after 500-mL irrigation with $1 \mathrm{mg}$ budesonide in a saline solution, twice daily for 3 months. ${ }^{362}$

\section{Surgery}

Procedures

Surgical intervention is used to treat CRS patients who are unresponsive to the maximal medical treatments after they have been administered for at least 12 weeks. ${ }^{363}$ Twenty years ago, Naumann ${ }^{364}$ described the OMC, which has become the anatomical basis for FESS, which is considered to be the first option for surgical intervention in CRS.

FESS can provide immediate and long-term symptom relief, and can improve QoL in $85 \%$ of the patients. ${ }^{365} \mathrm{FESS}$ involves the clearance of polyps and polypoid mucosa and the opening of the sinus ostia with the protection of normal and edematous mucosa. In FESS, CRS symptoms are alleviated by the removal of inflammatory tissues (including the mucosa and the underling bone), reduction of the antigenic load that triggers inflammation, and improvements in sinus ventilation and MCC. ESS is classified into routine and revision surgery based on changes in the pathophysiology of CRS patients. Major complications of surgery include cerebrospinal fluid leak, meningitis, hemorrhage and orbital injuries. The extent of FESS varies from uncinectomy to sphenoethmoidectomy with and without middle turbinate resection.

1) Surgical indications

ESS is considered for CRS that is unresponsive to medical intervention, complicated acute sinusitis, allergic fungal sinusitis, mucoceles and symptomatic polypoid disease that is inadequately managed by other medicines,.

2) Preoperative evaluation

Endoscopy

Endoscopic evaluation of the anatomy or lesions is important before surgery, particularly in patients who have had prior surgical intervention. It is necessary to determine whether the 0-degree 4-mm telescope can be introduced into the nose and bilaterally advanced to the anterior attachment of the middle turbinate. If the 0-degree telescope cannot be introduced into this region, septoplasty is required during surgical intervention. 
Imaging

It is essential to re-review a patient's CT scans before surgical intervention and preferably shortly before the surgery. Standardized methodology should be used to review the scans to ensure that no significant anatomic variations are missed. Although CT is the primary diagnostic modality for sinus disease, preoperative MRI is recommended for some sinus disorders, including complications of acute or chronic sinusitis, allergic fungal sinusitis, mucocele or tumors. Imaging via MRI is vital when differential diagnosis is necessary, and the disease is adjacent to the skull base erosion. Evaluation of dehiscent areas in the sphenoid sinus is very important for excluding the possibility of a carotid artery aneurysm.

\section{3) Surgical principles}

FESS is primarily aimed at reopening the dependent sinuses and at reestablishing drainage and ventilation of the sinuses. With the advent of through-cutting forceps, microdebriders, and improved hand instrumentation, the removal of diseased tissue and bone is now achieved with good mucoperiosteal preservation. The extent of FESS varies from simple uncinectomy to a complete sphenoethmoidectomy, antrostomy, and frontal sinusotomy. Extended frontal sinus procedures are generally not performed during the first surgery. However, when the involved mucosa and bone represent an inflammatory burden, the effect of FESS is limited, and radical endoscopic surgery is required.

Uncinectomy

Uncinectomy is usually the first step in ethmoidectomy. This procedure begins with dissection using a sickle knife or backward cutting "sewing door technique." The upper part of the uncinate process is used as an anatomical landmark for orientation of the drainage pathway of the frontal sinus and for exposing the ostium of the maxillary sinus (Fig. 3).

\section{Ethmoidectomy}

After the uncinectomy, the anterior wall of the ethmoidal bulla, the second lamella, can be observed and removed up to the basal lamella of the middle turbinate. The posterior ethmoidal cells can be cleared after resecting the basal lamella. The Onodi cell usually indicates the last posterior ethmoidal cell. The lateral wall of the ethmoidal sinus is the lamina papyracea. Dehiscence in the lamina can be identified once the lamina papyracea is identified and cleaned of cells (Fig. 4).
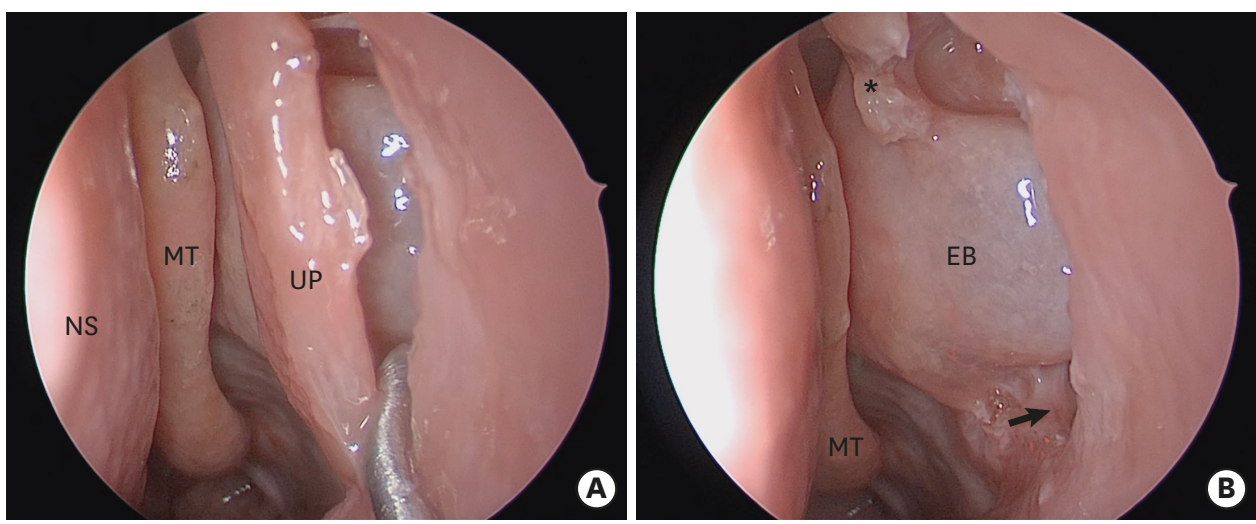

Fig. 3. Endoscopic view of an uncinectomy. (A) An incision was made with a sickle knife or elevator, along the anterior margin of the UP. (B) The EB was exposed after the removal of the UP, and natural ostium maxillary sinus $(\uparrow)$ can be observed.

NS, nasal septum; MT, middle turbinate; UP, uncinate process; EB, ethmoidal bulla.

*Upper attachment of UP. 
Fig. 4. Endoscopic view of ethmoidectomy (cadaver dissection).

PE, posterior ethmoidal sinus; ST, superior turbinate; MT, middle turbinate.

*The bottoms of adjacent ethmoidal cells at the same level indicate lamina papyracea.

\section{Sphenoidectomy}

The sphenoid sinus can be opened using transethmoidal and transnasal approaches. The lower third superior turbinate, an important landmark for locating the ostium through the superior meatus, can be removed; the ostium of the sphenoid sinus medial to the attachment of the superior turbinate can then be identified (Fig. 5). The anterior wall can then be resected through the natural ostium using the Kerrison punch. The transnasal approach often begins with a partial resection of the inferoposterior middle turbinate or lateralization of the middle turbinate; the sphenoid sinus is then opened using the technique used in the transethmoidal approach.

\section{Frontal sinus surgery}

The endoscopic frontal recess approach (Draf I frontal sinus surgery) is the primary means of managing chronic frontal sinusitis. Only the septal cells in the frontal recess need to be removed to improve the drainage and ventilation of the frontal sinus (Fig. 6). This approach is considered when only minor pathology is present in the frontal sinus.
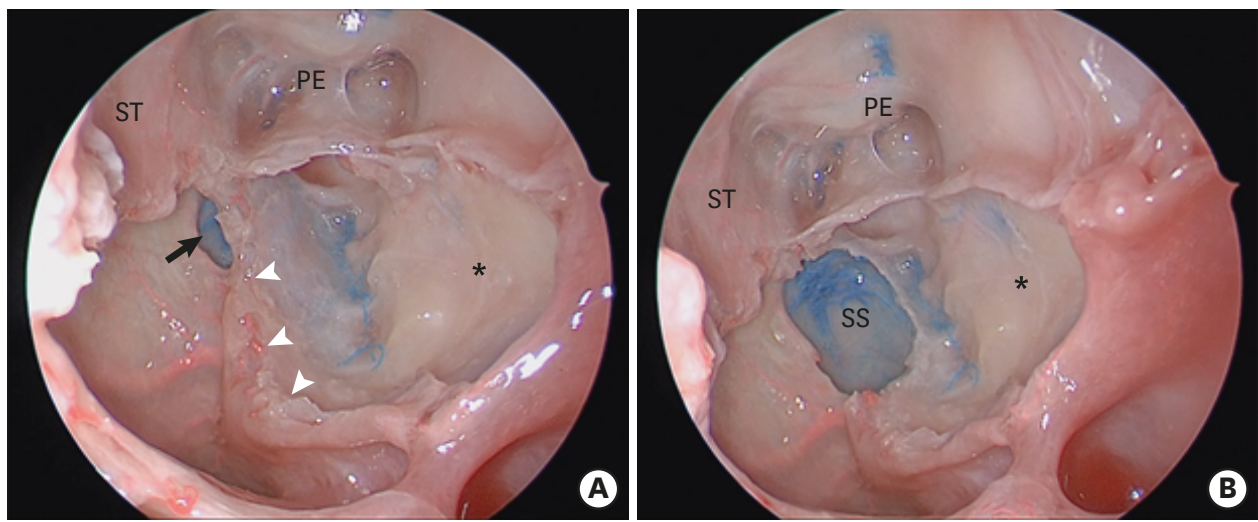

Fig. 5. Endoscopic image of the cadaver shows that: (A) After partial superior turbinectomy, the ostium of the SS $(\uparrow)$, located medially to the remnant ST $(\Delta \Delta \Delta)$, was well exposed; (B) the SS was opened by a Kerrison punch. ST, superior turbinate; SS, sphenoidal sinus; PE, posterior ethmoidal sinus.

*Lamina papyracea. 


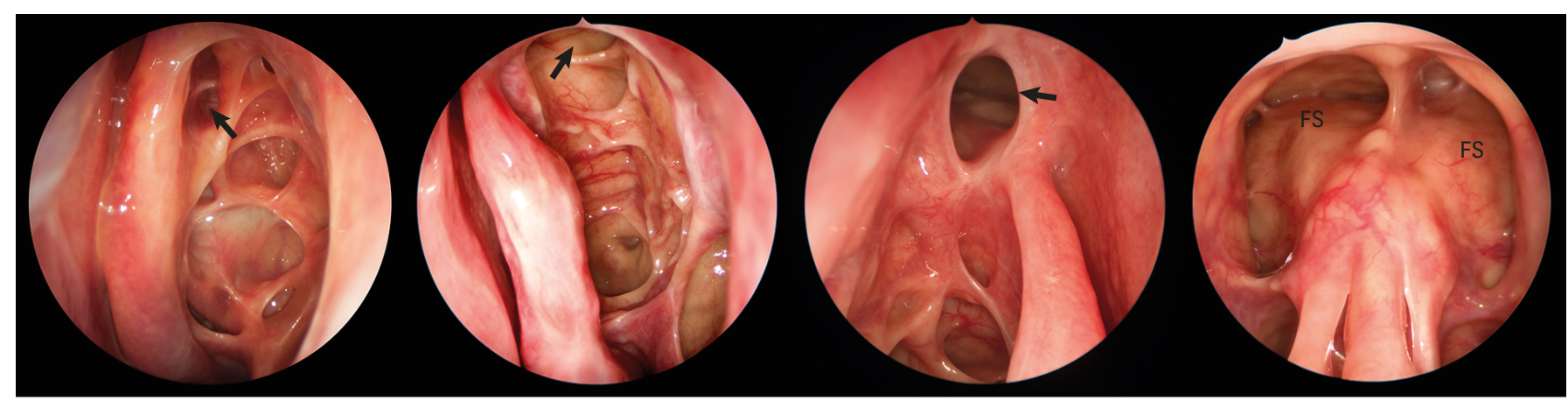

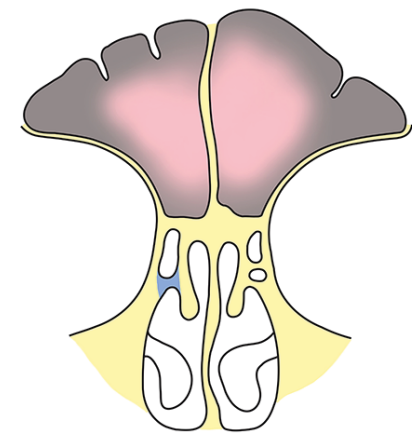

Draf I

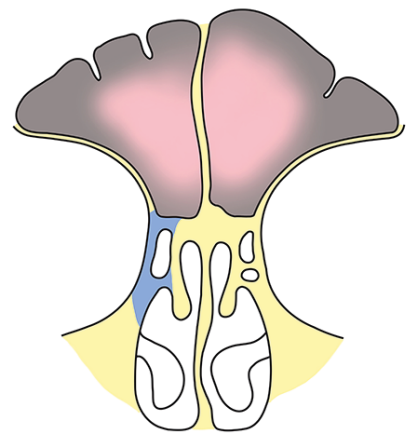

Draf IIa

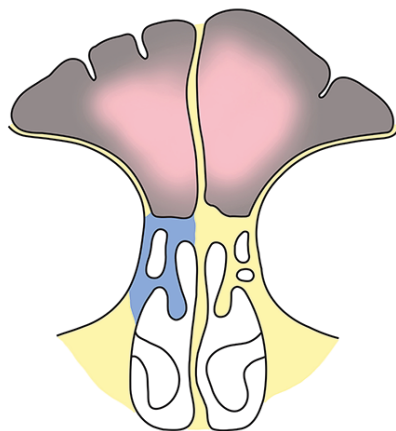

Draf IIb

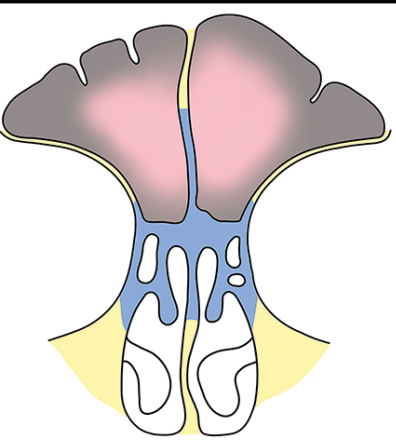

Draf III

Fig. 6. Postoperative endoscopy and images demonstrate Draf type frontal sinus surgeries: Draf I, II (a, b) and III. FS ( ). FS, frontal sinus.

Extended frontal sinus drainage is achieved after an ethmoidectomy by resecting the floor of the frontal sinus between the lamina papyracea and the middle turbinate (Draf II a) or nasal septum (Draf II b) anterior to the ventral margin of the olfactory fossa. Indications for Draf IIa include moderate or severe mucosal pathology, benign tumors, and mucocele. Draf II $b$ is utilized when Draf IIa fails or for treating benign tumors or recurrent polyps with hyperplastic bones in the frontal recess. For Draf IIb, the frontal process of the maxilla and frontal beak are removed by drilling.

Draf III, also called the median drainage procedure, is accomplished by resecting portions of the superior nasal septum, interfrontal septum, cells in the frontal recess, and the frontal sinus floor. Identifying the first olfactory fibers on both sides helps to achieve a maximal opening of the frontal sinus. Indications for Draf III vary and include failed ESS, osteogenesis in the frontal recess, and frontal ostium, frontal recess adhesion ${ }^{366,367}$ and benign and malignant tumors.

\section{4) Revision surgery}

Revision surgeries for recurrent CRS are based on the different pathogenic backgrounds. In revision surgery, key anatomic landmarks may be altered or missing, increasing the risk of severe complications, such as orbital injury, cerebrospinal fluid leak, and excessive bleeding. The middle turbinate, a commonly used landmark, may be altered or removed. During revision sinus surgery, preservation of the mucosa helps to avoid exposing the underlying bone, which can result in osteoneogenesis and osteitis. Radical endoscopic surgery (RES) is indicated ${ }^{368}$ when the sinus mucosa and bone represent an inflammatory burden, ${ }^{193}$ such as in CRSwNP and comorbid asthma, aspirin intolerance, and recurrent CRSwNP with or without the hyperplastic ethmoidal bone. These patients often exhibit high levels of eosinophils 
in their peripheral blood and/or mucosal tissue, high levels of specific IgE, and NPs in the middle turbinate and septum, which are the risk factors for recurrent CRS.

RES, which includes nasalization, extensive opening of the maxillary and sphenoid sinuses, and Draf IIb or III type frontal sinus surgeries, are the most common procedures in revision surgery (Fig. 7). Although these procedures are controversial, follow-ups have shown satisfactory outcomes. ${ }^{369}$ Surgery is only the beginning of the treatment; long-term periodical follow-ups and sustained medical therapies should be performed based on the pathophysiology of the chronic sinus disease. ${ }^{370,371}$

\section{Surgery in CRS with asthma}

Asthma is commonly concomitant with CRSwNP and CRSsNP. In CRS patients undergoing ESS, the prevalence of asthma is $10 \%$ compared to a $1 \%$ prevalence in the general adult population..$^{372,373}$ The prevalence of asthma in Chinese CRS patients is lower than that in patients of European descent. ${ }^{26,374}$ Sinus disease is more severe in CRS when asthma occurs as a comorbidity. These patients develop earlier and more severe olfactory dysfunctions and show higher CT olfactory scores. ${ }^{372}$ There are no differences between the asthmatic and nonasthmatic CRS patients with respect to total nasal resistance or bilateral nasal cavity volumes when assessed by acoustic rhinometry. ${ }^{375}$ Consistently, these patients have more severe asthma, and most are refractory to medical treatments. ESS is the mainstay for severe CRS with asthma. Asthma could be considered a risk factor for the most negative outcomes of ESS, ${ }^{376,377}$ but this is up for debate. ${ }^{378,379}$ Patients with both CRS and asthma might benefit from extended ESS. Chen et al. ${ }^{380,381}$ found that symptoms and endoscopic scores in CRS patients with asthma were improved significantly at the 1- and 3-year postoperative follow-ups (Fig. 8). Compared to FESS, extended ESS (partial middle turbinate and superior turbinate resection) showed better endoscopic appearance and olfactory symptom VAS scores in patients with CRS and asthma, postoperatively. ${ }^{382}$ Alsharif et al. ${ }^{383}$ proposed a reboot technique for type-2 CRSwNP. The aim of this technique was to maximally remove all the sinus mucosa and allow for a healthy re-epithelialization from the preserved nasal mucosa. They found that their reboot technique reduced the recurrence of NP in a 30-month follow-up.
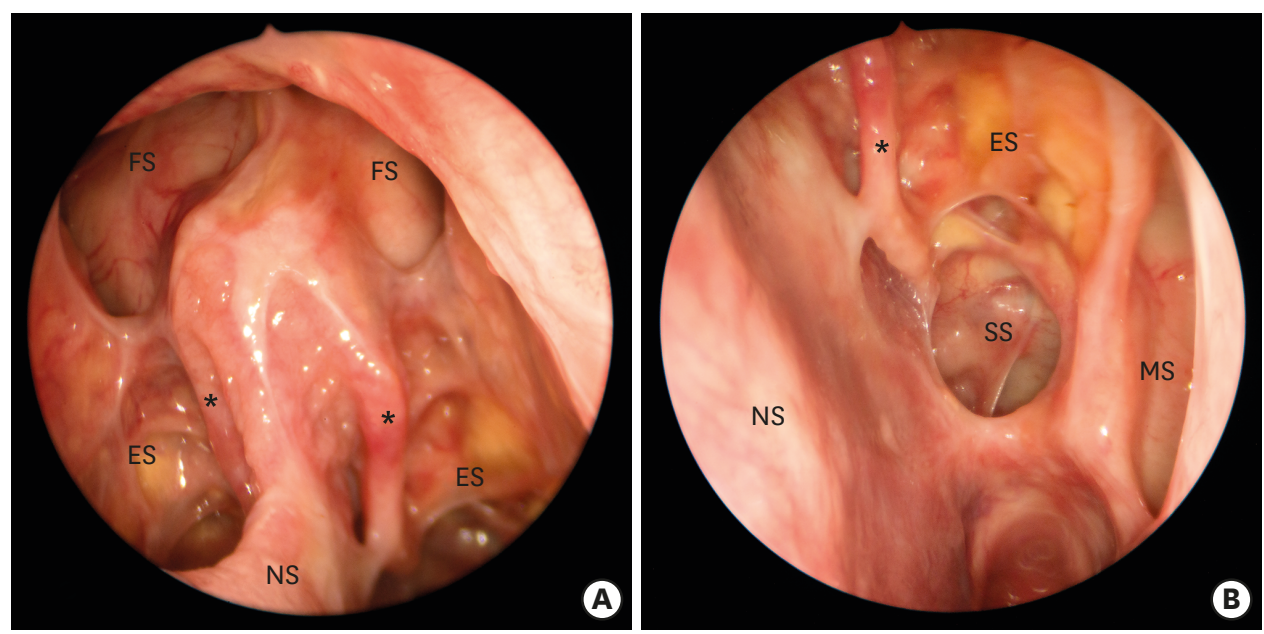

Fig. 7. Postoperative endoscopy. Well-epithelized nasal cavity after nasalization using the Draf III procedure. (A), endoscopic view of bilateral frontal sinuses and ethmoid sinuses. (B), endoscopic view of left ethmoid sinus, sphenoid sinus and maxillary sinus.

FS, frontal sinus; ES, ethmoidal sinus; SS, sphenoidal sinus; MS, maxillary sinus, NS, nasal septum. *Middle turbinate. 

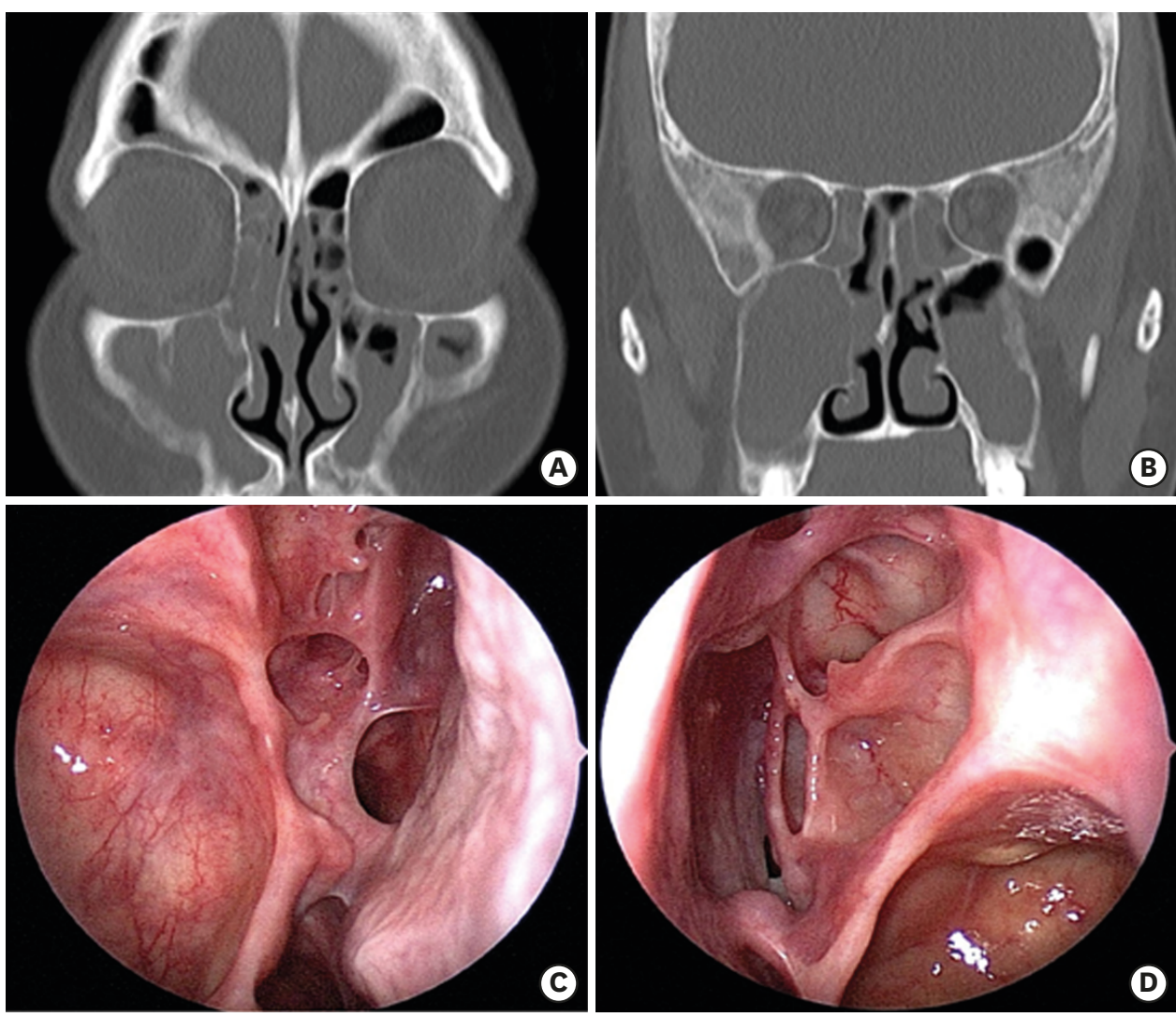

Fig. 8. Representative images of a preoperative computed tomographic scan (A, B) and 4-year postoperative endoscopic views of the sinuses (C, right nasal cavity; D, left nasal cavity) from a patient with chronic rhinosinusitis and asthma.

\section{Perioperative management and follow-up}

Perioperative management of chronic CRS includes surgery, medications, and other treatment strategies, 1 to 2 weeks before surgery, and 3 to 6 months after surgery.

\section{Preoperative management}

Preoperative management (conducted for 7 to 14 days) involves the control of infection and inflammation in the nasal cavity and/or sinuses and the management of conditions such as hypertension and coagulation dysfunction. Preoperative management is meant to improve surgical safety. ${ }^{384}$ Rules regarding these medications are outlined in section 8.1. Drugs and foods such as anticoagulants, aspirin and ginseng that can cause intraoperative bleeding should be discontinued at least 5 days prior to surgery. ${ }^{385}$

Blood pressure should be maintained under $150 / 95 \mathrm{mmHg}$ for 3 to 5 days. Fasting blood glucose levels should be $<9.0 \mathrm{mmol} / \mathrm{L}$. For patients with heart, lung, liver, or kidney dysfunctions, laboratory results should be in accordance with the requirements of general anesthesia.

\section{Intraoperative management}

The goal of intra-operative management is to assess the patient using a sinus CT, endoscope, and other correlated examinations. ${ }^{386}$ Minimally invasive surgery and function-conserving management should be considered. The choice of nasal packing and packing material should be left to the surgeons. ${ }^{387,388}$ 
Postoperative follow-up

Successful ESS in CRS is only a part of the therapeutic approach as postoperative follow-ups and comprehensive therapy are also essential in CRS. ${ }^{389}$ Postoperative therapies for CRS can be divided into 3 stages, cleaning, mucous transition, and epithelialization. Postoperative mucosal morphology and functional recovery usually require 3 months or more, and comprehensive therapy is necessary during this period. ${ }^{13}$ The principles of postoperative medication have been described in section 8.1.

Efficacy evaluations help to analyze the course of therapy and that of the disease via subjective and objective methods. Assessment of VAS, Lund-Mackay and Lund-Kennedy scores is recommended for CRS patients. SF-36 $6^{390}$ and SNOT-20 $0^{391}$ are also suggested and provide more comprehensive and scientific information. ${ }^{392}$

\section{Evaluation and prediction of surgical outcome}

ESS, the standard surgical intervention for $\mathrm{CRS},{ }^{287,393}$ is effective and safe. ${ }^{394,395}$ A systematic review $^{393}$ reported that ESS leads to symptomatic improvements in up to $98 \%$ of CRSwNP patients with a low frequency of major complications. Another review showed $91 \%$ symptom improvement rates after ESS. ${ }^{396}$ The 22-item version of the SNOT-22 can predict the likelihood of postsurgical symptom alleviation in CRS. ${ }^{397}$ Delayed surgery ( $>60$ months) leads to decreased improvement in long-term SNOT-22 scores regardless of the co-occurrence of co-morbid asthma and/or allergies. ${ }^{398}$ SNOT-22 is used to categorize CRS into 5 clusters having different outcomes. ${ }^{399}$

CRSwNP patients show higher recurrence rates than those with CRSsNP. ${ }^{400} \mathrm{~A}$ multicenter prospective cohort study demonstrated that the recurrence rates after ESS ranged from 35 to $40 \%$ when the follow-up period was prolonged from 6 to 18 months. ${ }^{401}$ Another study showed that $60 \%$ of the patients experienced polyp relapse within a follow-up period of 12 to 168 months. ${ }^{28}$ In agreement with the results obtained in the US, the postoperative polyp recurrence was found to be greater than $50 \%$ in Turkey. ${ }^{402}$ In the Chinese population, the recurrence rate was $55 \%$ when CRSwNP patients were followed after 3 years. ${ }^{403}$

Clinical factors, such as prior ESS, increased preoperative polyp severity, and eosinophilic density of the NP, $, 8,401,402$ are associated with an increased likelihood of polyp recurrence. Evaluation of the inflammatory cells and cytokine profiles help in the identification of biomarkers that can be used to assess the risk of recurrence.

Biomarkers can be identified from nasal polyp biopsies, nasal secretions, and peripheral blood. ${ }^{404}$ Lou et al ${ }^{403}$ demonstrated that CRSwNP patients with > 27\% eosinophils or 55 eosinophils/high power field (HPF) showed recurrence. Two Japanese studies ${ }^{215,377}$ showed that mucosal eosinophilia (> 70 eosinophils/HPF) results in poor prognosis. Mucosal eosinophilia at 120 cells/HPF is strongly correlated with recurrent CRS. ${ }^{405}$ Similarly, Grgić et al. ${ }^{406}$ showed that high tissue eosinophil infiltration (> 20/HPF) indicates high risk of recurrence. Thus, tissue eosinophilia provides valuable information regarding NP recurrence after ESS. The degree of tissue eosinophilia can be considered to be an important predictor of NP recurrence.

Blood eosinophilia can be used as a surrogate for tissue eosinophilic inflammation. ${ }^{210,405}$ Studies have shown the prognostic role of blood eosinophil counts and percentages in the recurrence of CRSwNP. ${ }^{37,405,407}$ However, various conditions, including allergy, autoimmune diseases, drugs, and parasitic infections, can alter the number of eosinophils in circulation. Thus, blood eosinophilia does not precisely reflect tissue eosinophilia, and its prognostic ability remains limited. ${ }^{403}$ 
The diversity of nasal microbiota in nasal secretions can affect surgical outcomes. ${ }^{408}$ The relative abundance of the phylum Actinobacteria and genus Corynebacterium indicates improved surgical outcomes ${ }^{408}$ whereas repeated sinus surgery frequently results in Pseudomonas aeruginosa positive bacterial cultures. ${ }^{409}$ However, the prognostic role of microbiota in ESS requires further study.

Recent immunological advancements may help to distinguish CRS with different recurrence rates. Grgić et al. ${ }^{406}$ showed that IL-5 levels in the tissue homogenates can be used to predict recurrence. Another study found a heterogeneous, rather than homogeneous, Th pattern in the nonrecurrent CRSwNP. ${ }^{206} \mathrm{Th} 1$, Th2 and Th17 cytokines, along with significantly increased levels of IFN- $\gamma$, were produced in most cases of the nonrecurrent CRSwNP whereas the recurrent CRSwNP expressed a predominantly Th2-type inflammation with increased levels of IL-5, ECP, IgE and SE-IgE. ${ }^{206}$ Therefore, understanding the diversity of the CRS endotypes across the world ${ }^{5}$ will be useful for predicting the outcomes in different regions.

\section{Targeted treatment with biologics}

Improved understanding of the pathophysiological mechanisms of CRS has spurred the development of targeted therapies based on the biomarkers of CRS patients, resulting in endotype-driven treatments. ${ }^{238,239}$ Among these endotypes, the type 2 inflammation-based endotype is well understood, but the non-type 2 inflammation-based, and other endotypes require further studies.

\section{Anti-IgE}

Omalizumab, a recombinant, humanized, anti-IgE mAb can bind circulating IgE via its high-affinity receptor (FcERI) and prevent it from binding to effector cells such as mast cells, basophils, DCs, and eosinophils. Subsequently, the expression of FceRI on effector cells is reduced. ${ }^{410}$ In CRSwNP patients with comorbid asthma, omalizumab can reduce the upper and lower airway symptoms, endoscopic NP scores, and the requirement for other medical or surgical treatments. ${ }^{411,412}$ However, omalizumab exerts scant and clinically irrelevant effects on CRS in which the presence of NPs was not taken into account. ${ }^{413}$ Until now, only omalizumab has been registered and approved for the treatment of asthma in China. However, other anti-IgE-based treatments are currently being developed; these include ligelizumab, which shows higher affinity for IgE, compared to omalizumab, ${ }^{414}$ and quilizumab, which targets the M1 epitope on the membrane IgE. ${ }^{415}$

\section{Anti-IL5}

Mepolizumab and reslizumab are humanized anti-IL5 mAbs that can neutralize IL-5. Reslizumab significantly reduces the blood eosinophil counts and nasal IL-5 levels in patients with NP and improves individual NP scores for up to 4 weeks in $50 \%$ of patients. ${ }^{416}$ Mepolizumab reduces NP scores in patients with severe and/or recurrent NPs. ${ }^{205}$ Reslizumab and mepolizumab are safe and well-tolerated in CRSwNP patients. ${ }^{205,416}$ Benralizumab, another humanized mAb against the highly-expressed IL-5R $\alpha$ receptor on eosinophils, has been shown to be safe and effective in uncontrolled asthma with eosinophilia in a phase III trial. ${ }^{417}$

\section{Anti-IL-4/IL-13}

IL-4 and - 13 share the IL-4R $\alpha$ subunit, which forms a functional IL-4 receptor, with the common $\gamma \mathrm{C}$ subunit, or an IL-4 and -13 receptor, with an IL-13R $\alpha$ subunit. ${ }^{418}$ Dupilumab, a fully human mAb against IL-4R $\alpha$, can inhibit the effects of IL- 4 and $-13^{232}$ and is used to treat atopic dermatitis and asthma. ${ }^{419,420}$ In a recent phase II trial, Bachert et al. ${ }^{204}$ evaluated 
the use of subcutaneously-administered dupilumab in the treatment of the uncontrolled CRSwNP. This therapy was shown to improve endoscopic NP scores, CT scores (obtained using the Lund-Mackay scoring system) and QoL, and reduce major symptoms including loss of smell, nasal obstruction and congestion, and nocturnal awakenings in more than half of the treated patients, compared to the placebo group. This effect was retained for up to 2 months and slowly decreased during the 16 weeks of follow-up after treatment cessation. ${ }^{204}$

\section{Additional anti-type 2 therapies}

New anti-type 2 therapies include a GATA-3 specific DNAzyme, which was evaluated in a phase IIb study for the treatment of allergic asthma. ${ }^{233}$ So far, these targeted treatments have not been investigated in rhinitis or CRS. Another mAb, AK001, targets siglec-8, a cell surface receptor selectively expressed on mast cells, eosinophils, and basophils. A phase II study is currently evaluating the efficacy of AK001 in CRSwNP patients. ${ }^{421}$

\section{Therapies targeting non-type 2 inflammation}

Different biologicals targeting non-type 2 inflammation have shown scant or no improvement in the clinically relevant parameters of asthma outcome. ${ }^{235,236}$ Therapies targeting non-type 2 inflammation have not been evaluated in rhinitis or CRS.

\section{UNMET NEEDS AND SUMMARY}

CRS affects approximately $8 \%$ of the adult population in China. The inflammatory and remodeling characteristics of CRS in Chinese patients have shown an eosinophilic shift over time and differ from the characteristics of patients of European descent. The development of precision treatments based on endotype-driven pathways hinges on improving our understanding of the pathophysiologic mechanisms involved in CRS. Traditionally, clinicians differentiate phenotypes of a disease based on its clinical manifestations; however, we now recognize that the inflammatory endotypes of CRS also show considerable variation. Disease recurrence after pharmacotherapy and surgery is associated with a significant Th2 bias and eosinophilic inflammation. CRS endotypes vary by region and environment with respect to genetic factors. China's population is twice as large as that of Europe, and numerous distinct CRS endotypes exist within the Chinese population. Conducting multi-center studies nationwide is necessary to define the CRS endotypes and develop precision therapies for the Chinese population.

The therapeutic approaches summarized in the current guidelines do not achieve long-term symptom control. Pharmacotherapy and surgery demonstrate limited effects with respect to controlling severe CRSwNP, which shows frequent recurrence and asthma comorbidity. Verification of the CRS endotypes and mapping of the eosinophilic shift will provide new targets for interventions. Future studies would identify biomarkers that will be suitable for endotyping and predicting therapeutic responses. The development of biotherapeutics in China currently trails that of Western countries by nearly 2 decades, highlighting the pressing need for the development of these drug types. Dosages and treatments for the endotypes specific to the Chinese patients will also require further studies. In summary, therapies, including pharmacotherapies, surgical approaches, and biotherapeutics, should be tailored to the individual CRS endotypes. 


\section{REFERENCES}

1. Rudmik L, Smith TL. Quality of life in patients with chronic rhinosinusitis. Curr Allergy Asthma Rep 2011;11:247-52. PUBMED | CROSSREF

2. Bhattacharyya N, Orlandi RR, Grebner J, Martinson M. Cost burden of chronic rhinosinusitis: a claimsbased study. Otolaryngol Head Neck Surg 2011;144:440-5. PUBMED | CROSSREF

3. Rudmik L, Smith TL, Schlosser RJ, Hwang PH, Mace JC, Soler ZM. Productivity costs in patients with refractory chronic rhinosinusitis. Laryngoscope 2014;124:2007-12. PUBMED | CROSSREF

4. Lee TJ, Fu CH, Wang $\mathrm{CH}$, Huang CC, Huang CC, Chang PH, et al. Impact of chronic rhinosinusitis on severe asthma patients. PLoS One 2017;12:e0171047. PUBMED | CROSSREF

5. Tomassen P, Vandeplas G, Van Zele T, Cardell LO, Arebro J, Olze H, et al. Inflammatory endotypes of chronic rhinosinusitis based on cluster analysis of biomarkers. J Allergy Clin Immunol 2016;137:14491456.e4. PUBMED | CROSSREF

6. Fokkens WJ, Lund VJ, Mullol J, Bachert C, Alobid I, Baroody F, et al. European position paper on rhinosinusitis and nasal polyps 2012. Rhinol Suppl 2012;23:3 p preceding table of contents, 1-298. PUBMED

7. Meltzer EO, Hamilos DL, Hadley JA, Lanza DC, Marple BF, Nicklas RA, et al. Rhinosinusitis: establishing definitions for clinical research and patient care. Otolaryngol Head Neck Surg 2004;131:S1-62. PUBMED | CROSSREF

8. Beule A. Epidemiology of chronic rhinosinusitis, selected risk factors, comorbidities, and economic burden. GMS Curr Top Otorhinolaryngol Head Neck Surg 2015;14:Doc11. PUBMED

9. Dietz de Loos DA, Hopkins C, Fokkens WJ. Symptoms in chronic rhinosinusitis with and without nasal polyps. Laryngoscope 2013;123:57-63. PUBMED | CROSSREF

10. Hastan D, Fokkens WJ, Bachert C, Newson RB, Bislimovska J, Bockelbrink A, et al. Chronic rhinosinusitis in Europe--an underestimated disease. A GA²LEN study. Allergy 2011;66:1216-23. PUBMED | CROSSREF

11. Pleis JR, Coles R. Summary health statistics for U.S. adults: National Health Interview Survey, 1998. Vital Health Stat 10 2002:1-113. PUBMED

12. Pilan RR, Pinna FR, Bezerra TF, Mori RL, Padua FG, Bento RF, et al. Prevalence of chronic rhinosinusitis in Sao Paulo. Rhinology 2012;50:129-38. PUBMED | CROSSREF

13. Kim JH, Cho C, Lee EJ, Suh YS, Choi BI, Kim KS. Prevalence and risk factors of chronic rhinosinusitis in South Korea according to diagnostic criteria. Rhinology 2016;54:329-35. PUBMED | CROSSREF

14. Chen Y, Dales R, Lin M. The epidemiology of chronic rhinosinusitis in Canadians. Laryngoscope 2003;113:1199-205. PUBMED | CROSSREF

15. Blackwell DL, Lucas JW, Clarke TC. Summary health statistics for U.S. adults: national health interview survey, 2012. Vital Health Stat 10 2014:1-161. PUBMED

16. Anand VK. Epidemiology and economic impact of rhinosinusitis. Ann Otol Rhinol Laryngol Suppl 2004;193:3-5. PUBMED | CROSSREF

17. Shi JB, Fu QL, Zhang H, Cheng L, Wang YJ, Zhu DD, et al. Epidemiology of chronic rhinosinusitis: results from a cross-sectional survey in seven Chinese cities. Allergy 2015;70:533-9. PUBMED | CROSSREF

18. Shah A. Allergic rhinitis, chronic rhinosinusitis and nasal polyposis in Asia Pacific: impact on quality of life and sleep. Asia Pac Allergy 2014;4:131-3. PUBMED | CROSSREF 
19. Lange B, Holst R, Thilsing T, Baelum J, Kjeldsen A. Quality of life and associated factors in persons with chronic rhinosinusitis in the general population: a prospective questionnaire and clinical cross-sectional study. Clin Otolaryngol 2013;38:474-80.

PUBMED | CROSSREF

20. Kim JY, Ko I, Kim MS, Yu MS, Cho BJ, Kim DK. Association of chronic rhinosinusitis with depression and anxiety in a nationwide insurance population. JAMA Otolaryngol Head Neck Surg 2019;145:313-9. PUBMED | CROSSREF

21. Schalek P, Otruba L, Hahn A. Quality of life in patients with chronic rhinosinusitis: a validation of the Czech version of SNOT-22 questionnaire. Eur Arch Otorhinolaryngol 2010;267:473-5. PUBMED | CROSSREF

22. Fu QL, Ma JX, Ou CQ, Guo C, Shen SQ, Xu G, et al. Influence of self-reported chronic rhinosinusitis on health-related quality of life: a population-based survey. PLoS One 2015;10:e0126881. PUBMED | CROSSREF

23. Ragab SM, Lund VJ, Scadding G, Saleh HA, Khalifa MA. Impact of chronic rhinosinusitis therapy on quality of life: a prospective randomized controlled trial. Rhinology 2010;48:305-11. PUBMED | CROSSREF

24. Yii ACA, Tay TR, Choo XN, Koh MSY, Tee AKH, Wang DY. Precision medicine in united airways disease: a "treatable traits" approach. Allergy 2018;73:1964-78. PUBMED | CROSSREF

25. Jarvis D, Newson R, Lotvall J, Hastan D, Tomassen P, Keil T, et al. Asthma in adults and its association with chronic rhinosinusitis: the GA2LEN survey in Europe. Allergy 2012;67:91-8. PUBMED | CROSSREF

26. Fan Y, Chen S, Qu X, Zuo K, Li X, Huang J, et al. A lower prevalence of asthma among patients with chronic rhinosinusitis in southern China. J Allergy Clin Immunol 2011;127:520-522.e1-5. PUBMED | CROSSREF

27. Rix I, Håkansson K, Larsen CG, Frend $\emptyset$ M, von Buchwald C. Management of chronic rhinosinusitis with nasal polyps and coexisting asthma: a systematic review. Am J Rhinol Allergy 2015;29:193-201. PUBMED | CROSSREF

28. Wynn R, Har-El G. Recurrence rates after endoscopic sinus surgery for massive sinus polyposis. Laryngoscope 2004;114:811-3. PUBMED | CROSSREF

29. Klossek JM, Neukirch F, Pribil C, Jankowski R, Serrano E, Chanal I, et al. Prevalence of nasal polyposis in France: a cross-sectional, case-control study. Allergy 2005;60:233-7. PUBMED | CROSSREF

30. Jani AL, Hamilos DL. Current thinking on the relationship between rhinosinusitis and asthma. J Asthma 2005;42:1-7. PUBMED | CROSSREF

31. Wu D, Bleier BS, Li L, Zhan X, Zhang L, Lv Q, et al. Clinical phenotypes of nasal polyps and comorbid asthma based on cluster analysis of disease history. J Allergy Clin Immunol Pract 2018;6:1297-1305.e1. PUBMED | CROSSREF

32. Kennedy JL, Stoner AN, Borish L. Aspirin-exacerbated respiratory disease: Prevalence, diagnosis, treatment, and considerations for the future. Am J Rhinol Allergy 2016;30:407-13. PUBMED | CROSSREF

33. Levy JM, Smith TL. Is aspirin desensitization indicated for the treatment recalcitrant chronic rhinosinusitis with nasal polyposis in aspirin-exacerbated respiratory disease? Laryngoscope 2017;127:776-7. PUBMED | CROSSREF

34. Tajudeen BA, Schwartz JS, Bosso JV. The role of aspirin desensitization in the management of aspirinexacerbated respiratory disease. Curr Opin Otolaryngol Head Neck Surg 2017;25:30-4. PUBMED | CROSSREF

35. Mfuna-Endam L, Zhang Y, Desrosiers MY. Genetics of rhinosinusitis. Curr Allergy Asthma Rep 2011;11:236-46. PUBMED | CROSSREF

36. Hsu J, Avila PC, Kern RC, Hayes MG, Schleimer RP, Pinto JM. Genetics of chronic rhinosinusitis: state of the field and directions forward. J Allergy Clin Immunol 2013;131:977-93, 993.e1-993.e5. PUBMED | CROSSREF

37. Orb Q, Curtin K, Oakley GM, Wong J, Meier J, Orlandi RR, et al. Familial risk of pediatric chronic rhinosinusitis. Laryngoscope 2016;126:739-45. PUBMED | CROSSREF 
38. Cohen NA, Widelitz JS, Chiu AG, Palmer JN, Kennedy DW. Familial aggregation of sinonasal polyps correlates with severity of disease. Otolaryngol Head Neck Surg 2006;134:601-4. PUBMED | CROSSREF

39. Delagrand A, Gilbert-Dussardier B, Burg S, Allano G, Gohler-Desmonts C, Lebreton JP, et al. Nasal polyposis: is there an inheritance pattern? A single family study. Rhinology 2008;46:125-30. PUBMED

40. Qu SH, Li TY, Li M, Shi JB, Wen WP, Wen WH. Genetic epidemiologic study on nasal polyps. Zhonghua Er Bi Yan Hou Tou Jing Wai Ke Za Zhi 2007;42:608-11. PUBMED

41. Lockey RF, Rucknagel DL, Vanselow NA. Familial occurrence of asthma, nasal polyps and aspirin intolerance. Ann Intern Med 1973;78:57-63. PUBMED | CROSSREF

42. Wang X, Moylan B, Leopold DA, Kim J, Rubenstein RC, Togias A, et al. Mutation in the gene responsible for cystic fibrosis and predisposition to chronic rhinosinusitis in the general population. JAMA 2000;284:1814-9. PUBMED | CROSSREF

43. Shi LL, Song J, Xiong P, Cao PP, Liao B, Ma J, et al. Disease-specific T-helper cell polarizing function of lesional dendritic cells in different types of chronic rhinosinusitis with nasal polyps. Am J Respir Crit Care Med 2014;190:628-38. PUBMED | CROSSREF

44. Yoo F, Suh JD. What is the evidence for genetics in chronic rhinosinusitis? Curr Opin Otolaryngol Head Neck Surg 2017;25:54-63. PUBMED | CROSSREF

45. Karjalainen J, Joki-Erkkilä VP, Hulkkonen J, Pessi T, Nieminen MM, Aromaa A, et al. The IL1A genotype is associated with nasal polyposis in asthmatic adults. Allergy 2003;58:393-6. PUBMED | CROSSREF

46. Erbek SS, Yurtcu E, Erbek S, Atac FB, Sahin FI, Cakmak O. Proinflammatory cytokine single nucleotide polymorphisms in nasal polyposis. Arch Otolaryngol Head Neck Surg 2007;133:705-9. PUBMED | CROSSREF

47. Mfuna Endam L, Cormier C, Bossé Y, Filali-Mouhim A, Desrosiers M. Association of IL1A, IL1B, and TNF gene polymorphisms with chronic rhinosinusitis with and without nasal polyposis: a replication study. Arch Otolaryngol Head Neck Surg 2010;136:187-92. PUBMED | CROSSREF

48. Zhang Y, Endam LM, Filali-Mouhim A, Zhao L, Desrosiers M, Han D, et al. Polymorphisms in RYBP and AOAH genes are associated with chronic rhinosinusitis in a Chinese population: a replication study. PLoS One 2012;7:e39247. PUBMED | CROSSREF

49. Henmyr V, Vandeplas G, Halldén C, Säll T, Olze H, Bachert C, et al. Replication study of genetic variants associated with chronic rhinosinusitis and nasal polyposis. J Allergy Clin Immunol 2014;133:273-5. PUBMED | CROSSREF

50. Bossé Y, Bacot F, Montpetit A, Rung J, Qu HQ, Engert JC, et al. Identification of susceptibility genes for complex diseases using pooling-based genome-wide association scans. Hum Genet 2009;125:305-18. PUBMED | CROSSREF

51. Cormier C, Mfuna Endam L, Filali-Mouhim A, Boisvert P, Boulet LP, Boulay ME, et al. A pooling-based genomewide association study identifies genetic variants associated with Staphylococcus aureus colonization in chronic rhinosinusitis patients. Int Forum Allergy Rhinol 2014;4:207-15. PUBMED | CROSSREF

52. Kristjansson RP, Benonisdottir S, Davidsson OB, Oddsson A, Tragante V, Sigurdsson JK, et al. A lossof-function variant in ALOX15 protects against nasal polyps and chronic rhinosinusitis. Nat Genet 2019;51:267-76. PUBMED | CROSSREF

53. Zhang Y, Gevaert E, Lou H, Wang X, Zhang L, Bachert C, et al. Chronic rhinosinusitis in Asia. J Allergy Clin Immunol 2017;140:1230-9.

PUBMED | CROSSREF

54. Zhang XH, Zhang YN, Liu Z. MicroRNA in chronic rhinosinusitis and allergic rhinitis. Curr Allergy Asthma Rep 2014;14:415. PUBMED | CROSSREF

55. Zheng YB, Zhao Y, Yue LY, Lin P, Liu YF, Xian JM, et al. Pilot study of DNA methylation in the pathogenesis of chronic rhinosinusitis with nasal polyps. Rhinology 2015;53:345-52. PUBMED | CROSSREF 
56. Zhang XH, Zhang YN, Li HB, Hu CY, Wang N, Cao PP, et al. Overexpression of miR-125b, a novel regulator of innate immunity, in eosinophilic chronic rhinosinusitis with nasal polyps. Am J Respir Crit Care Med 2012;185:140-51. PUBMED | CROSSREF

57. Ma ZX, Tan X, Shen Y, Ke X, Yang YC, He XB, et al. MicroRNA expression profile of mature dendritic cell in chronic rhinosinusitis. Inflamm Res 2015;64:885-93. PUBMED | CROSSREF

58. Hariri BM, Cohen NA. New insights into upper airway innate immunity. Am J Rhinol Allergy 2016;30:319-23. PUBMED | CROSSREF

59. Soyka MB, Wawrzyniak P, Eiwegger T, Holzmann D, Treis A, Wanke K, et al. Defective epithelial barrier in chronic rhinosinusitis: the regulation of tight junctions by IFN- $\gamma$ and IL-4. J Allergy Clin Immunol 2012;130:1087-1096.e10.

PUBMED | CROSSREF

60. Kim DW, Cho SH. Emerging endotypes of chronic rhinosinusitis and its application to precision medicine. Allergy Asthma Immunol Res 2017;9:299-306. PUBMED | CROSSREF

61. Miljkovic D, Bassiouni A, Cooksley C, Ou J, Hauben E, Wormald PJ, et al. Association between group 2 innate lymphoid cells enrichment, nasal polyps and allergy in chronic rhinosinusitis. Allergy 2014;69:1154-61. PUBMED | CROSSREF

62. Nagarkar DR, Poposki JA, Tan BK, Comeau MR, Peters AT, Hulse KE, et al. Thymic stromal lymphopoietin activity is increased in nasal polyps of patients with chronic rhinosinusitis. J Allergy Clin Immunol 2013;132:593-600.e12. PUBMED | CROSSREF

63. Ito T, Wang YH, Duramad O, Hori T, Delespesse GJ, Watanabe N, et al. TSLP-activated dendritic cells induce an inflammatory T helper type 2 cell response through OX40 ligand. J Exp Med 2005;202:1213-23. PUBMED | CROSSREF

64. Symowski C, Voehringer D. Interactions between innate lymphoid cells and cells of the innate and adaptive immune system. Front Immunol 2017;8:1422.

PUBMED | CROSSREF

65. McKenzie ANJ, Spits H, Eberl G. Innate lymphoid cells in inflammation and immunity. Immunity 2014;41:366-74. PUBMED | CROSSREF

66. Liao B, Cao PP, Zeng M, Zhen Z, Wang H, Zhang YN, et al. Interaction of thymic stromal lymphopoietin, IL-33, and their receptors in epithelial cells in eosinophilic chronic rhinosinusitis with nasal polyps. Allergy 2015;70:1169-80.

PUBMED | CROSSREF

67. Shin HW, Kim DK, Park MH, Eun KM, Lee M, So D, et al. IL-25 as a novel therapeutic target in nasal polyps of patients with chronic rhinosinusitis. J Allergy Clin Immunol 2015;135:1476-1485.e7. PUBMED | CROSSREF

68. Lee M, Kim DW, Shin HW. Targeting IL-25 as a novel therapy in chronic rhinosinusitis with nasal polyps. Curr Opin Allergy Clin Immunol 2017;17:17-22. PUBMED | CROSSREF

69. Kim DK, Jin HR, Eun KM, Mo JH, Cho SH, Oh S, et al. The role of interleukin-33 in chronic rhinosinusitis. Thorax 2017;72:635-45. PUBMED | CROSSREF

70. Poposki JA, Klingler AI, Tan BK, Soroosh P, Banie H, Lewis G, et al. Group 2 innate lymphoid cells are elevated and activated in chronic rhinosinusitis with nasal polyps. Immun Inflamm Dis 2017;5:233-43. PUBMED | CROSSREF

71. Mjösberg JM, Trifari S, Crellin NK, Peters CP, van Drunen CM, Piet B, et al. Human IL-25- and IL-33responsive type 2 innate lymphoid cells are defined by expression of CRTH2 and CD161. Nat Immunol 2011;12:1055-62. PUBMED | CROSSREF

72. Schleimer RP. Immunopathogenesis of chronic rhinosinusitis and nasal polyposis. Annu Rev Pathol 2017;12:331-57. PUBMED | CROSSREF

73. Poposki JA, Peterson S, Welch K, Schleimer RP, Hulse KE, Peters AT, et al. Elevated presence of myeloid dendritic cells in nasal polyps of patients with chronic rhinosinusitis. Clin Exp Allergy 2015;45:384-93. PUBMED | CROSSREF 
74. Kim DK, Park MH, Chang DY, Eun KM, Shin HW, Mo JH, et al. MBP-positive and CD11c-positive cells are associated with different phenotypes of Korean patients with non-asthmatic chronic rhinosinusitis. PLoS One 2014;9:e111352. PUBMED | CROSSREF

75. Scheckenbach K, Wagenmann M. Cytokine patterns and endotypes in acute and chronic rhinosinusitis. Curr Allergy Asthma Rep 2016;16:3. PUBMED | CROSSREF

76. Hulse KE, Stevens WW, Tan BK, Schleimer RP. Pathogenesis of nasal polyposis. Clin Exp Allergy 2015;45:328-46. PUBMED | CROSSREF

77. Mahdavinia M, Carter RG, Ocampo CJ, Stevens W, Kato A, Tan BK, et al. Basophils are elevated in nasal polyps of patients with chronic rhinosinusitis without aspirin sensitivity. J Allergy Clin Immunol 2014;133:1759-63. PUBMED | CROSSREF

78. Derycke L, Eyerich S, Van Crombruggen K, Perez-Novo C, Holtappels G, Deruyck N, et al. Mixed T helper cell signatures in chronic rhinosinusitis with and without polyps. PLoS One 2014;9:e97581. PUBMED | CROSSREF

79. Halderman A, Lane AP. Genetic and immune dysregulation in chronic rhinosinusitis. Otolaryngol Clin North Am 2017;50:13-28. PUBMED | CROSSREF

80. Van Zele T, Claeys S, Gevaert P, Van Maele G, Holtappels G, Van Cauwenberge P, et al. Differentiation of chronic sinus diseases by measurement of inflammatory mediators. Allergy 2006;61:1280-9. PUBMED | CROSSREF

81. Zhang N, Van Zele T, Perez-Novo C, Van Bruaene N, Holtappels G, DeRuyck N, et al. Different types of T-effector cells orchestrate mucosal inflammation in chronic sinus disease. J Allergy Clin Immunol 2008;122:961-8. PUBMED | CROSSREF

82. Cao PP, Li HB, Wang BF, Wang SB, You XJ, Cui YH, et al. Distinct immunopathologic characteristics of various types of chronic rhinosinusitis in adult Chinese. J Allergy Clin Immunol 2009;124:478-84, 484.e1-484.e2. PUBMED | CROSSREF

83. Saitoh T, Kusunoki T, Yao T, Kawano K, Kojima Y, Miyahara K, et al. Role of interleukin-17A in the eosinophil accumulation and mucosal remodeling in chronic rhinosinusitis with nasal polyps associated with asthma. Int Arch Allergy Immunol 2010;151:8-16. PUBMED | CROSSREF

84. Hulse KE. Immune mechanisms of chronic rhinosinusitis. Curr Allergy Asthma Rep 2016;16:1. PUBMED | CROSSREF

85. Hulse KE, Norton JE, Suh L, Zhong Q, Mahdavinia M, Simon P, et al. Chronic rhinosinusitis with nasal polyps is characterized by B-cell inflammation and EBV-induced protein 2 expression. J Allergy Clin Immunol 2013;131:1075-83, 1083.e1-1083.e7. PUBMED | CROSSREF

86. Gevaert P, Nouri-Aria KT, Wu H, Harper CE, Takhar P, Fear DJ, et al. Local receptor revision and class switching to IgE in chronic rhinosinusitis with nasal polyps. Allergy 2013;68:55-63. PUBMED | CROSSREF

87. Gevaert P, Calus L, Van Zele T, Blomme K, De Ruyck N, Bauters W, et al. Omalizumab is effective in allergic and nonallergic patients with nasal polyps and asthma. J Allergy Clin Immunol 2013;131:110-116.e1. PUBMED | CROSSREF

88. Van Roey GA, Vanison CC, Wu J, Huang JH, Suh LA, Carter RG, et al. Classical complement pathway activation in the nasal tissue of patients with chronic rhinosinusitis. J Allergy Clin Immunol 2017;140:89-100.e2. PUBMED | CROSSREF

89. Tan BK, Li QZ, Suh L, Kato A, Conley DB, Chandra RK, et al. Evidence for intranasal antinuclear autoantibodies in patients with chronic rhinosinusitis with nasal polyps. J Allergy Clin Immunol 2011;128:1198-1206.e1. PUBMED | CROSSREF

90. Gonçalves C, Pinaffi JV, Carvalho JF, Pinna FR, Constantino GT, Voegels RL, et al. Antineutrophil cytoplasmic antibodies in chronic rhinosinusitis may be a marker of undisclosed vasculitis. Am J Rhinol 2007;21:691-4. PUBMED | CROSSREF

91. Jeffe JS, Seshadri S, Hamill KJ, Huang JH, Carter R, Suh L, et al. A role for anti-BP180 autoantibodies in chronic rhinosinusitis. Laryngoscope 2013;123:2104-11.

PUBMED | CROSSREF 
92. Hoggard M, Wagner Mackenzie B, Jain R, Taylor MW, Biswas K, Douglas RG. Chronic rhinosinusitis and the evolving understanding of microbial ecology in chronic inflammatory mucosal disease. Clin Microbiol Rev 2017;30:321-48. PUBMED | CROSSREF

93. Browne HP, Forster SC, Anonye BO, Kumar N, Neville BA, Stares MD, et al. Culturing of 'unculturable' human microbiota reveals novel taxa and extensive sporulation. Nature 2016;533:543-6. PUBMED | CROSSREF

94. Hauser LJ, Feazel LM, Ir D, Fang R, Wagner BD, Robertson CE, et al. Sinus culture poorly predicts resident microbiota. Int Forum Allergy Rhinol 2015;5:3-9. PUBMED | CROSSREF

95. Mahdavinia M, Keshavarzian A, Tobin MC, Landay AL, Schleimer RP. A comprehensive review of the nasal microbiome in chronic rhinosinusitis (CRS). Clin Exp Allergy 2016;46:21-41. PUBMED | CROSSREF

96. Davies D. Understanding biofilm resistance to antibacterial agents. Nat Rev Drug Discov 2003;2:114-22. PUBMED | CROSSREF

97. Zernotti ME, Angel Villegas N, Roques Revol M, Baena-Cagnani CE, Arce Miranda JE, Paredes ME, et al. Evidence of bacterial biofilms in nasal polyposis. J Investig Allergol Clin Immunol 2010;20:380-5. PUBMED

98. Jain R, Douglas R. When and how should we treat biofilms in chronic sinusitis? Curr Opin Otolaryngol Head Neck Surg 2014;22:16-21. PUBMED | CROSSREF

99. Boase S, Foreman A, Cleland E, Tan L, Melton-Kreft R, Pant H, et al. The microbiome of chronic rhinosinusitis: culture, molecular diagnostics and biofilm detection. BMC Infect Dis 2013;13:210. PUBMED | CROSSREF

100. Seiberling KA, Conley DB, Tripathi A, Grammer LC, Shuh L, Haines GK 3rd, et al. Superantigens and chronic rhinosinusitis: detection of staphylococcal exotoxins in nasal polyps. Laryngoscope 2005;115:1580-5. PUBMED | CROSSREF

101. Yu RL, Dong Z. Proinflammatory impact of Staphylococcus aureus enterotoxin B on human nasal epithelial cells and inhibition by dexamethasone. Am J Rhinol Allergy 2009;23:15-20.

PUBMED | CROSSREF

102. Bachert C, Gevaert P, Holtappels G, Johansson SG, van Cauwenberge P. Total and specific IgE in nasal polyps is related to local eosinophilic inflammation. J Allergy Clin Immunol 2001;107:607-14. PUBMED | CROSSREF

103. Qiao F, Xie Y, Yin WJ, Kang M, Guo XJ, Chen HL, et al. Nasal colonization by opportunistic pathogens among health care workers: a survey. Zhonghua Yi Yuan Gan Ran Xue Za Zhi 2008;18:1371-3.

104. Ba L, Zhang N, Meng J, Zhang J, Lin P, Zhou P, et al. The association between bacterial colonization and inflammatory pattern in Chinese chronic rhinosinusitis patients with nasal polyps. Allergy 2011;66:1296-303. PUBMED | CROSSREF

105. Liu Q, Lu X, Bo M, Qing H, Wang X, Zhang L. The microbiology of chronic rhinosinusitis with and without nasal polyps. Acta Otolaryngol 2014;134:1251-8. PUBMED | CROSSREF

106. Abreu NA, Nagalingam NA, Song Y, Roediger FC, Pletcher SD, Goldberg AN, et al. Sinus microbiome diversity depletion and Corynebacterium tuberculostearicum enrichment mediates rhinosinusitis. Sci Transl Med 2012;4:151ra124. PUBMED | CROSSREF

107. Cleland EJ, Bassiouni A, Vreugde S, Wormald PJ. The bacterial microbiome in chronic rhinosinusitis: richness, diversity, postoperative changes, and patient outcomes. Am J Rhinol Allergy 2016;30:37-43. PUBMED | CROSSREF

108. Cleland EJ, Bassiouni A, Boase S, Dowd S, Vreugde S, Wormald PJ. The fungal microbiome in chronic rhinosinusitis: richness, diversity, postoperative changes and patient outcomes. Int Forum Allergy Rhinol 2014;4:259-65.

PUBMED | CROSSREF

109. Aurora R, Chatterjee D, Hentzleman J, Prasad G, Sindwani R, Sanford T. Contrasting the microbiomes from healthy volunteers and patients with chronic rhinosinusitis. JAMA Otolaryngol Head Neck Surg 2013;139:1328-38. PUBMED | CROSSREF

110. Lee JT, Frank DN, Ramakrishnan V. Microbiome of the paranasal sinuses: update and literature review. Am J Rhinol Allergy 2016;30:3-16.

PUBMED | CROSSREF 
111. Shirtliff ME, Peters BM, Jabra-Rizk MA. Cross-kingdom interactions: Candida albicans and bacteria. FEMS Microbiol Lett 2009;299:1-8. PUBMED | CROSSREF

112. Soler ZM, Oyer SL, Kern RC, Senior BA, Kountakis SE, Marple BF, et al. Antimicrobials and chronic rhinosinusitis with or without polyposis in adults: an evidenced-based review with recommendations. Int Forum Allergy Rhinol 2013;3:31-47. PUBMED | CROSSREF

113. Rank MA, Wollan P, Kita H, Yawn BP. Acute exacerbations of chronic rhinosinusitis occur in a distinct seasonal pattern. J Allergy Clin Immunol 2010;126:168-9.

PUBMED | CROSSREF

114. Cho GS, Moon BJ, Lee BJ, Gong CH, Kim NH, Kim YS, et al. High rates of detection of respiratory viruses in the nasal washes and mucosae of patients with chronic rhinosinusitis. J Clin Microbiol 2013;51:979-84. PUBMED | CROSSREF

115. Liao B, Hu CY, Liu T, Liu Z. Respiratory viral infection in the chronic persistent phase of chronic rhinosinusitis. Laryngoscope 2014;124:832-7.

PUBMED | CROSSREF

116. Wang JH, Kwon HJ, Jang YJ. Rhinovirus enhances various bacterial adhesions to nasal epithelial cells simultaneously. Laryngoscope 2009;119:1406-11. PUBMED | CROSSREF

117. Jackson DJ, Johnston SL. The role of viruses in acute exacerbations of asthma. J Allergy Clin Immunol 2010;125:1178-87. PUBMED | CROSSREF

118. Wang X, Zhang N, Glorieux S, Holtappels G, Vaneechoutte M, Krysko O, et al. Herpes simplex virus type 1 infection facilitates invasion of Staphylococcus aureus into the nasal mucosa and nasal polyp tissue. PLoS One 2012;7:e39875. PUBMED | CROSSREF

119. Lan F, Wang XD, Nauwynck HJ, Holtappels G, Zhang L, Johnston SL, et al. Th2 biased upper airway inflammation is associated with an impaired response to viral infection with Herpes simplex virus 1. Rhinology 2016;54:141-9.

PUBMED | CROSSREF

120. London NR Jr, Lane AP. Innate immunity and chronic rhinosinusitis: what we have learned from animal models. Laryngoscope Investig Otolaryngol 2016;1:49-56. PUBMED | CROSSREF

121. Wei Y, Xia W, Ye X, Fan Y, Shi J, Wen W, et al. The antimicrobial protein short palate, lung, and nasal epithelium clone 1 (SPLUNC1) is differentially modulated in eosinophilic and noneosinophilic chronic rhinosinusitis with nasal polyps. J Allergy Clin Immunol 2014;133:420-8. PUBMED | CROSSREF

122. Sims JE, Williams DE, Morrissey PJ, Garka K, Foxworthe D, Price V, et al. Molecular cloning and biological characterization of a novel murine lymphoid growth factor. J Exp Med 2000;192:671-80. PUBMED | CROSSREF

123. Liu YJ. Thymic stromal lymphopoietin: master switch for allergic inflammation. J Exp Med 2006;203:269-73. PUBMED | CROSSREF

124. Ouyang Y, Fan E, Li Y, Wang X, Zhang L. Clinical characteristics and expression of thymic stromal lymphopoetin in eosinophilic and non-eosinophilic chronic rhinosinusitis. ORL J Otorhinolaryngol Relat Spec 2013;75:37-45. PUBMED | CROSSREF

125. Movérare R, Elfman L, Stålenheim G, Björnsson E, Movérare R. Study of the Th1/Th2 balance, including IL-10 production, in cultures of peripheral blood mononuclear cells from birch-pollen-allergic patients. Allergy 2000;55:171-5. PUBMED | CROSSREF

126. Bousquet J, Khaltaev N, Cruz AA, Denburg J, Fokkens WJ, Togias A, et al. Allergic rhinitis and its impact on asthma (ARIA) 2008 update (in collaboration with the World Health Organization, GA(2)LEN and AllerGen). Allergy 2008;63 Suppl 86:8-160. PUBMED | CROSSREF

127. Ciprandi G, De Amici M, Murdaca G, Fenoglio D, Ricciardolo F, Marseglia G, et al. Serum interleukin-17 levels are related to clinical severity in allergic rhinitis. Allergy 2009;64:1375-8. PUBMED | CROSSREF

128. Hong HY, Chen FH, Sun YQ, Hu XT, Wei Y, Fan YP, et al. Local IL-25 contributes to Th2-biased inflammatory profiles in nasal polyps. Allergy 2018;73:459-69. PUBMED | CROSSREF 
129. Van Bruaene N, Pérez-Novo CA, Basinski TM, Van Zele T, Holtappels G, De Ruyck N, et al. T-cell regulation in chronic paranasal sinus disease. J Allergy Clin Immunol 2008;121:1435-41, 1441.e1-1441.e3. PUBMED | CROSSREF

130. Shi LL, Xiong P, Zhang L, Cao PP, Liao B, Lu X, et al. Features of airway remodeling in different types of Chinese chronic rhinosinusitis are associated with inflammation patterns. Allergy 2013;68:101-9. PUBMED | CROSSREF

131. Derycke L, Zhang N, Holtappels G, Dutré T, Bachert C. IL-17A as a regulator of neutrophil survival in nasal polyp disease of patients with and without cystic fibrosis. J Cyst Fibros 2012;11:193-200. PUBMED | CROSSREF

132. Makihara S, Okano M, Fujiwara T, Kariya S, Noda Y, Higaki T, et al. Regulation and characterization of IL-17A expression in patients with chronic rhinosinusitis and its relationship with eosinophilic inflammation. J Allergy Clin Immunol 2010;126:397-400, 400.e1-400.e11. PUBMED | CROSSREF

133. Jiang XD, Li GY, Li L, Dong Z, Zhu DD. The characterization of IL-17A expression in patients with chronic rhinosinusitis with nasal polyps. Am J Rhinol Allergy 2011;25:e171-5. PUBMED | CROSSREF

134. Wu X, Wang S, Han M, Song B, Ye P, Ma S, et al. Critical link between glycogen synthase kinase $3 \beta$ and forkhead box P3 in patients with chronic rhinosinusitis with nasal polyps. J Allergy Clin Immunol 2015;136:1698-1700.e12. PUBMED | CROSSREF

135. Ma J, Shi LL, Deng YK, Wang H, Cao PP, Long XB, et al. CD8(+) T cells with distinct cytokine-producing features and low cytotoxic activity in eosinophilic and non-eosinophilic chronic rhinosinusitis with nasal polyps. Clin Exp Allergy 2016;46:1162-75. PUBMED | CROSSREF

136. Miljkovic D, Psaltis A, Wormald PJ, Vreugde S. T regulatory and Th17 cells in chronic rhinosinusitis with polyps. Int Forum Allergy Rhinol 2016;6:826-34. PUBMED | CROSSREF

137. Pant $\mathrm{H}$, Hughes A, Schembri M, Miljkovic D, Krumbiegel D. $\mathrm{CD} 4^{+}$and $\mathrm{CD} 8^{+}$regulatory T cells in chronic rhinosinusitis mucosa. Am J Rhinol Allergy 2014;28:83-9.

PUBMED | CROSSREF

138. Kato A. Immunopathology of chronic rhinosinusitis. Allergol Int 2015;64:121-30. PUBMED | CROSSREF

139. Min JY, Hulse KE, Tan BK. B-Cells and antibody-mediated pathogenesis in chronic rhinosinusitis with nasal polyps. Adv Otorhinolaryngol 2016;79:48-57. PUBMED | CROSSREF

140. Kato A, Hulse KE, Tan BK, Schleimer RP. B-lymphocyte lineage cells and the respiratory system. J Allergy Clin Immunol 2013;131:933-57. PUBMED | CROSSREF

141. Dilidaer, Zheng Y, Liu Z, Hu X, Zhang J, Hu L, et al. Increased BAFF expression in nasal polyps is associated with local IgE production, Th2 response and concomitant asthma. Eur Arch Otorhinolaryngol 2017;274:1883-90. PUBMED | CROSSREF

142. Ryu G, Kim DK, Dhong HJ, Eun KM, Lee KE, Kong IG, et al. Immunological characteristics in refractory chronic rhinosinusitis with nasal polyps undergoing revision surgeries. Allergy Asthma Immunol Res 2019;11:664-76. PUBMED | CROSSREF

143. Baba S, Kondo K, Toma-Hirano M, Kanaya K, Suzukawa K, Ushio M, et al. Local increase in IgE and class switch recombination to IgE in nasal polyps in chronic rhinosinusitis. Clin Exp Allergy 2014;44:701-12. PUBMED | CROSSREF

144. Patadia M, Dixon J, Conley D, Chandra R, Peters A, Suh LA, et al. Evaluation of the presence of B-cell attractant chemokines in chronic rhinosinusitis. Am J Rhinol Allergy 2010;24:11-6. PUBMED | CROSSREF

145. Shinohara ML, Lu L, Bu J, Werneck MB, Kobayashi KS, Glimcher LH, et al. Osteopontin expression is essential for interferon-alpha production by plasmacytoid dendritic cells. Nat Immunol 2006;7:498-506. PUBMED | CROSSREF

146. Liu WL, Zhang H, Zheng Y, Wang HT, Chen FH, Xu L, et al. Expression and regulation of osteopontin in chronic rhinosinusitis with nasal polyps. Clin Exp Allergy 2015;45:414-22. PUBMED | CROSSREF 
147. Scaffidi P, Misteli T, Bianchi ME. Release of chromatin protein HMGB1 by necrotic cells triggers inflammation. Nature 2002;418:191-5.

PUBMED | CROSSREF

148. Müller S, Scaffidi P, Degryse B, Bonaldi T, Ronfani L, Agresti A, et al. New EMBO members' review: the double life of HMGB1 chromatin protein: architectural factor and extracellular signal. EMBO J 2001;20:4337-40. PUBMED | CROSSREF

149. Chen D, Mao M, Bellussi LM, Passali D, Chen L. Increase of high mobility group box chromosomal protein 1 in eosinophilic chronic rhinosinusitis with nasal polyps. Int Forum Allergy Rhinol 2014;4:453-62. PUBMED | CROSSREF

150. Suzuki H, Takahashi Y, Wataya H, Ikeda K, Nakabayashi S, Shimomura A, et al. Mechanism of neutrophil recruitment induced by IL-8 in chronic sinusitis. J Allergy Clin Immunol 1996;98:659-70. PUBMED | CROSSREF

151. Fridlender ZG, Sun J, Kim S, Kapoor V, Cheng G, Ling L, et al. Polarization of tumor-associated neutrophil phenotype by TGF-beta: "N1" versus “N2" TAN. Cancer Cell 2009;16:183-94. PUBMED | CROSSREF

152. Wang X, Du J, Zhao C. Bacterial biofilms are associated with inflammatory cells infiltration and the innate immunity in chronic rhinosinusitis with or without nasal polyps. Inflammation 2014;37:871-9. PUBMED | CROSSREF

153. Psaltis AJ, Weitzel EK, Ha KR, Wormald PJ. The effect of bacterial biofilms on post-sinus surgical outcomes. Am J Rhinol 2008;22:1-6. PUBMED | CROSSREF

154. Pothoven KL, Norton JE, Suh LA, Carter RG, Harris KE, Biyasheva A, et al. Neutrophils are a major source of the epithelial barrier disrupting cytokine oncostatin $\mathrm{M}$ in patients with mucosal airways disease. J Allergy Clin Immunol 2017;139:1966-1978.e9. PUBMED | CROSSREF

155. Kim DW, Kim DK, Jo A, Jin HR, Eun KM, Mo JH, et al. Age-related decline of neutrophilic inflammation is associated with better postoperative prognosis in non-eosinophilic nasal polyps. PLoS One 2016;11:e0148442. PUBMED | CROSSREF

156. Kim DK, Kim JY, Han YE, Kim JK, Lim HS, Eun KM, et al. Elastase-positive neutrophils are associated with refractoriness of chronic rhinosinusitis with nasal polyps in an Asian population. Allergy Asthma Immunol Res 2020;12:42-55. PUBMED | CROSSREF

157. Yoon BN, Choi NG, Lee HS, Cho KS, Roh HJ. Induction of interleukin-8 from nasal epithelial cells during bacterial infection: the role of IL-8 for neutrophil recruitment in chronic rhinosinusitis. Mediators Inflamm 2010;2010:813610. PUBMED | CROSSREF

158. Watanabe K, Gilchrist CA, Uddin MJ, Burgess SL, Abhyankar MM, Moonah SN, et al. Microbiomemediated neutrophil recruitment via CXCR2 and protection from amebic colitis. PLoS Pathog 2017;13:e1006513. PUBMED | CROSSREF

159. Rudack C, Sachse F, Alberty J. Primary role of growth-related oncogene-alpha and granulocyte chemotactic protein-2 as neutrophil chemoattractants in chronic rhinosinusitis. Clin Exp Allergy 2006;36:748-59. PUBMED | CROSSREF

160. Wang H, Pan L, Liu Z. Neutrophils as a protagonist and target in chronic rhinosinusitis. Clin Exp Otorhinolaryngol 2019;12:337-47. PUBMED | CROSSREF

161. Wang H, Li ZY, Jiang WX, Liao B, Zhai GT, Wang N, et al. The activation and function of IL-36y in neutrophilic inflammation in chronic rhinosinusitis. J Allergy Clin Immunol 2018;141:1646-58. PUBMED | CROSSREF

162. Wang X, Zhao C, Ji W, Xu Y, Guo H. Relationship of TLR2, TLR4 and tissue remodeling in chronic rhinosinusitis. Int J Clin Exp Pathol 2015;8:1199-212. PUBMED

163. Meng J, Zhou P, Liu Y, Liu F, Yi X, Liu S, et al. The development of nasal polyp disease involves early nasal mucosal inflammation and remodelling. PLoS One 2013;8:e82373. PUBMED | CROSSREF 
164. Li X, Meng J, Qiao X, Liu Y, Liu F, Zhang N, et al. Expression of TGF, matrix metalloproteinases, and tissue inhibitors in Chinese chronic rhinosinusitis. J Allergy Clin Immunol 2010;125:1061-8. PUBMED | CROSSREF

165. Hellquist HB. Nasal polyps update. Histopathology. Allergy Asthma Proc 1996;17:237-42. PUBMED | CROSSREF

166. Van Crombruggen K, Zhang N, Gevaert P, Tomassen P, Bachert C. Pathogenesis of chronic rhinosinusitis: inflammation. J Allergy Clin Immunol 2011;128:728-32. PUBMED | CROSSREF

167. Watelet JB, Dogne JM, Mullier F. Remodeling and repair in rhinosinusitis. Curr Allergy Asthma Rep 2015;15:34. PUBMED | CROSSREF

168. Li XS, Qian J, Li HE, Li JR. A review of tissue remodeling in chronic rhino-sinusitis. J Otolaryngol Ophthalmol Shandong Univ 2014;28:84-6. CROSSREF

169. Li YC, An YS, Wang T, Zang HR. Analysis of transforming growth factor $\beta$ signaling in chronic rhinosinusitis. Chin Med J (Engl) 2013;126:3340-3. PUBMED

170. Bhandari A, Takeuchi K, Suzuki S, Harada T, Hayashi S, Imanaka-Yoshida K, et al. Increased expression of matrix metalloproteinase-2 in nasal polyps. Acta Otolaryngol 2004;124:1165-70. PUBMED | CROSSREF

171. Kahveci OK, Derekoy FS, Yilmaz M, Serteser M, Altuntas A. The role of MMP-9 and TIMP-1 in nasal polyp formation. Swiss Med Wkly 2008;138:684-8. PUBMED | CROSSREF

172. Ebenezer JA, Christensen JM, Oliver BG, Oliver RA, Tjin G, Ho J, et al. Periostin as a marker of mucosal remodelling in chronic rhinosinusitis. Rhinology 2017;55:234-41. PUBMED | CROSSREF

173. Takabayashi T, Kato A, Peters AT, Hulse KE, Suh LA, Carter R, et al. Increased expression of factor XIII-A in patients with chronic rhinosinusitis with nasal polyps. J Allergy Clin Immunol 2013;132:584-592.e4. PUBMED | CROSSREF

174. Takabayashi T, Kato A, Peters AT, Hulse KE, Suh LA, Carter R, et al. Excessive fibrin deposition in nasal polyps caused by fibrinolytic impairment through reduction of tissue plasminogen activator expression. Am J Respir Crit Care Med 2013;187:49-57. PUBMED | CROSSREF

175. Kim DK, Jin HR, Eun KM, Mutusamy S, Cho SH, Oh S, et al. Non-eosinophilic nasal polyps shows increased epithelial proliferation and localized disease pattern in the early stage. PLoS One 2015;10:e0139945. PUBMED | CROSSREF

176. Saitoh T, Kusunoli T, Yao T, Kawano K, Kojima Y, Miyahara K, et al. Relationship between epithelial damage or basement membrane thickness and eosinophilic infiltration in nasal polyps with chronic rhinosinusitis. Rhinology 2009;47:275-9. PUBMED | CROSSREF

177. Lee YM, Kim SS, Kim HA, Suh YJ, Lee SK, Nahm DH, et al. Eosinophil inflammation of nasal polyp tissue: relationships with matrix metalloproteinases, tissue inhibitor of metalloproteinase-1, and transforming growth factor-beta1. J Korean Med Sci 2003;18:97-102. PUBMED | CROSSREF

178. Bousquet J, Jacot W, Vignola AM, Bachert C, Van Cauwenberge P. Allergic rhinitis: a disease remodeling the upper airways? J Allergy Clin Immunol 2004;113:43-9.

PUBMED | CROSSREF

179. Van Bruaene N, C PN, Van Crombruggen K, De Ruyck N, Holtappels G, Van Cauwenberge P, et al. Inflammation and remodelling patterns in early stage chronic rhinosinusitis. Clin Exp Allergy 2012;42:883-90. PUBMED | CROSSREF

180. Niessen CM. Tight junctions/adherens junctions: basic structure and function. J Invest Dermatol 2007;127:2525-32 PUBMED | CROSSREF

181. Kalluri R, Weinberg RA. The basics of epithelial-mesenchymal transition. J Clin Invest 2009;119:1420-8. PUBMED | CROSSREF

182. Hupin C, Gohy S, Bouzin C, Lecocq M, Polette M, Pilette C. Features of mesenchymal transition in the airway epithelium from chronic rhinosinusitis. Allergy 2014;69:1540-9.

PUBMED | CROSSREF 
183. Thiery JP, Acloque H, Huang RY, Nieto MA. Epithelial-mesenchymal transitions in development and disease. Cell 2009;139:871-90.

PUBMED | CROSSREF

184. Shin HW, Cho K, Kim DW, Han DH, Khalmuratova R, Kim SW, et al. Hypoxia-inducible factor 1 mediates nasal polypogenesis by inducing epithelial-to-mesenchymal transition. Am J Respir Crit Care Med 2012;185:944-54. PUBMED | CROSSREF

185. Yang J, Weinberg RA. Epithelial-mesenchymal transition: at the crossroads of development and tumor metastasis. Dev Cell 2008;14:818-29. PUBMED | CROSSREF

186. Kennedy DW, Senior BA, Gannon FH, Montone KT, Hwang P, Lanza DC. Histology and histomorphometry of ethmoid bone in chronic rhinosinusitis. Laryngoscope 1998;108:502-7. PUBMED | CROSSREF

187. Dougall WC, Glaccum M, Charrier K, Rohrbach K, Brasel K, De Smedt T, et al. RANK is essential for osteoclast and lymph node development. Genes Dev 1999;13:2412-24. PUBMED | CROSSREF

188. Palmqvist P, Persson E, Conaway HH, Lerner UH. IL-6, leukemia inhibitory factor, and oncostatin $\mathrm{M}$ stimulate bone resorption and regulate the expression of receptor activator of NF-kappa B ligand, osteoprotegerin, and receptor activator of NF-kappa B in mouse calvariae. J Immunol 2002;169:3353-62. PUBMED | CROSSREF

189. Oue S, Ramezanpour M, Paramasivan S, Miljkovic D, Cooksley CM, Bassiouni A, et al. Increased IL-13 expression is independently associated with neo-osteogenesis in patients with chronic rhinosinusitis. J Allergy Clin Immunol 2017;140:1444-1448.e11. PUBMED | CROSSREF

190. Khalmuratova R, Shin HW, Kim DW, Park JW. Interleukin (IL)-13 and IL-17A contribute to neoosteogenesis in chronic rhinosinusitis by inducing RUNX2. EBioMedicine 2019;46:330-41. PUBMED | CROSSREF

191. Okano K, Tsukazaki T, Ohtsuru A, Namba H, Osaki M, Iwasaki K, et al. Parathyroid hormone-related peptide in synovial fluid and disease activity of rheumatoid arthritis. Br J Rheumatol 1996;35:1056-62. PUBMED | CROSSREF

192. Funk JL, Cordaro LA, Wei H, Benjamin JB, Yocum DE. Synovium as a source of increased amino-terminal parathyroid hormone-related protein expression in rheumatoid arthritis. A possible role for locally produced parathyroid hormone-related protein in the pathogenesis of rheumatoid arthritis. J Clin Invest 1998;101:1362-71. PUBMED | CROSSREF

193. Wang M, Ye T, Liang N, Huang Z, Cui S, Li Y, et al. Differing roles for TGF- $\beta /$ Smad signaling in osteitis in chronic rhinosinusitis with and without nasal polyps. Am J Rhinol Allergy 2015;29:e152-9. PUBMED | CROSSREF

194. Giacchi RJ, Lebowitz RA, Yee HT, Light JP, Jacobs JB. Histopathologic evaluation of the ethmoid bone in chronic sinusitis. Am J Rhinol 2001;15:193-7. PUBMED | CROSSREF

195. Tovi F, Benharroch D, Gatot A, Hertzanu Y. Osteoblastic osteitis of the maxillary sinus. Laryngoscope 1992;102:426-30. PUBMED | CROSSREF

196. Lee JT, Kennedy DW, Palmer JN, Feldman M, Chiu AG. The incidence of concurrent osteitis in patients with chronic rhinosinusitis: a clinicopathological study. Am J Rhinol 2006;20:278-82. PUBMED | CROSSREF

197. Cho SH, Min HJ, Han HX, Paik SS, Kim KR. CT analysis and histopathology of bone remodeling in patients with chronic rhinosinusitis. Otolaryngol Head Neck Surg 2006;135:404-8. PUBMED | CROSSREF

198. Biedlingmaier JF, Whelan P, Zoarski G, Rothman M. Histopathology and CT analysis of partially resected middle turbinates. Laryngoscope 1996;106:102-4. PUBMED | CROSSREF

199. Georgalas C, Videler W, Freling N, Fokkens W. Global Osteitis Scoring Scale and chronic rhinosinusitis: a marker of revision surgery. Clin Otolaryngol 2010;35:455-61. PUBMED | CROSSREF

200. Dong Y, Zhou B, Huang Z, Huang Q, Cui S, Li Y, et al. Evaluating bone remodeling by measuring Hounsfield units in a rabbit model of rhinosinusitis: is it superior to measuring bone thickness? Int Forum Allergy Rhinol 2018;8:1342-8.

PUBMED | CROSSREF 
201. Meltzer EO, Hamilos DL, Hadley JA, Lanza DC, Marple BF, Nicklas RA, et al. Rhinosinusitis: establishing definitions for clinical research and patient care. J Allergy Clin Immunol 2004;114:155-212. PUBMED | CROSSREF

202. Van Zele T, Gevaert P, Holtappels G, Beule A, Wormald PJ, Mayr S, et al. Oral steroids and doxycycline: two different approaches to treat nasal polyps. J Allergy Clin Immunol 2010;125:1069-1076.e4. PUBMED | CROSSREF

203. Akdis CA, Bachert C, Cingi C, Dykewicz MS, Hellings PW, Naclerio RM, et al. Endotypes and phenotypes of chronic rhinosinusitis: a PRACTALL document of the European Academy of Allergy and Clinical Immunology and the American Academy of Allergy, Asthma \& Immunology. J Allergy Clin Immunol 2013;131:1479-90. PUBMED | CROSSREF

204. Bachert C, Mannent L, Naclerio RM, Mullol J, Ferguson BJ, Gevaert P, et al. Effect of subcutaneous dupilumab on nasal polyp burden in patients with chronic sinusitis and nasal polyposis: a randomized clinical trial. JAMA 2016;315:469-79. PUBMED | CROSSREF

205. Gevaert P, Van Bruaene N, Cattaert T, Van Steen K, Van Zele T, Acke F, et al. Mepolizumab, a humanized antiIL-5 mAb, as a treatment option for severe nasal polyposis. J Allergy Clin Immunol 2011;128:989-995.e1-8. PUBMED | CROSSREF

206. Van Zele T, Holtappels G, Gevaert P, Bachert C. Differences in initial immunoprofiles between recurrent and nonrecurrent chronic rhinosinusitis with nasal polyps. Am J Rhinol Allergy 2014;28:192-8. PUBMED | CROSSREF

207. Wang XD, Zheng M, Lou HF, Wang CS, Zhang Y, Bo MY, et al. An increased prevalence of self-reported allergic rhinitis in major Chinese cities from 2005 to 2011. Allergy 2016;71:1170-80. PUBMED | CROSSREF

208. Mygind N. Nasal polyps. In: Mygind N, editor. Nasal allergy. 2nd ed. Oxford: Blackwell scientific publications; 1978. 233-8.

209. Wenzel SE, Schwartz LB, Langmack EL, Halliday JL, Trudeau JB, Gibbs RL, et al. Evidence that severe asthma can be divided pathologically into two inflammatory subtypes with distinct physiologic and clinical characteristics. Am J Respir Crit Care Med 1999;160:1001-8.

PUBMED | CROSSREF

210. Hu Y, Cao PP, Liang GT, Cui YH, Liu Z. Diagnostic significance of blood eosinophil count in eosinophilic chronic rhinosinusitis with nasal polyps in Chinese adults. Laryngoscope 2012;122:498-503. PUBMED | CROSSREF

211. Zuo K, Guo J, Chen F, Xu R, Xu G, Shi J, et al. Clinical characteristics and surrogate markers of eosinophilic chronic rhinosinusitis in Southern China. Eur Arch Otorhinolaryngol 2014;271:2461-8. PUBMED | CROSSREF

212. Payne SC, Early SB, Huyett P, Han JK, Borish L, Steinke JW. Evidence for distinct histologic profile of nasal polyps with and without eosinophilia. Laryngoscope 2011;121:2262-7. PUBMED | CROSSREF

213. Cao PP, Zhang YN, Liao B, Ma J, Wang BF, Wang H, et al. Increased local IgE production induced by common aeroallergens and phenotypic alteration of mast cells in Chinese eosinophilic, but not noneosinophilic, chronic rhinosinusitis with nasal polyps. Clin Exp Allergy 2014;44:690-700. PUBMED | CROSSREF

214. Kim SJ, Lee KH, Kim SW, Cho JS, Park YK, Shin SY. Changes in histological features of nasal polyps in a Korean population over a 17-year period. Otolaryngol Head Neck Surg 2013;149:431-7. PUBMED | CROSSREF

215. Nakayama T, Yoshikawa M, Asaka D, Okushi T, Matsuwaki Y, Otori N, et al. Mucosal eosinophilia and recurrence of nasal polyps - new classification of chronic rhinosinusitis. Rhinology 2011;49:392-6. PUBMED

216. Tikaram A, Prepageran N. Asian nasal polyps: a separate entity? Med J Malaysia 2013;68:445-7. PUBMED

217. Mahdavinia M, Suh LA, Carter RG, Stevens WW, Norton JE, Kato A, et al. Increased noneosinophilic nasal polyps in chronic rhinosinusitis in US second-generation Asians suggest genetic regulation of eosinophilia. J Allergy Clin Immunol 2015;135:576-9. PUBMED | CROSSREF

218. Katotomichelakis M, Tantilipikorn P, Holtappels G, De Ruyck N, Feng L, Van Zele T, et al. Inflammatory patterns in upper airway disease in the same geographical area may change over time. Am J Rhinol Allergy 2013;27:354-60.

PUBMED | CROSSREF 
219. Shin SH, Ye MK, Kim JK, Cho CH. Histological characteristics of chronic rhinosinusitis with nasal polyps: recent 10-year experience of a single center in Daegu, Korea. Am J Rhinol Allergy 2014;28:95-8. PUBMED | CROSSREF

220. Wang W, Gao Y, Zhu Z, Zha Y, Wang X, Qi F, et al. Changes in the clinical and histological characteristics of Chinese chronic rhinosinusitis with nasal polyps over 11 years. Int Forum Allergy Rhinol 2019;9:149-57 PUBMED

221. Jiang WX, Cao PP, Li ZY, Zhai GT, Liao B, Lu X, et al. A retrospective study of changes of histopathology of nasal polyps in adult Chinese in central China. Rhinology 2019;57:261-7. PUBMED | CROSSREF

222. Zhang N, Holtappels G, Claeys C, Huang G, van Cauwenberge P, Bachert C. Pattern of inflammation and impact of Staphylococcus aureus enterotoxins in nasal polyps from southern China. Am J Rhinol 2006;20:445-50.

PUBMED | CROSSREF

223. Moore WC, Meyers DA, Wenzel SE, Teague WG, Li H, Li X, et al. Identification of asthma phenotypes using cluster analysis in the Severe Asthma Research Program. Am J Respir Crit Care Med 2010;181:315-23. PUBMED | CROSSREF

224. Weatherall M, Shirtcliffe P, Travers J, Beasley R. Use of cluster analysis to define COPD phenotypes. Eur Respir J 2010;36:472-4. PUBMED | CROSSREF

225. Zinchuk AV, Jeon S, Koo BB, Yan X, Bravata DM, Qin L, et al. Polysomnographic phenotypes and their cardiovascular implications in obstructive sleep apnoea. Thorax 2018;73:472-80. PUBMED | CROSSREF

226. Nakayama T, Asaka D, Yoshikawa M, Okushi T, Matsuwaki Y, Moriyama H, et al. Identification of chronic rhinosinusitis phenotypes using cluster analysis. Am J Rhinol Allergy 2012;26:172-6. PUBMED | CROSSREF

227. Lou H, Meng Y, Piao Y, Zhang N, Bachert C, Wang C, et al. Cellular phenotyping of chronic rhinosinusitis with nasal polyps. Rhinology 2016;54:150-9. PUBMED | CROSSREF

228. Wang X, Zhang N, Bo M, Holtappels G, Zheng M, Lou H, et al. Diversity of $\mathrm{T}_{\mathrm{H}}$ cytokine profiles in patients with chronic rhinosinusitis: a multicenter study in Europe, Asia, and Oceania. J Allergy Clin Immunol 2016;138:1344-53. PUBMED | CROSSREF

229. Liao B, Liu JX, Li ZY, Zhen Z, Cao PP, Yao Y, et al. Multidimensional endotypes of chronic rhinosinusitis and their association with treatment outcomes. Allergy 2018;73:1459-69. PUBMED | CROSSREF

230. Turner JH, Chandra RK, Li P, Bonnet K, Schlundt DG. Identification of clinically relevant chronic rhinosinusitis endotypes using cluster analysis of mucus cytokines. J Allergy Clin Immunol 2018;141:1895-1897.e7. PUBMED | CROSSREF

231. Kim DK, Kang SI, Kong IG, Cho YH, Song SK, Hyun SJ, et al. Two-track medical treatment strategy according to the clinical scoring system for chronic rhinosinusitis. Allergy Asthma Immunol Res 2018;10:490-502. PUBMED | CROSSREF

232. Wenzel S, Ford L, Pearlman D, Spector S, Sher L, Skobieranda F, et al. Dupilumab in persistent asthma with elevated eosinophil levels. N Engl J Med 2013;368:2455-66. PUBMED | CROSSREF

233. Krug N, Hohlfeld JM, Kirsten AM, Kornmann O, Beeh KM, Kappeler D, et al. Allergen-induced asthmatic responses modified by a GATA3-specific DNAzyme. N Engl J Med 2015;372:1987-95. PUBMED | CROSSREF

234. Nair P, Gaga M, Zervas E, Alagha K, Hargreave FE, O'Byrne PM, et al. Safety and efficacy of a CXCR2 antagonist in patients with severe asthma and sputum neutrophils: a randomized, placebo-controlled clinical trial. Clin Exp Allergy 2012;42:1097-103. PUBMED | CROSSREF

235. O'Byrne PM, Metev H, Puu M, Richter K, Keen C, Uddin M, et al. Efficacy and safety of a CXCR2 antagonist, AZD5069, in patients with uncontrolled persistent asthma: a randomised, double-blind, placebo-controlled trial. Lancet Respir Med 2016;4:797-806. PUBMED | CROSSREF

236. Busse WW, Holgate S, Kerwin E, Chon Y, Feng J, Lin J, et al. Randomized, double-blind, placebocontrolled study of brodalumab, a human anti-IL-17 receptor monoclonal antibody, in moderate to severe asthma. Am J Respir Crit Care Med 2013;188:1294-302.

PUBMED | CROSSREF 
237. Collins FS, Varmus H. A new initiative on precision medicine. N Engl J Med 2015;372:793-5. PUBMED | CROSSREF

238. Bachert C, Zhang L, Gevaert P. Current and future treatment options for adult chronic rhinosinusitis: focus on nasal polyposis. J Allergy Clin Immunol 2015;136:1431-40. PUBMED | CROSSREF

239. De Greve G, Hellings PW, Fokkens WJ, Pugin B, Steelant B, Seys SF. Endotype-driven treatment in chronic upper airway diseases. Clin Transl Allergy 2017;7:22. PUBMED | CROSSREF

240. Lim M, Lew-Gor S, Darby Y, Brookes N, Scadding G, Lund VJ. The relationship between subjective assessment instruments in chronic rhinosinusitis. Rhinology 2007;45:144-7. PUBMED

241. Ryan WR, Ramachandra T, Hwang PH. Correlations between symptoms, nasal endoscopy, and in-office computed tomography in post-surgical chronic rhinosinusitis patients. Laryngoscope 2011;121:674-8. PUBMED | CROSSREF

242. Zhang L, Tao JH, Han DM, Ge WT, Zhou B, Wang XZ, et al. Spiral computed tomography analysis of frontoethmoidal cells in normal subjects. Zhonghua Er Bi Yan Hou Tou Jing Wai Ke Za Zhi 2007;42:898-903. PUBMED

243. Zinreich SJ. Imaging of chronic sinusitis in adults: X-ray, computed tomography, and magnetic resonance imaging. J Allergy Clin Immunol 1992;90:445-51. PUBMED | CROSSREF

244. Mossa-Basha M, Ilica AT, Maluf F, Karakoç Ö, Izbudak I, Aygün N. The many faces of fungal disease of the paranasal sinuses: CT and MRI findings. Diagn Interv Radiol 2013;19:195-200. PUBMED

245. Lund VJ, Kennedy DW. Staging for rhinosinusitis. Otolaryngol Head Neck Surg 1997;117:S35-40. PUBMED | CROSSREF

246. Ishitoya J, Sakuma Y, Tsukuda M. Eosinophilic chronic rhinosinusitis in Japan. Allergol Int 2010;59:239-45. PUBMED | CROSSREF

247. Meng Y, Lou H, Wang C, Zhang L. Predictive significance of computed tomography in eosinophilic chronic rhinosinusitis with nasal polyps. Int Forum Allergy Rhinol 2016;6:812-9. PUBMED | CROSSREF

248. Marple BF. Allergic fungal rhinosinusitis: current theories and management strategies. Laryngoscope 2001;111:1006-19. PUBMED | CROSSREF

249. She W, Yang J, Wang C, Zhang L. Diagnostic value of nasal cytology in chronic rhinosinusitis assessed by a liquid-based cytological technique. Am J Rhinol Allergy 2018;32:181-7. PUBMED | CROSSREF

250. Jankowski R, Persoons M, Foliguet B, Coffinet L, Thomas C, Verient-Montaut B. Eosinophil count in nasal secretions of subjects with and without nasal symptoms. Rhinology 2000;38:23-32. PUBMED

251. Gelardi M, Cassano P, Fiorella ML, Luperto P, Fiorella R. The cytological research in nasal polyposis. Int Congr Ser 2003;1240:1087-9.

252. Gelardi M, Fiorella ML, Leo G, Incorvaia C. Cytology in the diagnosis of rhinosinusitis. Pediatr Allergy Immunol 2007;18 Suppl 18:50-2. PUBMED | CROSSREF

253. Pant H, Kette FE, Smith WB, Macardle PJ, Wormald PJ. Eosinophilic mucus chronic rhinosinusitis: clinical subgroups or a homogeneous pathogenic entity? Laryngoscope 2006;116:1241-7. PUBMED | CROSSREF

254. Bent JP 3rd, Kuhn FA. Diagnosis of allergic fungal sinusitis. Otolaryngol Head Neck Surg 1994;111:580-8. PUBMED | CROSSREF

255. Wise SK, Ghegan MD, Gorham E, Schlosser RJ. Socioeconomic factors in the diagnosis of allergic fungal rhinosinusitis. Otolaryngol Head Neck Surg 2008;138:38-42. PUBMED | CROSSREF

256. Xu R, Ma L, Xu G. Diagnosis and treatment of allergic fungal rhinosinusitis. Zhonghua Er Bi Yan Hou Tou Jing Wai Ke Za Zhi 2016;51:635-40. PUBMED

257. Hoyt AE, Borish L, Gurrola J, Payne S. Allergic fungal rhinosinusitis. J Allergy Clin Immunol Pract 2016;4:599-604. PUBMED | CROSSREF 
258. Thompson GR 3rd, Patterson TF. Fungal disease of the nose and paranasal sinuses. J Allergy Clin Immunol 2012;129:321-6. PUBMED | CROSSREF

259. Uri N, Ronen O, Marshak T, Parpara O, Nashashibi M, Gruber M. Allergic fungal sinusitis and eosinophilic mucin rhinosinusitis: diagnostic criteria. J Laryngol Otol 2013;127:867-71. PUBMED | CROSSREF

260. Zhou B, Liu M, Han DM, Wang ZC, Zhang L, Xian JF, et al. Characteristics of computed tomography of allergic fungal sinusitis. Zhonghua Er Bi Yan Hou Tou Jing Wai Ke Za Zhi 2006;41:493-6. PUBMED

261. Hu CH, Wei HZ, He S, Liu X, Li YC. Imaging charateristics of bony erosion and fungal culture analysis in allergic fungal rhinosinusitis. Lin Chung Er Bi Yan Hou Tou Jing Wai Ke Za Zhi 2017;31:1824-7, 1832. PUBMED | CROSSREF

262. Chaaban MR, Walsh EM, Woodworth BA. Epidemiology and differential diagnosis of nasal polyps. Am J Rhinol Allergy 2013;27:473-8. PUBMED | CROSSREF

263. Braun H, Buzina W, Freudenschuss K, Beham A, Stammberger H. 'Eosinophilic fungal rhinosinusitis': a common disorder in Europe? Laryngoscope 2003;113:264-9. PUBMED | CROSSREF

264. Pant H, Kette FE, Smith WB, Wormald PJ, Macardle PJ. Fungal-specific humoral response in eosinophilic mucus chronic rhinosinusitis. Laryngoscope 2005;115:601-6. PUBMED | CROSSREF

265. Guo C, Ghadersohi S, Kephart GM, Laine RA, Sherris DA, Kita H, et al. Improving the detection of fungi in eosinophilic mucin: seeing what we could not see before. Otolaryngol Head Neck Surg 2012;147:943-9. PUBMED | CROSSREF

266. Samter M, Beers RF Jr. Intolerance to aspirin. Clinical studies and consideration of its pathogenesis. Ann Intern Med 1968;68:975-83. PUBMED | CROSSREF

267. Rajan JP, Wineinger NE, Stevenson DD, White AA. Prevalence of aspirin-exacerbated respiratory disease among asthmatic patients: a meta-analysis of the literature. J Allergy Clin Immunol 2015;135:676-681.e1. PUBMED | CROSSREF

268. Fan Y, Feng S, Xia W, Qu L, Li X, Chen S, et al. Aspirin-exacerbated respiratory disease in China: a cohort investigation and literature review. Am J Rhinol Allergy 2012;26:e20-2. PUBMED | CROSSREF

269. Jenkins C, Costello J, Hodge L. Systematic review of prevalence of aspirin induced asthma and its implications for clinical practice. BMJ 2004;328:434. PUBMED | CROSSREF

270. White AA. An update on the epidemiology of aspirin-exacerbated respiratory disease. Am J Rhinol Allergy 2017;31:299-301. PUBMED | CROSSREF

271. Stevens WW, Schleimer RP. Aspirin-exacerbated respiratory disease as an endotype of chronic rhinosinusitis. Immunol Allergy Clin North Am 2016;36:669-80. PUBMED | CROSSREF

272. Moteki H, Yasuo M, Hamano H, Uehara T, Usami S. IgG4-related chronic rhinosinusitis: a new clinical entity of nasal disease. Acta Otolaryngol 2011;131:518-26. PUBMED | CROSSREF

273. Fujita A, Sakai O, Chapman MN, Sugimoto H. IgG4-related disease of the head and neck: CT and MR imaging manifestations. Radiographics 2012;32:1945-58. PUBMED | CROSSREF

274. Horger M, Lamprecht HG, Bares R, Spira D, Schmalzing M, Claussen CD, et al. Systemic IgG4-related sclerosing disease: spectrum of imaging findings and differential diagnosis. AJR Am J Roentgenol 2012;199:W276-82. PUBMED | CROSSREF

275. Deshpande V, Zen Y, Chan JK, Yi EE, Sato Y, Yoshino T, et al. Consensus statement on the pathology of IgG4-related disease. Mod Pathol 2012;25:1181-92. PUBMED | CROSSREF

276. Piao Y, Wang C, Yu W, Mao M, Yue C, Liu H, et al. Concomitant occurrence of Mikulicz's disease and immunoglobulin G4-related chronic rhinosinusitis: a clinicopathological study of 12 cases. Histopathology 2016;68:502-12. PUBMED | CROSSREF 
277. Piao Y, Zhang Y, Yue C, Wang C, Zhang L. Immunoglobulin G4-related chronic rhinosinusitis: a pitfall in the differential diagnosis of granulomatosis with polyangiitis, Rosai-Dorfman disease, and fungal rhinosinusitis. Hum Pathol 2018;73:82-8. PUBMED | CROSSREF

278. Sun Q, An L, Zheng J, Zhu D. Advances in recurrence and malignant transformation of sinonasal inverted papillomas. Oncol Lett 2017;13:4585-92. PUBMED | CROSSREF

279. Cui N, An LF, Zhu DD. Surgical management of huge nasopharyngeal pleomorphic adenoma two cases. Zhonghua Er Bi Yan Hou Tou Jing Wai Ke Za Zhi 2010;45:603-4. PUBMED

280. Xindong F, Minjun D, Runjie S, Peihua W, Dehui W. Adjunctive embolization for juvenile nasopharyngeal angiofibroma. Zhonghua Fang She Xue Za Zhi 2006;40:1197-9.

281. Sunaryo PL, Svider PF, Husain Q, Choudhry OJ, Eloy JA, Liu JK. Schwannomas of the sinonasal tract and anterior skull base: a systematic review of 94 cases. Am J Rhinol Allergy 2014;28:39-9. PUBMED | CROSSREF

282. Li H, Peng X, Li J, Yang K. A rare solitary neurofibroma of the frontal sinus. J Craniofac Surg 2014;25:1542-4. PUBMED | CROSSREF

283. Zhang YI, Teng WQ, Chen XP, Wu J. Ectopic meningioma in the bilateral nasal olfactory cleft: a case report and literature review. Oncol Lett 2015;9:1743-6. PUBMED | CROSSREF

284. She CP, Ma FM, Tong YF. Ala nasal leiomyoma misdiagnosed as nasal vestibular cyst: a case report. Zhonghua Er Bi Yan Hou Tou Jing Wai Ke Za Zhi 2012;47:154. PUBMED

285. Zhao J, Zhang H, Zhang J, Pi Y, Xu M. Angioleiomyoma with mature adipocytes of nasal vestibule: report of a case. Zhonghua Bing Li Xue Za Zhi 2015;44:288-9. PUBMED

286. Chen NX, Zhang XX, Chen L, Wang JL, Yan F, Ma L. Clinical analysis of multimodal treatment for orbital organ preservation in T4b squamous cell carcinoma of nasal cavity and paranasal sinuses. Zhonghua Er Bi Yan Hou Tou Jing Wai Ke Za Zhi 2016;51:497-503. PUBMED | CROSSREF

287. Fokkens WJ, Lund VJ, Mullol J, Bachert C, Alobid I, Baroody F, et al. EPOS 2012: European position paper on rhinosinusitis and nasal polyps 2012. A summary for otorhinolaryngologists. Rhinology 2012;50:1-12. PUBMED | CROSSREF

288. Hissaria P, Smith W, Wormald PJ, Taylor J, Vadas M, Gillis D, et al. Short course of systemic corticosteroids in sinonasal polyposis: a double-blind, randomized, placebo-controlled trial with evaluation of outcome measures. J Allergy Clin Immunol 2006;118:128-33. PUBMED | CROSSREF

289. Vaidyanathan S, Barnes M, Williamson P, Hopkinson P, Donnan PT, Lipworth B. Treatment of chronic rhinosinusitis with nasal polyposis with oral steroids followed by topical steroids: a randomized trial. Ann Intern Med 2011;154:293-302. PUBMED | CROSSREF

290. Orlandi RR, Kingdom TT, Hwang PH, Smith TL, Alt JA, Baroody FM, et al. International consensus statement on allergy and rhinology: rhinosinusitis. Int Forum Allergy Rhinol 2016;6 Suppl 1:S22-209. PUBMED | CROSSREF

291. Bachert C, Pawankar R, Zhang L, Bunnag C, Fokkens WJ, Hamilos DL, et al. ICON: chronic rhinosinusitis. World Allergy Organ J 2014;7:25. PUBMED | CROSSREF

292. Bensch GW. Safety of intranasal corticosteroids. Ann Allergy Asthma Immunol 2016;117:601-5. PUBMED | CROSSREF

293. Skoner DP, Gentile D, Angelini B, Kane R, Birdsall D, Banerji D. The effects of intranasal triamcinolone acetonide and intranasal fluticasone propionate on short-term bone growth and HPA axis in children with allergic rhinitis. Ann Allergy Asthma Immunol 2003;90:56-62. PUBMED | CROSSREF

294. Wang C, Lou H, Wang X, Wang Y, Fan E, Li Y, et al. Effect of budesonide transnasal nebulization in patients with eosinophilic chronic rhinosinusitis with nasal polyps. J Allergy Clin Immunol 2015;135:922-929.e6. PUBMED | CROSSREF 
295. Steinke JW, Payne SC, Tessier ME, Borish LO, Han JK, Borish LC. Pilot study of budesonide inhalant suspension irrigations for chronic eosinophilic sinusitis. J Allergy Clin Immunol 2009;124:1352-1354.e7. PUBMED | CROSSREF

296. Wen W, Liu W, Zhang L, Bai J, Fan Y, Xia W, et al. Increased neutrophilia in nasal polyps reduces the response to oral corticosteroid therapy. J Allergy Clin Immunol 2012;129:1522-1528.e5. PUBMED | CROSSREF

297. Milara J, Peiró T, Armengot M, Frias S, Morell A, Serrano A, et al. Mucin 1 downregulation associates with corticosteroid resistance in chronic rhinosinusitis with nasal polyps. J Allergy Clin Immunol 2015;135:470-6. PUBMED | CROSSREF

298. Milara J, Morell A, Ballester B, Armengot M, Morcillo E, Cortijo J. MUC4 impairs the anti-inflammatory effects of corticosteroids in patients with chronic rhinosinusitis with nasal polyps. J Allergy Clin Immunol 2017;139:855-862.e13. PUBMED | CROSSREF

299. Aminov R. History of antimicrobial drug discovery: major classes and health impact. Biochem Pharmacol 2017;133:4-19. PUBMED | CROSSREF

300. Bearden DT, Rodvold KA. Penetration of macrolides into pulmonary sites of infection. Infect Med 1999;16:480-484A.

301. Suzaki H, Sugita K, Kudoh S, Oritsu S, Kurashima A, Nagai H. The effects of low-dose longterm erythromycin administration treatment on chronic rhinosinusitis complicated by diffuse panbronchiolitis. Ther Res 1990;11:29-31.

302. Cervin A, Wallwork B. Macrolide therapy of chronic rhinosinusitis. Rhinology 2007;45:259-67. PUBMED

303. Nonaka M, Pawankar R, Saji F, Yagi T. Effect of roxithromycin on IL-8 synthesis and proliferation of nasal polyp fibroblasts. Acta Otolaryngol Suppl 1998;539:71-5. PUBMED

304. Akamatsu H, Yamawaki M, Horio T. Effects of roxithromycin on adhesion molecules expressed on endothelial cells of the dermal microvasculature. J Int Med Res 2001;29:523-7. PUBMED | CROSSREF

305. Matsuoka N, Eguchi K, Kawakami A, Tsuboi M, Kawabe Y, Aoyagi T, et al. Inhibitory effect of clarithromycin on costimulatory molecule expression and cytokine production by synovial fibroblast-like cells. Clin Exp Immunol 1996;104:501-8. PUBMED | CROSSREF

306. Shimizu T, Suzaki H. Past, present and future of macrolide therapy for chronic rhinosinusitis in Japan. Auris Nasus Larynx 2016;43:131-6. PUBMED | CROSSREF

307. Fokkens W, Lund V, Mullol J; European Position Paper on Rhinosinusitis and Nasal Polyps group. European position paper on rhinosinusitis and nasal polyps 2007. Rhinol Suppl 2007;20:1-136. PUBMED

308. Wallwork B, Coman W, Mackay-Sim A, Greiff L, Cervin A. A double-blind, randomized, placebocontrolled trial of macrolide in the treatment of chronic rhinosinusitis. Laryngoscope 2006;116:189-93. PUBMED | CROSSREF

309. Videler WJ, Badia L, Harvey RJ, Gane S, Georgalas C, van der Meulen FW, et al. Lack of efficacy of long-term, low-dose azithromycin in chronic rhinosinusitis: a randomized controlled trial. Allergy 2011;66:1457-68.

PUBMED | CROSSREF

310. Zeng M, Long XB, Cui YH, Liu Z. Comparison of efficacy of mometasone furoate versus clarithromycin in the treatment of chronic rhinosinusitis without nasal polyps in Chinese adults. Am J Rhinol Allergy 2011;25:e203-7. PUBMED | CROSSREF

311. Luo Q, Chen F, Liu W, Li Z, Xu R, Fan Y, et al. Evaluation of long-term clarithromycin treatment in adult Chinese patients with chronic rhinosinusitis without nasal polyps. ORL J Otorhinolaryngol Relat Spec 2011;73:206-11. PUBMED | CROSSREF

312. Perić A, Baletić N, Milojević M, Sotirović J, Živić L, Perić AV, et al. Effects of preoperative clarithromycin administration in patients with nasal polyposis. West Indian Med J 2014;63:721-7. PUBMED 
313. Haruna S, Shimada C, Ozawa M, Fukami S, Moriyama H. A study of poor responders for long-term, lowdose macrolide administration for chronic sinusitis. Rhinology 2009;47:66-71. PUBMED

314. Varvyanskaya A, Lopatin A. Efficacy of long-term low-dose macrolide therapy in preventing early recurrence of nasal polyps after endoscopic sinus surgery. Int Forum Allergy Rhinol 2014;4:533-41. PUBMED | CROSSREF

315. Yamada T, Fujieda S, Mori S, Yamamoto H, Saito H. Macrolide treatment decreased the size of nasal polyps and IL-8 levels in nasal lavage. Am J Rhinol 2000;14:143-8. PUBMED | CROSSREF

316. Geng X. Low-dosed, long-termed macrolides for treating chronic rhinosinusitis. Zhonghua Er Bi Yan Hou Tou Jing Wai Ke Za Zhi 2013;2:48.

317. Shen S, Lou H, Wang C, Zhang L. Macrolide antibiotics in the treatment of chronic rhinosinusitis: evidence from a meta-analysis. J Thorac Dis 2018;10:5913-23. PUBMED | CROSSREF

318. Namyslowski G, Misiolek M, Czecior E, Malafiej E, Orecka B, Namyslowski P, et al. Comparison of the efficacy and tolerability of amoxycillin/clavulanic acid $875 \mathrm{mg}$ b.i.d. with cefuroxime $500 \mathrm{mg}$ b.i.d. in the treatment of chronic and acute exacerbation of chronic sinusitis in adults. J Chemother 2002;14:508-17. PUBMED | CROSSREF

319. Legent F, Bordure P, Beauvillain C, Berche P. A double-blind comparison of ciprofloxacin and amoxycillin/ clavulanic acid in the treatment of chronic sinusitis. Chemotherapy 1994;40 Suppl 1:8-15. PUBMED | CROSSREF

320. Head K, Chong LY, Piromchai P, Hopkins C, Philpott C, Schilder AG, et al. Systemic and topical antibiotics for chronic rhinosinusitis. Cochrane Database Syst Rev 2016;4:CD011994. PUBMED | CROSSREF

321. Sacks PL, Harvey RJ, Rimmer J, Gallagher RM, Sacks R. Topical and systemic antifungal therapy for the symptomatic treatment of chronic rhinosinusitis. Cochrane Database Syst Rev 2011:CD008263. PUBMED | CROSSREF

322. Pérez-Novo CA, Claeys C, Van Zele T, Holtapples G, Van Cauwenberge P, Bachert C. Eicosanoid metabolism and eosinophilic inflammation in nasal polyp patients with immune response to Staphylococcus aureus enterotoxins. Am J Rhinol 2006;20:456-60. PUBMED | CROSSREF

323. Wu X, Hong H, Zuo K, Han M, Li J, Wen W, et al. Expression of leukotriene and its receptors in eosinophilic chronic rhinosinusitis with nasal polyps. Int Forum Allergy Rhinol 2016;6:75-81. PUBMED | CROSSREF

324. Chen K, Yu Z, Yang J, Li H. Expression of cysteinyl leukotriene receptor GPR17 in eosinophilic and noneosinophilic chronic rhinosinusitis with nasal polyps. Asian Pac J Allergy Immunol 2018;36:93-100. PUBMED

325. Schäper C, Noga O, Koch B, Ewert R, Felix SB, Gläser S, et al. Anti-inflammatory properties of montelukast, a leukotriene receptor antagonist in patients with asthma and nasal polyposis. J Investig Allergol Clin Immunol 2011;21:51-8. PUBMED

326. Pauli C, Fintelmann R, Klemens C, Hilgert E, Jund F, Rasp G, et al. Polyposis nasi--improvement in quality of life by the influence of leukotrien receptor antagonists. Laryngorhinootologie 2007;86:282-6. PUBMED | CROSSREF

327. Du J, Ba L, Zhou J, Yu L, Liu R, Zhang J, et al. The role of cysteinyl leukotrienes and their receptors in refractory nasal polyps. Prostaglandins Leukot Essent Fatty Acids 2017;126:39-48. PUBMED | CROSSREF

328. Stewart RA, Ram B, Hamilton G, Weiner J, Kane KJ. Montelukast as an adjunct to oral and inhaled steroid therapy in chronic nasal polyposis. Otolaryngol Head Neck Surg 2008;139:682-7. PUBMED | CROSSREF

329. Kieff DA, Busaba NY. Efficacy of montelukast in the treatment of nasal polyposis. Ann Otol Rhinol Laryngol 2005;114:941-5.

PUBMED | CROSSREF

330. Nonaka M, Sakanushi A, Kusama K, Ogihara N, Yagi T. One-year evaluation of combined treatment with an intranasal corticosteroid and montelukast for chronic rhinosinusitis associated with asthma. J Nippon Med Sch 2010;77:21-8. PUBMED | CROSSREF

331. Yazıcı ZM, Sayın I, Bozkurt E, Kayhan FT. Effect of montelukast on quality of life in subjects with nasal polyposis accompanying bronchial asthma. Kulak Burun Bogaz Ihtis Derg 2011;21:210-4. PUBMED | CROSSREF 
332. Wentzel JL, Soler ZM, DeYoung K, Nguyen SA, Lohia S, Schlosser RJ. Leukotriene antagonists in nasal polyposis: a meta-analysis and systematic review. Am J Rhinol Allergy 2013;27:482-9. PUBMED | CROSSREF

333. Vuralkan E, Saka C, Akin I, Hucumenoglu S, Unal BU, Kuran G, et al. Comparison of montelukast and mometasone furoate in the prevention of recurrent nasal polyps. Ther Adv Respir Dis 2012;6:5-10. PUBMED | CROSSREF

334. Van Gerven L, Langdon C, Cordero A, Cardelús S, Mullol J, Alobid I. Lack of long-term add-on effect by montelukast in postoperative chronic rhinosinusitis patients with nasal polyps. Laryngoscope 2018;128:1743-51. PUBMED | CROSSREF

335. Simons FE, Simons KJ. Histamine and H1-antihistamines: celebrating a century of progress. J Allergy Clin Immunol 2011;128:1139-1150.e4. PUBMED | CROSSREF

336. Mullol J, de Borja Callejas F, Martínez-Antón MA, Méndez-Arancibia E, Alobid I, Pujols L, et al. Mometasone and desloratadine additive effect on eosinophil survival and cytokine secretion from epithelial cells. Respir Res 2011;12:23. PUBMED | CROSSREF

337. März RW, Ismail C, Popp MA. Profile and effectiveness of a phytogenic combination preparation for treatment of sinusitis. Wien Med Wochenschr 1999;149:202-8. PUBMED

338. Passali D, Cambi J, Passali FM, Bellussi LM. Phytoneering: a new way of therapy for rhinosinusitis. Acta Otorhinolaryngol Ital 2015;35:1-8. PUBMED

339. Glatthaar-Saalmüller B, Rauchhaus U, Rode S, Haunschild J, Saalmüller A. Antiviral activity in vitro of two preparations of the herbal medicinal product Sinupret ${ }^{\circledR}$ against viruses causing respiratory infections. Phytomedicine 2011;19:1-7. PUBMED | CROSSREF

340. Palm J, Steiner I, Abramov-Sommariva D, Ammendola A, Mitzenheim S, Steindl H, et al. Assessment of efficacy and safety of the herbal medicinal product BNO 1016 in chronic rhinosinusitis. Rhinology 2017;55:142-51. PUBMED | CROSSREF

341. Guo R, Canter PH, Ernst E. Herbal medicines for the treatment of rhinosinusitis: a systematic review. Otolaryngol Head Neck Surg 2006;135:496-506. PUBMED | CROSSREF

342. Huang ZX, Li YX, Wu YB, Liu HC, Zhou B. Preoperative and postoperative medical therapies for chronic rhinosinusitis: national surveys among Chinese otolaryngologists. World J Otorhinolaryngol Head Neck Surg 2018;4:258-62. PUBMED | CROSSREF

343. Pritchard S, Glover M, Guthrie G, Brum J, Ramsey D, Kappler G, et al. Effectiveness of 0.05\% oxymetazoline (Vicks Sinex Micromist ${ }^{\circledR}$ ) nasal spray in the treatment of objective nasal congestion demonstrated to $12 \mathrm{~h}$ post-administration by magnetic resonance imaging. Pulm Pharmacol Ther 2014;27:121-6. PUBMED | CROSSREF

344. Scadding GK, Durham SR, Mirakian R, Jones NS, Drake-Lee AB, Ryan D, et al. BSACI guidelines for the management of rhinosinusitis and nasal polyposis. Clin Exp Allergy 2008;38:260-75. PUBMED | CROSSREF

345. Kirtsreesakul V, Khanuengkitkong T, Ruttanaphol S. Does oxymetazoline increase the efficacy of nasal steroids in treating nasal polyposis? Am J Rhinol Allergy 2016;30:195-200. PUBMED | CROSSREF

346. Jurkiewicz D, Zielnik-Jurkiewicz B. Bacterial lysates in the prevention of respiratory tract infections. Otolaryngol Pol 2018;72:1-8. PUBMED | CROSSREF

347. Triantafillou V, Workman AD, Patel NN, Maina IW, Tong CC, Kuan EC, et al. Broncho-Vaxom ${ }^{\circledR}(\mathrm{OM}-85$ BV) soluble components stimulate sinonasal innate immunity. Int Forum Allergy Rhinol 2019;9:370-7. PUBMED | CROSSREF

348. Zhang Y, Xu Y, Xu Y, Tao Z. Extramedullary plasmacytoma associated with an ectopic tooth in the nasal cavity. Ear Nose Throat J 2015;94:E43-6. PUBMED

349. Heintz B, Schlenter WW, Kirsten R, Nelson K. Clinical efficacy of Broncho-Vaxom in adult patients with chronic purulent sinusitis--a multi-centric, placebo-controlled, double-blind study. Int J Clin Pharmacol Ther Toxicol 1989;27:530-4. PUBMED 
350. Chen J, Zhou Y, Nie J, Wang Y, Zhang L, Shi Q, et al. Bacterial lysate for the prevention of chronic rhinosinusitis recurrence in children. J Laryngol Otol 2017;131:523-8. PUBMED | CROSSREF

351. Barham HP, Harvey RJ. Nasal saline irrigation: therapeutic or homeopathic. Rev Bras Otorrinolaringol (Engl Ed) 2015;81:457-8. PUBMED

352. Friedman M, Hamilton C, Samuelson CG, Maley A, Wilson MN, Venkatesan TK, et al. Dead Sea salt irrigations vs saline irrigations with nasal steroids for symptomatic treatment of chronic rhinosinusitis: a randomized, prospective double-blind study. Int Forum Allergy Rhinol 2012;2:252-7. PUBMED | CROSSREF

353. Adappa ND, Wei CC, Palmer JN. Nasal irrigation with or without drugs: the evidence. Curr Opin Otolaryngol Head Neck Surg 2012;20:53-7.

PUBMED | CROSSREF

354. Lin L, Tang X, Wei J, Dai F, Sun G. Xylitol nasal irrigation in the treatment of chronic rhinosinusitis. Am J Otolaryngol 2017;38:383-9. PUBMED | CROSSREF

355. Smith KA, French G, Mechor B, Rudmik L. Safety of long-term high-volume sinonasal budesonide irrigations for chronic rhinosinusitis. Int Forum Allergy Rhinol 2016;6:228-32. PUBMED | CROSSREF

356. Harvey R, Hannan SA, Badia L, Scadding G. Nasal saline irrigations for the symptoms of chronic rhinosinusitis. Cochrane Database Syst Rev 2007:CD006394. PUBMED

357. Chong LY, Head K, Hopkins C, Philpott C, Glew S, Scadding G, et al. Saline irrigation for chronic rhinosinusitis. Cochrane Database Syst Rev 2016:CD011995. PUBMED

358. Gonzalez CD, Petersen MG, Miller M, Park AH, Wilson KF. Complex nontuberculous mycobacterial cervicofacial lymphadenitis: What is the optimal approach? Laryngoscope 2016;126:1677-80. PUBMED | CROSSREF

359. Thamboo A, Manji J, Szeitz A, Santos RD, Hathorn I, Gan EC, et al. The safety and efficacy of short-term budesonide delivered via mucosal atomization device for chronic rhinosinusitis without nasal polyposis. Int Forum Allergy Rhinol 2014;4:397-402. PUBMED | CROSSREF

360. Kim ST, Sung UH, Jung JH, Paik JY, Woo JH, Cha HE, et al. The effect of maxillary sinus irrigation on early prognostic factors after endoscopic sinus surgery: a preliminary study. Am J Rhinol Allergy 2013;27:e158-61. PUBMED | CROSSREF

361. Kang TW, Chung JH, Cho SH, Lee SH, Kim KR, Jeong JH. The effectiveness of budesonide nasal irrigation after endoscopic sinus surgery in chronic rhinosinusitis with asthma. Clin Exp Otorhinolaryngol 2017;10:91-6. PUBMED | CROSSREF

362. Kosugi EM, Moussalem GF, Simões JC, Souza RP, Chen VG, Saraceni Neto P, et al. Topical therapy with high-volume budesonide nasal irrigations in difficult-to-treat chronic rhinosinusitis. Rev Bras Otorrinolaringol (Engl Ed) 2016;82:191-7. PUBMED

363. Lund VJ. Maximal medical therapy for chronic rhinosinusitis [x.]. Otolaryngol Clin North Am 2005;38:1301-10 PUBMED | CROSSREF

364. Naumann H, editor. Pathologische anatomie der chronischen rhinitis und sinusitis. Proceedings VIII International Congress of Oto-Rhino-Laryngology; 1965 Oct 24-30; Tokyo, Japan. Amsterdam: Excerpta Medica; 1965.80 p.

365. Krings JG, Kallogjeri D, Wineland A, Nepple KG, Piccirillo JF, Getz AE. Complications of primary and revision functional endoscopic sinus surgery for chronic rhinosinusitis. Laryngoscope 2014;124:838-45. PUBMED | CROSSREF

366. Zhang X, Ye T, Huang Z, Huang Q, Xian J, Li J, et al. Clinical predictors of frontal ostium restenosis after Draf 3 procedure for refractory chronic rhinosinusitis. Am J Rhinol Allergy 2018;32:287-93. PUBMED | CROSSREF

367. Ye T, Hwang PH, Huang Z, Huang Q, Xian J, Li C, et al. Frontal ostium neo-osteogenesis and patency after Draf III procedure: a computer-assisted study. Int Forum Allergy Rhinol 2014;4:739-44. PUBMED | CROSSREF 
368. Wang MJ, Lin F, Zhang XQ, Zhou B, Cui SJ, Li YC. Analysis of surgical outcomes of functional endoscopic sinus surgery and radical sinus surgery for refractory rhinosinusitis. Lin Chung Er Bi Yan Hou Tou Jing Wai Ke Za Zhi 2017;31:185-90. PUBMED

369. Georgalas C, Hansen F, Videler WJ, Fokkens WJ. Long terms results of Draf type III (modified endoscopic Lothrop) frontal sinus drainage procedure in 122 patients: a single centre experience. Rhinology 2011;49:195-201. PUBMED | CROSSREF

370. Zhou B. Interpretation of diagnosis of chronic rhinosinusitis. Zhonghua Er Bi Yan Hou Tou Jing Wai Ke Za Zhi 2013;48:96-7. PUBMED

371. Zhou B, Han DM. Changes of concepts of diagnosis and treatment of chronic rhinosinusitis after clinical practice. Zhonghua Er Bi Yan Hou Tou Jing Wai Ke Za Zhi 2013;48:89-91. PUBMED

372. Chen F, Luo X, Xu R, Deng J, Zuo K, Li H, et al. Evaluation of airway hyperresponsiveness in chronic rhinosinusitis: values of sinus computed tomography. Ann Allergy Asthma Immunol 2014;113:609-13. PUBMED | CROSSREF

373. To T, Stanojevic S, Moores G, Gershon AS, Bateman ED, Cruz AA, et al. Global asthma prevalence in adults: findings from the cross-sectional world health survey. BMC Public Health 2012;12:204. PUBMED | CROSSREF

374. Batra PS, Kern RC, Tripathi A, Conley DB, Ditto AM, Haines GK 3rd, et al. Outcome analysis of endoscopic sinus surgery in patients with nasal polyps and asthma. Laryngoscope 2003;113:1703-6. PUBMED | CROSSREF

375. Huang Z, Zhou B, Zhang Q, Huang Q, Sun Y, Wang M, et al. The role of upper and lower airway patency in chronic rhinosinusitis with nasal polyps and asthma. Laryngoscope 2013;123:569-73. PUBMED | CROSSREF

376. Veloso-Teles R, Cerejeira R. Endoscopic sinus surgery for chronic rhinosinusitis with nasal polyps: Clinical outcome and predictive factors of recurrence. Am J Rhinol Allergy 2017;31:56-62. PUBMED | CROSSREF

377. Tokunaga T, Sakashita M, Haruna T, Asaka D, Takeno S, Ikeda H, et al. Novel scoring system and algorithm for classifying chronic rhinosinusitis: the JESREC Study. Allergy 2015;70:995-1003. PUBMED | CROSSREF

378. van der Veen J, Seys SF, Timmermans M, Levie P, Jorissen M, Fokkens WJ, et al. Real-life study showing uncontrolled rhinosinusitis after sinus surgery in a tertiary referral centre. Allergy 2017;72:282-90. PUBMED | CROSSREF

379. Wu AW, Ting JY, Platt MP, Tierney HT, Metson R. Factors affecting time to revision sinus surgery for nasal polyps: a 25-year experience. Laryngoscope 2014;124:29-33. PUBMED | CROSSREF

380. Chen FH, Xu R, Zuo KJ, Guo YB, Li ZP, Shi JB. Efficacy of endoscopic sinus surgery-based on multidisciplinary treatment for chronic rhinosinusitis with asthma. Zhonghua Er Bi Yan Hou Tou Jing Wai Ke Za Zhi 2011;46:444-8. PUBMED

381. Chen FH, Zuo KJ, Guo YB, Li ZP, Xu G, Xu R, et al. Long-term results of endoscopic sinus surgeryoriented treatment for chronic rhinosinusitis with asthma. Laryngoscope 2014;124:24-8. PUBMED | CROSSREF

382. Chen FH, Deng J, Hong HY, Xu R, Guo JB, Hou WJ, et al. Extensive versus functional endoscopic sinus surgery for chronic rhinosinusitis with nasal polyps and asthma: a 1-year study. Am J Rhinol Allergy 2016;30:143-8. PUBMED | CROSSREF

383. Alsharif S, Jonstam K, van Zele T, Gevaert P, Holtappels G, Bachert C. Endoscopic sinus surgery for type-2 CRS wNP: an endotype-based retrospective study. Laryngoscope 2019;129:1286-92. PUBMED | CROSSREF

384. Subspecialty Group of Rhinology, Editorial Board of Chinese Journal of Otorhinolaryngology Head and Neck Surgery; Subspecialty Group of Rhinology, Society of Otorhinolaryngology Head and Neck Surgery, Chinese Medical Association. Guidelines for diagnosis and treatment of chronic rhinosinusitis (2012, Kunming). Zhonghua Er Bi Yan Hou Tou Jing Wai Ke Za Zhi 2013;48:92-4. PUBMED

385. Shi JB, Xu G. Perioperative treatment of chronic rhinosinusitis. Zhonghua Er Bi Yan Hou Tou Jing Wai Ke Za Zhi 2013;48:111-3.

PUBMED 
386. Cashman EC, Macmahon PJ, Smyth D. Computed tomography scans of paranasal sinuses before functional endoscopic sinus surgery. World J Radiol 2011;3:199-204.

PUBMED | CROSSREF

387. Valentine R, Wormald PJ, Sindwani R. Advances in absorbable biomaterials and nasal packing. Otolaryngol Clin North Am 2009;42:813-28.

PUBMED | CROSSREF

388. Berlucchi M, Castelnuovo P, Vincenzi A, Morra B, Pasquini E. Endoscopic outcomes of resorbable nasal packing after functional endoscopic sinus surgery: a multicenter prospective randomized controlled study. Eur Arch Otorhinolaryngol 2009;266:839-45. PUBMED | CROSSREF

389. Han DM. Pay attention to the standard treatment of chronic rhinosinusitis. Zhonghua Er Bi Yan Hou Tou Jing Wai Ke Za Zhi 2009;44:1-2. PUBMED

390. Dietz de Loos DA, Segboer CL, Gevorgyan A, Fokkens WJ. Disease-specific quality-of-life questionnaires in rhinitis and rhinosinusitis: review and evaluation. Curr Allergy Asthma Rep 2013;13:162-70. PUBMED | CROSSREF

391. Piccirillo JF, Merritt MG Jr, Richards ML. Psychometric and clinimetric validity of the 20-item sino-nasal outcome test (SNOT-20). Otolaryngol Head Neck Surg 2002;126:41-7. PUBMED | CROSSREF

392. Zhao CQ, Xu G. Evaluation of the treatment efficacy in CRS: how to understand and use it. Zhonghua Er Bi Yan Hou Tou Jing Wai Ke Za Zhi 2013;48:115-6. PUBMED

393. Dalziel K, Stein K, Round A, Garside R, Royle P. Endoscopic sinus surgery for the excision of nasal polyps: a systematic review of safety and effectiveness. Am J Rhinol 2006;20:506-19. PUBMED | CROSSREF

394. Hopkins C, Slack R, Lund V, Brown P, Copley L, Browne J. Long-term outcomes from the English national comparative audit of surgery for nasal polyposis and chronic rhinosinusitis. Laryngoscope 2009;119:2459-65. PUBMED | CROSSREF

395. Hopkins C, Browne JP, Slack R, Lund V, Topham J, Reeves B, et al. The national comparative audit of surgery for nasal polyposis and chronic rhinosinusitis. Clin Otolaryngol 2006;31:390-8. PUBMED | CROSSREF

396. Terris MH, Davidson TM. Review of published results for endoscopic sinus surgery. Ear Nose Throat J 1994;73:574-80. PUBMED | CROSSREF

397. Kennedy JL, Hubbard MA, Huyett P, Patrie JT, Borish L, Payne SC. Sino-nasal outcome test (SNOT-22): a predictor of postsurgical improvement in patients with chronic sinusitis. Ann Allergy Asthma Immunol 2013;111:246-251.e2. PUBMED | CROSSREF

398. Hopkins C, Rimmer J, Lund VJ. Does time to endoscopic sinus surgery impact outcomes in chronic rhinosinusitis? Prospective findings from the national comparative audit of surgery for nasal polyposis and chronic rhinosinusitis. Rhinology 2015;53:10-7. PUBMED | CROSSREF

399. Soler ZM, Hyer JM, Rudmik L, Ramakrishnan V, Smith TL, Schlosser RJ. Cluster analysis and prediction of treatment outcomes for chronic rhinosinusitis. J Allergy Clin Immunol 2016;137:1054-62. PUBMED | CROSSREF

400. Bachert C. Innovative therapeutic targets in chronic sinusitis with nasal polyps. Braz J Otorhinolaryngol 2016;82:251-2. PUBMED

401. DeConde AS, Mace JC, Levy JM, Rudmik L, Alt JA, Smith TL. Prevalence of polyp recurrence after endoscopic sinus surgery for chronic rhinosinusitis with nasal polyposis. Laryngoscope 2017;127:550-5. PUBMED | CROSSREF

402. Tosun F, Arslan HH, Karslioglu Y, Deveci MS, Durmaz A. Relationship between postoperative recurrence rate and eosinophil density of nasal polyps. Ann Otol Rhinol Laryngol 2010;119:455-9. PUBMED | CROSSREF

403. Lou H, Meng Y, Piao Y, Wang C, Zhang L, Bachert C. Predictive significance of tissue eosinophilia for nasal polyp recurrence in the Chinese population. Am J Rhinol Allergy 2015;29:350-6. PUBMED | CROSSREF

404. Yao Y, Xie S, Yang C, Zhang J, Wu X, Sun H. Biomarkers in the evaluation and management of chronic rhinosinusitis with nasal polyposis. Eur Arch Otorhinolaryngol 2017;274:3559-66.

PUBMED | CROSSREF 
405. Matsuwaki Y, Ookushi T, Asaka D, Mori E, Nakajima T, Yoshida T, et al. Chronic rhinosinusitis: risk factors for the recurrence of chronic rhinosinusitis based on 5-year follow-up after endoscopic sinus surgery. Int Arch Allergy Immunol 2008;146 Suppl 1:77-81.

PUBMED | CROSSREF

406. Grgić MV, Ćupić H, Kalogjera L, Baudoin T. Surgical treatment for nasal polyposis: predictors of outcome. Eur Arch Otorhinolaryngol 2015;272:3735-43.

PUBMED | CROSSREF

407. Brescia G, Barion U, Zanotti C, Giacomelli L, Martini A, Marioni G. The prognostic role of serum eosinophil and basophil levels in sinonasal polyposis. Int Forum Allergy Rhinol 2017;7:261-7. PUBMED | CROSSREF

408. Ramakrishnan VR, Hauser LJ, Feazel LM, Ir D, Robertson CE, Frank DN. Sinus microbiota varies among chronic rhinosinusitis p0henotypes and predicts surgical outcome. J Allergy Clin Immunol 2015;136:334-342.e1. PUBMED | CROSSREF

409. Tsou YA, Chen CM, Lin TC, Hu FW, Tai CJ, Chen HC, et al. Decreased SPLUNC1 expression is associated with Pseudomonas infection in surgically treated chronic rhinosinusitis patients who may require repeated sinus surgery. Laryngoscope 2013;123:845-51. PUBMED | CROSSREF

410. Lin H, Boesel KM, Griffith DT, Prussin C, Foster B, Romero FA, et al. Omalizumab rapidly decreases nasal allergic response and FcepsilonRI on basophils. J Allergy Clin Immunol 2004;113:297-302. PUBMED | CROSSREF

411. Vennera MC, Picado C, Mullol J, Alobid I, Bernal-Sprekelsen M. Efficacy of omalizumab in the treatment of nasal polyps. Thorax 2011;66:824-5.

PUBMED | CROSSREF

412. Penn R, Mikula S. The role of anti-IgE immunoglobulin therapy in nasal polyposis: a pilot study. Am J Rhinol 2007;21:428-32. PUBMED | CROSSREF

413. Pinto JM, Mehta N, DiTineo M, Wang J, Baroody FM, Naclerio RM. A randomized, double-blind, placebocontrolled trial of anti-IgE for chronic rhinosinusitis. Rhinology 2010;48:318-24. PUBMED | CROSSREF

414. Arm JP, Bottoli I, Skerjanec A, Floch D, Groenewegen A, Maahs S, et al. Pharmacokinetics, pharmacodynamics and safety of QGE031 (ligelizumab), a novel high-affinity anti-IgE antibody, in atopic subjects. Clin Exp Allergy 2014;44:1371-85. PUBMED | CROSSREF

415. Gauvreau GM, Harris JM, Boulet LP, Scheerens H, Fitzgerald JM, Putnam WS, et al. Targeting membraneexpressed IgE B cell receptor with an antibody to the M1 prime epitope reduces IgE production. Sci Transl Med 2014;6:243ra85.

PUBMED | CROSSREF

416. Gevaert P, Lang-Loidolt D, Lackner A, Stammberger H, Staudinger H, Van Zele T, et al. Nasal IL-5 levels determine the response to anti-IL-5 treatment in patients with nasal polyps. J Allergy Clin Immunol 2006;118:1133-41. PUBMED | CROSSREF

417. Bleecker ER, FitzGerald JM, Chanez P, Papi A, Weinstein SF, Barker P, et al. Efficacy and safety of benralizumab for patients with severe asthma uncontrolled with high-dosage inhaled corticosteroids and long-acting $\beta_{2}$-agonists (SIROCCO): a randomised, multicentre, placebo-controlled phase 3 trial. Lancet 2016;388:2115-27. PUBMED | CROSSREF

418. Ul-Haq Z, Naz S, Mesaik MA. Interleukin-4 receptor signaling and its binding mechanism: a therapeutic insight from inhibitors tool box. Cytokine Growth Factor Rev 2016;32:3-15. PUBMED | CROSSREF

419. Wenzel SE, Jayawardena S, Graham NM, Pirozzi G, Teper A. Severe asthma and asthma-chronic obstructive pulmonary disease syndrome - Authors' reply. Lancet 2016;388:2742. PUBMED | CROSSREF

420. Simpson EL, Bieber T, Guttman-Yassky E, Beck LA, Blauvelt A, Cork MJ, et al. Two phase 3 trials of dupilumab versus placebo in atopic dermatitis. N Engl J Med 2016;375:2335-48. PUBMED | CROSSREF

421. Macauley MS, Crocker PR, Paulson JC. Siglec-mediated regulation of immune cell function in disease. Nat Rev Immunol 2014;14:653-66. PUBMED | CROSSREF 
422. Watelet JB, Claeys C, Perez-Novo C, Gevaert P, Van Cauwenberge P, Bachert C. Transforming growth factor beta1 in nasal remodeling: differences between chronic rhinosinusitis and nasal polyposis. Am J Rhinol 2004;18:267-72. PUBMED | CROSSREF

423. Liu Z, Lu X, Wang H, Gao Q, Cui Y. The up-regulated expression of tenascin C in human nasal polyp tissues is related to eosinophil-derived transforming growth factor beta1. Am J Rhinol 2006;20:629-33. PUBMED | CROSSREF

424. Wang LF, Chien CY, Chiang FY, Chai CY, Tai CF. Expression of matrix metalloproteinase-2 and matrix metalloproteinase-9 in recurrent chronic rhinosinusitis with nasal polyposis. Kaohsiung J Med Sci 2013;29:26-31. PUBMED | CROSSREF

425. Shimizu S, Gabazza EC, Ogawa T, Tojima I, Hoshi E, Kouzaki H, et al. Role of thrombin in chronic rhinosinusitis-associated tissue remodeling. Am J Rhinol Allergy 2011;25:7-11. PUBMED | CROSSREF

426. Shimizu S, Ogawa T, Takezawa K, Tojima I, Kouzaki H, Shimizu T. Tissue factor and tissue factor pathway inhibitor in nasal mucosa and nasal secretions of chronic rhinosinusitis with nasal polyp. Am J Rhinol Allergy 2015;29:235-42. PUBMED | CROSSREF

427. Coste A, Wang QP, Roudot-Thoraval F, Chapelin C, Bedbeder P, Poron F, et al. Epithelial cell proliferation in nasal polyps could be up-regulated by platelet-derived growth factor. Laryngoscope 1996;106:578-83. PUBMED | CROSSREF

428. Hu KH, Lee FP, Cheng YJ, Huang HM. Vascular endothelial growth factor and children featuring nasal polyps. Int J Pediatr Otorhinolaryngol 2007;71:23-8. PUBMED | CROSSREF

429. Kouzaki H, Seno S, Fukui J, Owaki S, Shimizu T. Role of platelet-derived growth factor in airway remodeling in rhinosinusitis. Am J Rhinol Allergy 2009;23:273-80. PUBMED | CROSSREF

430. Lee HS, Myers A, Kim J. Vascular endothelial growth factor drives autocrine epithelial cell proliferation and survival in chronic rhinosinusitis with nasal polyposis. Am J Respir Crit Care Med 2009;180:1056-67. PUBMED | CROSSREF

431. Bayar Muluk N, Arıkan OK, Atasoy P, Kılıç R, Tuna Yalçinozan E. The role of platelet-derived growth factor in the pathogenesis of sinonasal polyps: immunohistochemical assessment in epithelial, subepithelial and deep layers of the mucosa. Clin Exp Otorhinolaryngol 2013;6:152-60. PUBMED | CROSSREF

432. Lin H, Lin D, Xiong XS, Dai XX, Lin T. Role of platelet-derived growth factor- $\alpha$ in eosinophilic and noneosinophilic chronic rhinosinusitis with nasal polyps. Int Forum Allergy Rhinol 2014;4:909-14. PUBMED | CROSSREF

433. Hu S, You X, Chen C, Liu Z, Cui Y. The expression of VEGF and the regulation of clarithromycin on it in chronic rhinosinusitis with nasal polys. Lin Chung Er Bi Yan Hou Tou Jing Wai Ke Za Zhi 2014;28:303-5. PUBMED

434. Li J, Zheng CQ, Li Y, Yang C, Lin H, Duan HG. Hepatocyte growth factor gene-modified mesenchymal stem cells augment sinonasal wound healing. Stem Cells Dev 2015;24:1817-30. PUBMED | CROSSREF

435. Sha M, Li Y, Li J. The balance of HGF and TGF- $\beta 1$ in the remodeling of chronic rhinosinusitis. Chin J Gen Pract 2017;15:663-6.

436. Azizzadeh Delshad A, Jalali Nadoushan M, Davati A, Rostami A. Expression of vascular endothelial growth factor in nasal polyp and chronic rhinosinusitis. Iran J Pathol 2016;11:231-7. PUBMED 